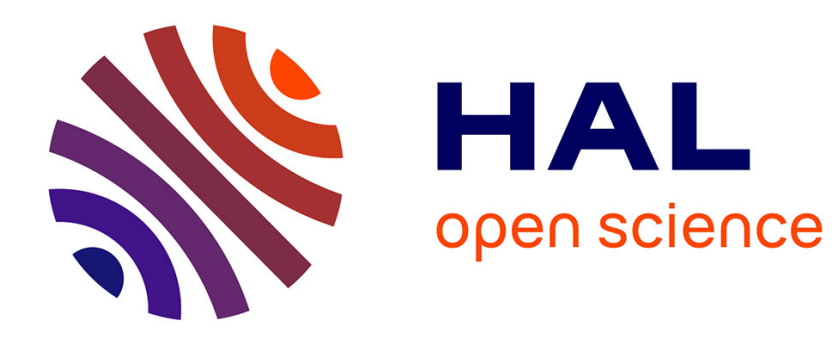

\title{
Child Discipline and Social Programs: Evidence from Colombia
}

\author{
Diana Lopez-Avila
}

\section{To cite this version:}

Diana Lopez-Avila. Child Discipline and Social Programs: Evidence from Colombia. 2016. halshs01305961

\section{HAL Id: halshs-01305961 \\ https://shs.hal.science/halshs-01305961}

Preprint submitted on 22 Apr 2016

HAL is a multi-disciplinary open access archive for the deposit and dissemination of scientific research documents, whether they are published or not. The documents may come from teaching and research institutions in France or abroad, or from public or private research centers.
L'archive ouverte pluridisciplinaire HAL, est destinée au dépôt et à la diffusion de documents scientifiques de niveau recherche, publiés ou non, émanant des établissements d'enseignement et de recherche français ou étrangers, des laboratoires publics ou privés. 


\section{PARISSCHOOL OF ECONOMICS}

WORKING PAPER N $2016-10$

Child Discipline and Social Programs:

Evidence from Colombia

Diana Lopez-Avila

JEL Codes: D1, J13, J18, 015

Keywords: Early Childhood Development, Childcare, Parenting, Domestic Violence

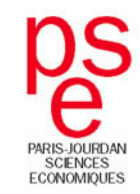




\title{
Child Discipline and Social Programs: Evidence from Colombia *
}

\author{
Diana Lopez-Avila ${ }^{\dagger}$ \\ Paris School of Economics
}

This version: April 1, 2016

\begin{abstract}
This paper examines how interventions during early childhood affect disciplining methods in Colombia, where poor households are eligible for a number of social programs targeted to young children, based on a proxy means index. These programs include child care options, nutritional programs and health checks. I analyze whether these programs affect parents' disciplining methods through two different identification strategies. I implement a regression discontinuity design exploiting the discontinuity on the probability of benefiting from these programs, as a function of the proxy means index used for targeting. I also implement a propensity score matching using differences in length of exposure to one of these programs, a subsidized child care program. Results from the first identification strategy show that fathers of children who benefit from these programs to a larger extent, use less physical ways to discipline their children. On the other hand, mothers of children who have been exposed longer to the subsidized child care option, appear to move to more pedagogic ways of discipline. These results hold in particular for households with working or more educated mothers.
\end{abstract}

Keywords: Early Childhood Development, Childcare, Parenting, Domestic Violence

JEL classification: D1, J13, J18, O15

\footnotetext{
*I'm grateful to Karen Macours for her thorough guidance in this work. This work received the support of the French National Research Agency, through the program Investissements d'Avenir, ANR-10-LABX_93-01 to visit some Hogares Comunitarios in Colombia in December 2013. I'm grateful to Maria Consuelo Gaitan Clavijo at Instituto Colombiano de Bienestar Familiar (ICBF) for her help contacting the regional offices of ICBF to perform the visits, as well as the people who helped in the regional offices of Cundinamarca and Quindío. I also want to thank Francisco Espinosa at Departamento Nacional de Planeación (DNP) and Raquel Bernal at Universidad de Los Andes who facilitated me the data to make this work possible. I also thank Carlos Medina at Banco de la República in Medellín, Lina Sanchez and Maritza Lopez for their help. I also thank my thesis committee for all useful comments received, I thank Sylvie Lambert, Raquel Bernal and Orazio Attanasio. Any errors are mine.

$\dagger$ diana.lopez@psemail.eu
} 


\section{Introduction}

Families are usually thought to be places where children are protected and their rights are guaranteed. Sadly, within a family, children can also be maltreated or abused; physically, sexually or psychologically. Young children tend to be more vulnerable to violence at home and are more likely to be victimized by primary care givers and other family members. This may happen in part because they are still very dependent and have limited social interactions outside home Pinhero, 2006. Evidence suggests that physical violence 1 against children is common throughout the world, and violence at home is the most common form of violence against children [Hoeffler and Fearon, 2014], Pinhero, 2006]. On average, 4 out of 5 children, 2 to 14 years old, are subjected to some kind of violent discipline in their homes. Percentages range from $45 \%$ in Panama, to 95\% in Yemen [Unicef, 2014.

Experiencing or witnessing violence as a child can have important effects latter in life [Unicef, 2014]. Children who are victims of violence are at a higher risk of dropping out of high school and college than their non-abused peers [Duncan, 2000]. Adolescents, maltreated early in life, are more likely to be absent from school and have higher levels of aggression, anxiety/depression, dissociation, post traumatic stress disorder symptoms, social problems, thought problems, and social withdrawal Lansford et al. 2002. Being abused or neglected as a child increases one's risk for delinquency, adult criminal behavior, and violent criminal behavior [Widom, 1989]. Also maltreated children are more likely to become maltreating parents [Kaufman and Zigler, 1987], [Lansford et al., 2007]. Children with absent fathers, and especially absent fathers and working mothers, have higher rates of child maltreatment, Paxson and Waldfogell, 1999]. Single-headed household are at a higher risk of providing inadequate childcare conditions, a risk that is also related to how the child is being punished [Berger, 2004]. Young mothers, those who report more parental stress, or report their child has a more difficult temperament are more likely to spank, MacKenzie et al., 2011, Bartlett and Easterbrooks, 2012. Community environment also seems to matter, neighborhoods with a higher percentage of 3- and 4-year-old attending preschool or nursery school, both locally and in adjacent neighborhoods, show lower rates of early maltreatment Klein, 2011.

Interventions during early childhood have begun to gain importance in the social policy agenda in developing countries. This kind of interventions have been mostly designed to address health, nutritional and cognitive deficiencies. Accordingly, early childhood development studies have been mostly focused on these outcomes. Less evidence exists on disciplining practices and spousal violence, factors that also affect children's development. Parents and care givers usually use violent and non-violent disciplinary practices, cases where only nonviolent disciplining is used are very exceptional. Violent practices can be either physical, such as hitting, kicking, pinching or burning; or psychological, such as insulting, belittling, isolating or rejecting. Caregivers may also rely more on physical ways of discipline to control children at young ages because they cannot think of alternative non-violent methods Unicef,

\footnotetext{
${ }^{1}$ Physical punishment is defined as "any punishment in which physical force is used and intended to cause some degree of pain or discomfort, however light" Pinhero, 2006
} 
2014. According to figures from the Demographic and Health Survey of 2005, Profamilia, 2005, in Colombia the three most common ways parents use to discipline children are verbal reprimand, hitting with objects and slaps. Among fathers, these figures are $75 \%, 41 \%$ and $22 \%$, and among mothers $77 \%, 47 \%$ and $34 \%$. Despite these figures, parenting quality and particularly, discipline practices, is a topic that has not been thoroughly analyzed in the research agenda in developing countries.

This paper sets out to start filling this gap, by exploiting the quasi-experimental variation in the design of different social programs in Colombia. A large set of social programs in Colombia are targeted using a proxy means index, called Sisben. The proxy means index is a function of a set of household demographic characteristics, consumption of durable goods, capital endowments and current income Castaño et al. 1999, it ranks from 0-100 and 6 levels are defined. Population in levels 1 and 2 are eligible for a large set of early childhood interventions, which include child care options, nutritional programs and a health care plan including health checks (growth and development (G\&D) checks). This paper aims at understanding how such social programs affect parents' disciplining methods? To my knowledge, this is a research question that has not been addressed yet, and whose answer can help designing more effective policies. I use two different identification strategies to answer this question. I implement a Regression Discontinuity analysis using as a forcing variable the proxy means index, and comparing population before and after the Sisben level 2 threshold. I also implement a Propensity Score Matching using differences in length of exposure to a subsidized child care program, Hogares Comunitarios de Bienestar (HCB). For this, I compare children exposed 16 months or more, to children exposed only 2-15 months.

The results suggest that attendance to G\&D checks or to a HCB are having an impact on child rearing practices. G\&D checks cover 3 components, an educational content for parents, development and growth. The educational content for parents covers topics such as nutrition, early stimulation, parenting, and prevention and management of frequent illness; and discipline begins to be addressed when the child is 13 months old. Parents are told about the importance of not using physical punishment and are taught alternative strategies to discipline children. Children who attend a HCB have to follow a routine during the time they are in the Hogar, and their parents are invited to attend bi-monthly talks on topics such as parenting, domestic violence and nutrition, among others.

For the Regression Discontinuity (RD) analysis, I use the Demographic and Health Survey for 2005 in Colombia (DHS05), and use the Sisben Index as the forcing variable. The results I obtain show that children in households above the Sisben 2 threshold are indeed less likely to attend G\&D checks, particularly they are 26 percentage points less likely to attend at least 3 G\&D checks over the last year $3^{3}$ Analyzing the impact on child discipline, results show

\footnotetext{
${ }^{2}$ The two data sets I use, provide information on physical and pedagogic ways of discipline, but not on ways referring to insulting or belittling. Anecdotal evidence suggests that among poor parents, it is common to insult or belittle children when they misbehave. Unfortunately, I cannot test for changes in this particular method.

${ }^{3}$ Table A.2 shows the optimal number of G\&D checks children must attend according to their age. On average, children up to 4 y.o should attend 3 checks during a year.
} 
that fathers of children who attend regularly G\&D checks, use less physical ways of discipline (0.37 standard deviations less). This result is particularly true for households with mothers that work outside the household. In this type of households, fathers and mothers of children who attend less frequently to the G\&D checks, use physical discipline in nearly 1 standard deviation more. While these local treatment effects (LATE) are large, they probably should be interpreted as the combined impact of different social programs whose eligibility is determined by the Sisben ${ }^{4}$.

In the second part of the paper, I concentrate on one specific program and use an alternative identification strategy, together with a different data set, to obtain a second independent impact measure. I use a Propensity Score Matching strategy (PSM) to evaluate the impact of attendance to a subsidized child care program, Hogares Comunitarios de Bienestar (HCB) $)^{5}$ on maternal discipline practices. I eliminate a first set of concerns about selection into the program by comparing children who have been exposed to the program 16 months or more, to those that have been exposed only 2-15 months, following Bernal and Fernandez, 2013. For this strategy, I use the data collected for the evaluation of the program in 2007. Data covers children 0-6 y.o., and provides information on how the mother punishes the child. Results show that, overall, mothers of children who have been exposed longer to the program, use more neglecting and pedagogic ways of discipline. By analyzing differences by mother's labor force participation, results show that working women use less physical ways of discipline (0.07 standard deviations), and more pedagogic ways (0.1 standard deviations), the longer their children have been attending the HCB. For non-working mothers, an increase in the use of neglecting ways of discipline is observed (0.14 standard deviations).

To interpret these findings, I suggest that the interaction with parents seems to be key for changing their behavior; either through a change in social norms [Elster, 1999, or through learning better parenting practices. Attending a HCB or G\&D checks on a regular basis can make parents "feel bad" about the possibility that doctors, nurses or Madres Comunitarias (Mother from the community) find out the child has been physically punished. Hence, they stop using physical punishment. In the particular case of HCB, mothers whose children have been attending longer the HCB are more likely to attend the meetings organized by the Madre Comunitaria. Also, children longer exposed to the program are less likely to behave bad at interacting with other children. This last set of results suggest that a longer attendance to the HCB may generate a change in discipline methods both, through a change in mothers' and a change in children's behavior.

After having established the impact on disciplining, I also analyze the impact on spousal violence. Evidence has shown that in families where one form of violence is present, there is an increase risk of experiencing the other one Herrenkohl et al., 2008. Children who are exposed to this "Doubly Whammy" effect fare worse than those exposed to only one risk factor, Herrenkohl et al., 2008, [Hughes et al., 1989]. It is hence, a priori, possible that a

\footnotetext{
${ }^{4}$ Among these programs, we have child care programs, nutritional programs, and educational programs.

${ }^{5}$ This program is also targeted to population in Sisben levels 1 and 2, however I don't find a discontinuity using the DHS05 data. This can be explained by the fact other eligibility criteria is taken into account. I'll go further on this on Section 2.4
} 
reduction in spousal violence is part of the mechanism underlying the results on disciplining ${ }^{6}$. In none of the identification strategies I find a robust impact on spousal violence.

This paper aims to contribute to the literature on early childhood development, which has focused on short and long term benefits of preschool interventions, but that has not studied deeply disciplining outcomes, particularly in developing countries. Studies of well known programs in the United States such as the Perry Preschool Program, the Carolina Abecederian and Head Start have shown that children who participate in these programs are less likely to drop out from high school and more likely to have higher test scores. Some of these programs have addressed parenting behavior by incorporating discussions with parents, showing a positive effect on nurturance and, sometimes, a decrease in spanking together with an increase in reasoning as a form of discipline, Schady, 2006].

Evidence from Latin America and the Caribbean has shown large differences in cognitive development by socio-economic status, Shchady et al., 2014], Rubio-Codina et al., 2013], having important implications for long term outcomes. Children with insufficient levels of nutrition and cognitive and socio-emotional development, tend to do badly in school, to have a higher incidence of teenage pregnancy, and to be more likely to use drugs or to be involved in criminal activities. The relationship between socio-economic status and cognitive development can be partially explained by child health and measures of parenting quality, Paxon and Schady, 2007]. Particularly, children whose parents have better HOME[ scores, reflecting warmer and less punitive behavior, have significantly higher TVIP test scores.

In general, programs in Latin America have impacted positively children's well-being. Children who receive a cash transfer are more likely to attend school and less likely to drop out, as well as have better nutritional and development outcomes, Behrman et al. 2004b], Attanasio et al., 2005a b], "Macours et al., 2012, [Fiszben and Schady, 2009 and [Paxon and Schady, 2010]. Child care programs, Hogares Comunitarios in Colombia and $\mathrm{PIDI}^{8}$ in Bolivia, have a positive impact on cognitive development and socio-emotional abilities, but depending on the length of exposure to the program. In Colombia the impact is found for those who attend at least 15 months, while in Bolivia for those who attend at least 7 months, "Bernal and Fernandez, 2013], Behrman et al. 2004a. Pre-primary education programs in Argentina and Uruguay have shown important benefits in the subsequent years of children's life. By age 15, children who have attended preschool have accumulated 0.8 extra years of education and are 27 percentage points more likely to be in school as compared to their untreated siblings Berlinski et al., 2008. Children also increase their self control in third grade when they have attended pre-primary education, Berlinski et al., 2009.

\footnotetext{
${ }^{6}[$ Dong et al. 2004$]$ finds that the likelihood of experience some form of child maltreatment is higher in the presence of domestic violence at home. Using data from 8,629 adult members of a health plan in the US, authors find that the prevalence of physical child abuse was $57 \%$ for adults who reported earlier domestic violence exposure and $22 \%$ for those who reported no prior exposure. According to figures from the DHS05, Profamilia, 2005, in Colombia 39\% of women have ever experienced physical violence from her partner.

'Home Observation for Measurement of the Environment scale

${ }^{8}$ Proyecto Integral de Desarrollo Infantil
} 
Results found in this paper shed some light on an outcome not analyzed much in early childhood development studies, child discipline. Evidence provided here shows that early childhood interventions can affect parents' behavior by decreasing the use of physical punishment as a way of discipline. Though there is no guide on how to raise a child, psychologists have suggested what parents should not do. They should not be inconsistent, should not hit a child when he misbehaves, among others. For low-income parents, poverty-related concerns consume mental resources, which leaves fewer resources for other tasks, such as parenting Anandi et al., 2013. Social programs can help parents overcoming these constraints.

This paper shows that early childhood interventions addressing mainly health, nutrition and cognitive development have an extra benefit on parenting behavior. This raises the question of whether or not interventions focused more on parenting can further boost these impacts. Studying similar programs in the region could help elicit the program features that are pushing the change in parents' behavior, as a way to better understand the mechanisms at play. Interventions in the region have begun to include home visits to work closer with parents and the interactions with their children. As a first step, policy makers could include discipline practices as one of the topics covered in these meetings, to tackle better parents and children needs.

The rest of this paper is organized as follows. Section 1 describes the setting of the interventions. Section 2 explains the Regression Discontinuity identification strategy in which the impact of Growth and Development checks is addressed, as well as the data used and the results. Section 3 explains the Propensity Score Matching used to evaluate the impact of Hogares Comunitarios, together with the data and the results. Finally, Section 4 concludes.

\section{Programs}

Over the last decade, the Colombian government has increased its efforts to offer pertinent services to young children with the goal of providing a comprehensive package of services for children's development [ICBF, a b], [DNP, 2007]. This package of programs encompasses two components, health and education. The health component is managed by the local health providers who must guarantee women's access to contraceptive plans, prenatal care and breastfeeding training, children's vaccination schemes and nutritional programs, among others. The educational component is managed by the Instituto Colombiano de Bienestar Familiar (ICBF), which offers different kind of programs for pregnant women and mothers of young children, as well as to children and adolescents. Access to health services in Colombia can be either through the subsidized or the contributory regime [Bottia et al. 2012. The subsidized regime is targeted to the poorest population in the country, those who belong to Sisben levels 1 and 29 .

\footnotetext{
${ }^{9}$ In principle, services should not differ whether they are provided by the subsidized or the contributory regime. However, in practice, differences in quality may arise.
} 
Table A.1 shows the different kind of programs targeted using the Sisben index. Upper panel shows the programs targeted to young children, children aged 0-6 years old (y.o.), and the lower panel the ones targeted to older children and adults. Among the programs targeted to young children we find the set of programs offered by the ICBF, the subsidized health regime and Familias en Accion ${ }^{10}$. Having access to social security offers access to services such as children's vaccination schemes and nutritional programs, through growth and development (G\&D) checks. Familias en Accion offers two components, a nutritional and an educational one. The nutritional component is targeted to children up to 6 y.o and consists of vaccination and G\&D checks for children; and courses of nutrition, hygiene and contraception for mothers. The educational component targets children 7-17 y.o. The ICBF offers different kind of child care options, such as Hogares Comunitarios, Hogares Infantiles and Jardines Comunitarios, which besides providing a child care option to parents, offer talks to parents on topics such as parenting, child-rearing guidelines, nutritional and health, and encourage parents to take children to G\&D checks.

G\&D checks are targeted to children from 0 to 10 years and 11 months, and aim at decreasing infant mortality rates through the provision of comprehensive attention to children, MinProteccion. During the first year of age, G\&D checks aim at preventing more frequent illness in the newborn, at encouraging breastfeeding among mothers, and at providing child care guidelines to parents and care givers. From 1 to 10 y.o., G\&D checks are focused on health checks, child care guidelines, visual assessment, and prevention and promotion of oral health. Table A.2 describes the outline of G\&D checks according to children's age.

G\&D checks cover 3 components, an educational content for parents, development and growth 11 . The educational content for parents covers topics such as nutrition, early stimulation, parenting, and prevention and management of frequent illness, and begins to cover discipline when the child is 13 months old. Parents are encouraged to offer a positive environment in which the permanent use of "Do not'" 12 is avoided, to establish clear but flexible rules and to listen to the children and respect their opinions. Likewise, the importance of limiting the use of physical punishment is emphasized. The development evaluation focuses on gross and fine motor skills, speech-language and hearing, and personal/social skills. The growth evaluation contains a medical exam and a nutritional check. Table A.3 shows an example of the protocol that should be followed in the G\&D check for children 13-16 months old. From qualitative interviews with people in charge of G\&D checks, the procedure in case of observing signs of physical abuse or maltreatment changes according to the health provider. In some cases, mothers are sent to therapies with the psychologist; in others the ICBF is called and the child is put under its supervision until parents show to be capable of taking care of him 13 In most public child care options, as well as in public schools, it is a

\footnotetext{
${ }^{10}$ Familias en Accion is a Conditional Cash Transfer program implemented in since 1992 and it is only targeted to population in Sisben level 1.

${ }^{11}$ Every check last approximately 1 hour

${ }^{12}$ Using sentences such as don't touch, don't do, etc.

${ }^{13}$ Usually a form should be filled up in which the information on the event observed is registered. For the particular case of Bogota, the local health department (Secretaria de Salud) has an information system in which all events of domestic violence, child maltreatment or sexual abuse should be registered (Sistema de
} 
requirement to show that the child has attended the G\&D checks up to date in order to enroll.

Among the programs offered by the ICFB, we find Hogares Comunitarios de Bienes$\operatorname{tar}(\mathrm{HCB})$. HCB is a home-based childcare program established in Colombia since $1986^{14}$ with the main goal of providing a childcare option for vulnerable population and promoting women's labor force participation [Bernal et al., 2009], [Bernal and Fernandez, 2013]. Traditional HCB childcare homes are led by a Madre Comunitaria (Mother from the community), who hosts 12 to 14 children from 2 to 5 years old ${ }^{15}$. Children should receive up to $70 \%$ of the daily allowance of supplementary nutrition, as well as promotion of physical growth, health, social and cognitive development. Madres Comunitarias should be between 18 to 45 y.o, have at least a high school level, and have lived in the neighborhood where the HCB is going to operate for at least a year ${ }^{16}$

Parents who want to enroll their children in a $\mathrm{HCB}^{17}$ need to not only have their children registered in the G\&D checks, but also to show that checks are up to date. Besides, Madres Comunitarias encourage G\&D attendance and vaccination [Bernal et al., 2009]. Madres Comunitarias also organize bimonthly meetings with parents in which they cover different topics such as nutrition, health, parenting, domestic violence, among others. The topics covered in these talks are chosen by the Madres Comunitarias based on the needs detected from the interaction with the children, the parents and the community, as well as the suggestions received by the $\mathrm{ICBF}^{18}$.

Children who wish to attend any of the childcare options offered by the ICBF should fulfill

vigilancia epidemiologica de la violencia intrafamiliar, el maltrato infantil y la violencia sexual (SIVIM))

${ }^{14}$ Hogares Infantiles were created in 1974, then in 1986 the coverage was extended with the $\mathrm{HCB}$. Among HCB there are different modalities, traditional, grouped and corporate childcare homes DNP 2009], being the traditional childcare homes the ones that account for around $65 \%$ of the total beneficiary population (Figure taken based on the number of beneficiaries by February 2014. https://sinergia.dnp.gov.co/portaldnp/default.aspx). Grouped childcare homes are those where 2 madres comunitarias gather together to provide service to 26-28 children. Corporate childcare homes have the support of a company aiming at providing childcare to the employees' children. Corporate childcare homes receive children from 0 to 6 y.o and usually host around 40 children. For these childcare homes, the monthly fee is a bit higher as compared to the one of traditional childcare homes. Besides these childcare homes, there is another program that targets pregnant women and children 0-2 y.o, Hogares FAMI(Familia, Mujer e Infancia). These homes are mostly located in rural disperse areas and tackle non-working women, they aim at boosting the relation between mothers and children, though not provide childcare as the HCB.

${ }^{15}$ From qualitative interviews with people in charge of the program, the ICBF encourages madres comunitarias to receive children from 2 years old given that younger children require special care. However, when a madre comunitaria receives children younger than 2 y.o, she should not receive more than 1.

${ }^{16}$ All Madres Comunitarias are required to attend a 40-hours pre-service training on child development, health, nutrition, safety, and community participation Bernal and Fernandez, 2013. Though Madres Comunitarias, their homes and the services they provide should fulfill into the criteria defined by the ICBF, there is great variation on the quality of the service provided Bernal et al. 2009, DNP, 2009.

${ }^{17} \mathrm{HCB}$ usually host children between $8 \mathrm{am}$ and $3 \mathrm{pm}$. Children follow a schedule given by different moments organized as follow, 1) Welcome, 2) Let's explore, 3) Let's create, 4) Let's play, 5) Let's eat and 6) Let's go home, ICBF, 2006.

${ }^{18}$ Madres Comunitarias encourage both parents to participate in these meetings, though is mostly mothers the ones who attend. 
the following criteria ICBF, 2013]: Have less than 5 years and 11 months of age, belong to Red Unidos 5 , belong to Sisben levels 1 and $2^{20}$, and have a family income up to 1.5 daily minimum wages (ONLY for Hogar Infantil). Priority is also given to displaced population.

\section{Impact of Growth and Development checks on Child Discipline}

\subsection{Sisben}

Colombia has two methods for targeting social spending. One is a geographical targeting instrument, called Socio-economic Stratification 21, used mostly to target subsidies for potable water and electricity. The other one is a proxy-means test instrument, known as System for Selecting Beneficiaries of Social Spending (Sisben), which is based on assessment of living conditions on individual families Castañeda, 2005]. The Sisben index is a function of a set of household demographic characteristics and variables related to the consumption of durable goods, capital endowments and current income [Castaño et al. 1999]. The Sisben has been widely used since 1994 to target subsidies for health insurance, scholarships, conditional cash transfers, public works, youth training and subsidies for elderly poor and children, among others, Castañeda, 2005]. The Sisben Index ranks from 0 to 100, and 6 levels are defined. From 1995 on, different methodologies ${ }^{22}$ have been implemented to compute the Sisben index, trying to overcome caveats observed in its implementation and possible manipulation by beneficiaries and municipal authorities Castañeda, 2005], Camacho et al. 2010], Bottia et al., 2012], Camacho and Conover, 2009. For the current analysis, the methodology that holds is Methodology II given that the year of interest is 2005. Table A.4 shows the thresholds defined with this methodology. Thresholds are different for urban and rural population.

Some studies have exploited the discontinuity in program eligibility based on the Sisben index. [Barrera-Osorio et al., 2007] exploit the discontinuity for the Gratuidad program in Bogotá ${ }^{23}$, finding that the fee reductions offered to individuals in Sisben 1 and 2 have a positive effect on enrollment. Impact is found for primary enrollment for students in Sisben level 1, and in high school enrollment for students in Sisben level 2.

Table A.1 shows that different programs targeted to different age groups use the Sisben index, making it difficult to isolate the impact of only one program. However, it is possible to

\footnotetext{
${ }^{19}$ Families registered in the Red Unidos correspond to families in the lowest quintile of families belonging to Sisben level 1, that is, the poorest population in the country. For more information on Red Unidos: http://www.anspe.gov.co/es/programa/estrategia-unidos

${ }^{20}$ From 2011-2012 programs began to be targeted with the newest methodology of the Sisben, Methodology III. Thresholds for program eligibility change from program to program with this new methodology. Now programs are not assigned to particular levels but to particular groups depending on the thresholds ICBF, 2013

${ }^{21}$ Based on assessment of the outside characteristics of neighborhoods and dwellings.

${ }^{22}$ Methodology I from 1995-2002, methodology II from 2003-2010 and methodology III from 2011 on.

${ }^{23}$ Gratuidad is a program providing school fee reductions for enrollment in primary and secondary
} 
look at the impact of the set of programs using the Sisben index. Given that the population of interest of a large part of these programs is children, particularly young children; I seek to establish how the package of programs targeting Sisben levels 1 and 2 impact children discipline, and shed light on which program seems to be the one driving the results.

\subsection{Data}

To implement the Regression Discontinuity (RD) analysis I use the Demographic and Health Survey of 2005 (DHS05). In this round, the survey asked women for the Sisben score; however, a large number of respondents did not remember either one of them or both, and data turned out quite noisy and with a lot of missing values ${ }^{24}$. Because of this, governmental authorities decided to re-compute the Sisben index based on the socio-economic characteristics reported in the survey, and using the official formula and weight:25.

The DHS is a National representative survey of women in reproductive age (15-49 y.o), providing information on household characteristics, woman reproductive history, contraception, pregnancy, children's health and vaccination, sexual behavior, fertility, AIDS and domestic violence. I focus on the sample of women with children 0-18 y.o. residing in urban areas. I decided to focus only on urban areas given that around $80 \%$ of households reside in urban areas (capital municipalities and seat of the municipal government), which leaves not enough observations to have enough power to estimate a regression discontinuity around the eligibility threshold for rural areas.

The DHS has an extensive section on Domestic Violence, covering how parents discipline children under 18 y.o. The question is asked separately for mother and father way of punishment, and provides information on the occurrence rather than on the frequency ${ }^{26}$, I implement a factor analysis to create a variable describing the way parents discipline children, following [Attanasio et al. 2015 27. A latent factor model is usually done to investigate concepts that are not easily and directly measured. In this case, different observed variables are associated with parental discipline, the variable I am interested in measuring. The factor analysis allows me to understand the patterns across the different observed variables, helping me to identify different forms of parental discipline.

For the factor analysis, I first selected a sub-sample of the ways to discipline children, based on the rates in which each of them is used. I selected those that have a rate higher than 1\%. Table A.5 shows the rates in which each measure of child discipline is used. The sub-sample in which I focus includes the following: spanking, pushing, verbal reprimand,

\footnotetext{
${ }^{24}$ There is no answer on Sisben level for around $40 \%$ of the sample and no answer on Sisben index for nearly $88 \%$.

${ }^{25}$ The official formula and weights are not publicly available

${ }^{26}$ Question is framed to get information on how children in the household are punished, rather than how each child in the household is punished. For each possible way of punishment it is asked whether or not the parent punishes children in that way. Answers are given by the woman.

${ }^{27}$ But contrary to Attanasio et al. 2015, I do not assume a dedicated measurement system, that is one in which each measure only proxies one factor
} 
prohibiting something children like, hitting with objects, keeping children looked up and ignoring them. As it can be seen, all of them point out towards a neglecting or physical way to discipline children. Using these seven ways of discipline, I obtained three factors for fathers and mothers disciplining methods, factors which eigenvalues are larger than one ${ }^{28}$. Table 1 shows the description for each of the factors. For both, mothers and fathers, the loads for factor 1 are always positive; while for factor 2 and 3, some loads are positive and other are negative ${ }^{29}$. Ways of discipline, such as verbal reprimand or prohibiting children something they like, can be considered as neglecting ways of discipline. However, the information provided in the survey is not enough to clearly establish if these methods corresponds to aggressive or non-aggressive ways of disciplining. For example, we do not know if the verbal reprimand corresponds to shouting or dialoguing with the child. I consider that this may help explaining why in some cases the loadings are positive and in others they are negative. When we compare the loadings of the different factors between mothers and fathers, we observe than factor 1 loads mainly on physical ways of disciplining, such as pushing and spanking. While, factor 2 and 3, load on a mix of physical and neglecting punishment; and loadings do not always point in the same direction 30 . Table A.6 shows the factor loadings for the gender based violence analysis. This analysis suggested two factor which eigenvalues were larger than 1 . In this case, factor 1 loads mainly on aggressive and physical ways of violence, while factor 2 loads mainly on controlling behaviors.

\subsection{Identification Strategy}

Table A.1 showed that a large number of programs, targeted to population in Sisben levels 1 and 2 , are focused on young children. The only program targeted exclusively to Sisben 1 is Familias en Accion, which also includes G\&D checks. Families in Sisben 1 and 2 have access to a relatively similar and large supply of programs as compared to families in Sisben 3, therefore the current analysis focuses only on the threshold from Sisben 2 to 3 . In the Suplementary Appendix, estimations of discontinuity on G\&D checks in the threshold from Sisben 1 to 2 are provided, showing no evidence of a discontinuity ${ }^{31}$. Though attendance to G\&D checks is a requirement to receive the transfer of Familias en Accion, there is also an enforcement mechanism for households in Sisben 2. One of the requirements to attend a Hogar Comunitario is to show that the G\&D checks are up date.

The Sisben index provided at the DHS05 corresponds to a re-computed index, done by governmental authorities and using the official formula and weights. 32 . Although it uses the official algorithm, it may be the case it differs from the original index because the data

\footnotetext{
${ }^{28}$ For those three factors the eigenvalues are $1.27,1.15$ and 1 , respectively

${ }^{29}$ To estimate the factor, I use the regression scoring (Thomson (1951)), which is defined as: $\hat{f}=\Phi \wedge^{\prime} \Sigma^{-1} x$. Where, $\Phi$ is the correlation matrix of the common factors, $\wedge$ represents the factor loading matrix, and $x$ the vector of observed variables

${ }^{30}$ For both, fathers and mothers, Factor 1 explains $18 \%$ of the total variance, Factor 2, $16 \%$ and Factor 3 , $15 \%$.

${ }^{31}$ DHS05 data doesn't provide information on Familias en Accion participation, not allowing to test for a discontinuity.

${ }^{32}$ Formula and weights that are not publicly available.
} 
sources are different. Figure 1 shows the distributions of the Sisben index computed with data from the Sisben survey (top graph); and of the one re-computed using DHS05 data (bottom graph). Distributions differ particular at the left tail. At the left tail there is a higher density when using the Sisben survey. Around the threshold of interest (Sisben index 22) distributions behave relatively similar. The date of data collection of the DHS falls just in the middle of the time period in which data for the Sisben survey was collected ${ }^{33}$. This allows to think that on average, households may not have substantially changed their consumption of durable goods or the household physical characteristics. Based on this evidence, I rely on the Sisben index computed with the DHS05 data.

In order to get consistent estimators through a RD analysis, it is important to test for manipulation of the forcing variable and discontinuity in variables that can affect the outcome of interest Lee and Lemieux, 2010]. Studies have shown evidence of possible manipulation of the Sisben index, particularly by local authorities and using data from the previous Sisben Methodologies (Methodology I), [Camacho and Conover, 2009]. Manipulation is not a big concern for the current analysis because of two main reasons. First, the methodology that applies is a subsequent methodology (Methodology II), which was designed trying to overcome possible manipulation problems. Second, the index provided at the DHS05 is based on a survey which purpose was not to collect data to compute the index and target social programs, putting strategic answer as a second order problem. Anyhow, I test for continuity in the running variable. Figure 2 shows the graph corresponding to the McCrary Density test McCrary, 2008], which provides evidence of continuity of the running variable around the threshold.

The Sisben index is computed based on a set of household demographic characteristics and variables related to the consumption of durable goods, capital endowments and current income. I check for possible discontinuities on the variables used to compute the Sisben index, as well as on the wealth index provided at the DHS054 The wealth index is included to rule out that the differences observed are due to wealth rather than to access to programs.

All subsequent estimations, to test for discontinuities around the threshold, will correspond to Equation $1 \|^{5}$.

$$
y_{i}=\alpha_{0}+\beta_{1} 1\left\{S_{i} \geq 22\right\}+\beta_{2} f_{2}\left(\tilde{S}_{i}\right)+\beta_{3} f_{2}\left(\tilde{S}_{i}\right) * 1\left\{S_{i} \geq 22\right\}+\beta_{4} C_{i}+\mu_{i}
$$

Where $y_{i}$ is the outcome of interest at the individual or household level. $S_{i}$ is the Sisben index. $\tilde{S}_{i}=S_{i}-22$ is the normalized score. $1\left\{S_{i} \geq 22\right\}$ identifies those who are after the

\footnotetext{
${ }^{33}$ The data collection for the Sisben, Methodology II, took place between January 2003 and July 2007

${ }^{34}$ The wealth index is a composite measure of a household's cumulative living standard provided in the DHS. It's calculated based on data on households ownership of selected assets, such as televisions and bicycles; materials used for housing construction; and types of water access and sanitation facilities. DHS separates all interviewed households into five wealth quintiles to compare the influence of wealth on various population, health and nutrition indicators. Taken from http://dhsprogram.com/topics/Wealth-Index.cfm on July 30th 2014

${ }^{35}$ The Suplementary Appendix contains the estimations with a linear polynomial
} 
threshold and $f_{2}\left(\tilde{S}_{i}\right)$ corresponds to a quadratic polynomial on the normalized score, which I allow to be different after the threshold with the interaction $f_{2}\left(\tilde{S}_{i}\right) * 1\left\{S_{i} \geq 22\right\}$. C represents a the set of household controls ${ }^{36}$. Impact of the program is given by $\beta_{1}$, which represents the change in $y$ at the eligibility threshold, in this case 22 .

All estimations presented next are either on the rank [19-25] or the rank [18-26]. The test for optimal bandwidth proposed by [Imbens and Kalyanaraman, 2010] suggested a bandwidth of 2.6. I perform some heterogeneity analysis, for I which I divide my sample. Therefore, in these cases I run the estimations on the rank [18-26] to get power on the estimations. Table 2 shows the sample size for children and mothers in the Sisben score ranks: [18-26] and [19-25], for each of the children's age ranges of interest: children 0-4 y.o, children 0-18 y.o in households with at least a child 0-4 y.o, and children 5-18 y.o in households with no child 0-4 y.o. First panel shows the observations for all children; second panel for those for which I have information on discipline methods; and third panel for those that I have information on discipline and on all controls used (eg. household composition, woman and partner's age and education, and wealth index).

Results from Table A.7 do not show a systematic difference around the threshold in the variables used to compute the Sisben index. Although evidence of a possible discontinuity is observed in the socio-economic strata, number of toilets, owning a water heater or oven, and number members older than 65 y.o; not all changes point in the same direction and in some cases discontinuities are quite sensible to the order of the polynomial used. All following estimations will include as controls household composition by age group ${ }^{37}$, woman's and partner's education and age; and the household wealth index.

\subsection{Results}

\subsubsection{Main Results}

DHS05 data provide information on HCB attendance for children 0-6 y.o. and G\&D checks for children 0-4 y.o. ${ }^{38}$ Using this information, I take into account number of G\&D checks attended, having attended at least $3 \mathrm{G} \& \mathrm{D}$ check\& 39 and attendance to a HCB. Figure 3 suggests a discontinuity in the likelihood that a child has attended at least 3 G\&D checks.

Table 3 shows the estimation of Equation 1 for programs' attendance. Results are given for number of G\&D checks attended over last 12 months, attendance to at least 3 G\&D checks and attendance to HCB. Children 0-4 y.o belonging to households right above the threshold of Sisben level 2 are 27 percentage points less likely to attend at least 3 G\&D checks. On average, the likelihood that children above the threshold attend at least $3 \mathrm{G} \& \mathrm{D}$ checks is

\footnotetext{
${ }^{36}$ This term is not included when I test for discontinuities in the variables used to compute the Sisben index

${ }^{37} 0-6$ y.o., $7-14$ y.o., $15-24$ y.o., $25-64$ y.o. and 65 y.o. and above

${ }^{38} \mathrm{I}$ focus on children $0-4$ y.o because for them I have information on both programs.

${ }^{39}$ Table A.2 shows the optimal number of G\&D checks children must attend according to their age, on average, children up to 4 y.o should attend 3 checks during a year.
} 
$23 \%$, while it is $50 \%$ for those below the threshold. As it can be seen, results are pretty similar for all type of households, are well as for households with mother and father present. Though attendance to HCB is lower after the threshold, it is not statistically significant. The lack of discontinuity in HCB attendance can have two probable explanations. First, Madres Comunitarias can ask ICBF authorities to allow children, who do not belong to Sisben 2 but who are in a vulnerable situation, to enroll into the program. Second, corporate HCB aim to benefit employee's children and some of them may belong to households in Sisben level 3.

Figure 4 and Figure 5 show the pattern of each of the factors (standardized) of disciplining methods of fathers and mothers, around the threshold. The figures suggest a discontinuity in factor 1 of mothers and fathers. For the other two factors, the graphical analysis does not seem to suggest a difference between those before and those after the threshold 40 . This result seems to be consistent to what was found in the factor description presented in Section 2.2 , where it was not clear whether factor 2 and 3 pointed towards an aggressive or non-aggresive way of disciplining. I decide to focus my analysis only on factor 1 because of two main reasons. On one hand, factor one explains most of the variation (18\%), all loadings are positive and the main loadings point towards an aggressive way to discipline children. One the other hand, the main loadings for factor 1 are the same for fathers and mothers way of disciplining: spanking, pushing and ignoring. This latter characteristic allows me to compare factor 1 between mothers and fathers. The other two factors point to different types of discipline, making it difficult not only to establish whether they describe aggressive discipline practices; but making it difficult to compare them between mothers and fathers.

Table 4 shows the estimation of Equation 1 for factor 1 (standardized) of fathers and mothers. As was suggested by the figures, fathers above the threshold of Sisben 2 are 0.37 standard deviations more likely to use physical and neglecting ways to discipline their children, as compared to fathers below the threshold. As before, results are very much the same between all households and households with mother and father present. I decided to work with the whole sample of children (eg. children 0-18 y.o.), because what is learned for the children 0-4 y.o, who attend the G\&D checks, can be also used to discipline other children in the household. I also used the whole sample of children because the question that is asked is "How father/mother discipline children 0-18 y.o in the household", rather than how each child is disciplined 4 .

Given that no particular difference arises by whether or not the father is present at home, all the subsequent analysis will focus on all type of households. In $67 \%$ of the households children are disciplined by both parents, in $27 \%$ only by the mother, and in $4 \%$ only by the father. I also estimate the impact of fathers and mothers' discipline methods, conditional on whether both parents punish the children ${ }^{42}$. Table 5 shows a higher impact on father's way of discipline. Fathers above the threshold of Sisben 2 are 0.6 standard deviations more likely to use physical and neglecting ways to discipline their children, as compared to fathers below the threshold.

\footnotetext{
${ }^{40}$ Though graphically it seems to be a discontinuity on factor 3 for fathers, it's no statistically significant

${ }^{41}$ This the reason why the number of observations are larger in Table 4 as compared to Table 3

${ }^{42} \mathrm{I}$ did not find an impact on whether it is the mother or the father the one who punishes
} 
I also implemented a heterogeneity analysis by looking at differences of whether or not the mother works outside the household. Women who don't work or who work inside the household, may spend more time with their children and, presumably, could be more under stress. Therefore it'll be interesting to see in which group the intervention is more effective at generating an impact. Table 6 shows the results on program attendance by whether or not mothers work outside the household 434 . Results show that children from households above the threshold of Sisben 2, from both type of mothers, are around 0.3 percentage points less likely to attend at least $3 \mathrm{G} \& \mathrm{D}$ checks over last month. Though it is only statistically significant for mothers who work inside the household or do not work, the point estimate in the other group is not significantly different. Table 7 shows the results on child discipline. Though attendance to the health checks didn't show any particular difference between the two type of households, a change in parents' behavior is seen only in households in which the mother work outside the household. Besides, in this type of households a change in behavior is also observed for mothers. Fathers and mothers above the Sisben 2 threshold increase the use of physical and neglecting ways of discipline by around 1 standard deviation. Figure 6 shows the corresponding graphs for mothers and fathers way of discipline when the mother works outside the household.

Table A.8 shows some household characteristics describing the whole sample, the sample of mothers that work outside the household and the sample of mothers that do not. Households in which women work outside the household have fewer children 0-6 y.o., women and partners are more educated, and women are older. Based on previous figures, we may think that the fact that parents are more educated (eg. parents that are more likely to have technical post-secondary education), is playing an important role for the intervention to generate a change in behavior.

To check if in fact mothers' education is playing a role, I implemented a heterogeneity analysis by whether or not mother's education is higher than secondary 45 . Table 8 shows the results on attendance to at least $3 \mathrm{G} \& \mathrm{D}$ checks. Difference in G\&D checks is nearly significant in both groups and the magnitude of the change is not significantly different neither across the two type of households, nor as compared to the full sample. Children above the Sisben 2 threshold are 0.26 percentage points less likely to attend at least $3 \mathrm{G} \& \mathrm{D}$ checks over the last 12 months. Table 9 shows that, as expected, the difference in discipline practices is seen in households with highly educated mothers and, fathers ${ }^{46}$. In households with highly educated mothers, fathers above the Sisben 2 threshold increase the use of physical and neglecting ways of discipline by 0.6 standard deviations. Though change in mother's behavior is not

\footnotetext{
${ }^{43}$ Around $40 \%$ of women work outside the household. I tested for whether or not there was a discontinuity on the likelihood mothers work outside the household at the threshold of interest, and there is no discontinuity.

${ }^{44}$ Given that the sample was separately into women that work outside the household, and women that work inside the household or do not work, I decided to present the estimations on the rank [18-26] to gain power for my estimations.

${ }^{45}$ Around $17 \%$ of mothers have education higher than secondary.

${ }^{46}$ On average, partner's education is secondary for mothers with education secondary or lower; and technical post secondary for mothers with education higher than secondary.
} 
statistically significant, the magnitude of the change is nearly the same as the one observed for fathers. Figure 7 shows the corresponding graphs for mothers and fathers way of discipline according to mother's education. Though the differences observed in child disciplining go in the same direction for households where mothers work outside the household, or households with more educated mothers; magnitudes are higher in the first case. This may be suggesting that there may be some unobserved characteristics that make households with mothers that work outside more willing to change their discipline practices.

\subsubsection{Robustness Checks}

The Sisben index is used to target different programs to young children, old children and adults. With this work, I aim to establish the impact of the package of social programs, particularly social programs targeted to young children, on parents' disciplining methods. Therefore, the presence of young children in the household is going to be essential for the change in parents' behavior. I use the sample of children 5-18 y.o. in households with no child 0-4 y.o. to do a placebo test ${ }^{47}$. The change in behavior may not be necessarily coming from programs targeted to young children if an impact is found in this sample. Table A.9 shows that in households where there is no child 0-4 y.o, there is no evidence of a change in parents' disciplining methods. This ensures that the impact is coming from programs targeted to young children, rather than from other programs or from other variables that could change at the threshold.

As I previously mentioned, I decided to work with the whole sample of children 0-18 y.o. given the way the question was framed and the fact that discipline practices learned for one child may be used with the rest of the children. However, it may be expected that the main change in behavior is going to come from the discipline practices used with children 0-4 y.o. The upper panel of Table A.10 shows the results for discipline practices used with children 0-4 y.o, and lower panel with children 5-18 y.o (in households with at least a child 0-4 y.o.) For father's ways of disciplining, magnitudes are not particularly different between children 0-4 y.o. and children 5-18 y.o. For mothers, results are not significant for either group, but the point estimates do point in opposite directions, possible suggesting that the change in behavior is concentrated on the younger children.

Another way to check that the impact is coming from the package of programs targeted to young children is to check at spousal violence. If an impact is observed in the violence of the partner towards the woman, then it may be that either other program is pushing the change in behavior, or some other household variables change at the threshold. Besides, given the evidence that households that experience spousal violence are more likely to experience child maltreatment, and vice versa; a reduction in spousal violence may be part of the mechanism underlying the results on child disciplining. Table A.11 shows the impact on the two factors describing gender based violence. Results show that there is no change in this type of violence.

\footnotetext{
${ }^{47}$ In $46 \%$ households have at least 1 member $0-4$ y.o
} 
Table A.12 check for differences in other outcomes that may affect levels of violence at home, such as women's empowerment, women's marriage history or the number of children living outside and inside the household. To approach women's empowerment I also implemented a factor analysis. For the factor analysis I used measures of women empowerment such as education; labor participation; use of contraceptive methods; if she considers that a woman can refuse having sex with her partner if she does not want; if she participates in household decisions such as which type of food to buy and cook, and visiting family and friends; and if she is the only who decides how to spend her income. The factor analysis suggested three factors. Factor 1 loads mainly on participation in household decisions and the use of contraceptive methods. Factor 2 loads on income and education. And factor 3 loads on agreement to refuse to have sex and the use of contraceptive methods. I decide to focus on factor 1 because it explains most of the variation (20\%) and also because factor 2 had already been indirectly approached through the estimations presented in Table A.7, where I check for discontinuities in the variables used to compute the Sisben score. Table A.12 shows no evidence for a discontinuity on factor 1 (standardized) of women's empowerment.

For women's marriage history, I take into account if she has been in more than one union and age at first marriage, no discontinuity is found in any of them. Finally, I look at number of children living outside and inside the household, as one may think that children leave home in the presence of a violent environment, again no differences are found. The fact I don't find a difference around the threshold on any of these outcomes suggests that the channel through which the intervention is impacting is through the attendance to the G\&D checks, rather than through other factors that may make these households different. In order for children to enroll in a public school or child care option, parents need to show that the child has up to date the G\&D checks. Public schools are quite inflexible with this requirement, which works as an enforcement mechanism for parents to take children on time to the G\&D checks

G\&D checks aims at decreasing infant mortality. For this reason, it is possible that the program is also impacting anthropometric outcomes, such as weight-for-age and height-forage. In the DHS05, for some of these variables there is a high presence of missing data, which makes the estimations subject to bias and lack of power. Among the 959 children 0-4 y.o. in the Sisben rank [18-26], there is information on weight for 856 and on height for 851 children. After computing the $\mathrm{z}$ scores, there is information on weight-for-age for 851, height-for-age for 522 and weight-for-height for 640 children 50 . Table A.13 displays the results for these three outcomes for all children, and boys and girls separately, showing no impact on any of them 51

\footnotetext{
${ }^{48}$ The variation explained by factor 2 is $18 \%$ and by factor $3,16 \%$

${ }^{49}$ The target population of G\&D checks is a quite vulnerable population. From qualitative interviews with people in charge of the G\&D checks, it seems that mothers see a lot of advantages in taking their children to the checks, even if they may receive a sanction in case the child has been physically punished. Also, it may be that in some cases (though not that many), mothers do not dare to report that their partners punish their children physically, and prefer for doctors to find out.

${ }^{50} \mathrm{I}$ control for weight and height at birth. Weight is available for 832 and height for 753

${ }^{51}$ Given the few observations I have for some of the outcomes, I decided to work on the rank [18-26].
} 
Besides the factor analysis to approach parents' disciplining behavior, I also defined two additional indicators. I define physical punishment as slaps, pushing, feeding deprivation, hitting with objects, leaving them locked, forcing them to do inadequate activities and throwing them water. With these categories I built two different indicators, number of yes and any yes. Table A.14 shows the corresponding results for all type of households and households where the father is present. Results go in line to what was found with the factor analysis. There is a higher use of physical ways of discipline by fathers whose children attend less frequently the G\&D checks (eg. Those above the Sisben 2 threshold). On the other hand, with this set of indicators, a higher use of physical ways of discipline is also observed in mothers who are in a union.

The Suplementary Appendix presents the estimations with a liner polynomial. It also provides the results when instrumenting attendance to at least $3 \mathrm{G} \& \mathrm{D}$ checks (during the year), with a dummy identifying those after the threshold. Results from the IV go in the same direction.

\section{Impact of Hogares Comunitarios on Discipline}

\subsection{Data}

To provide additional evidence on how social programs affect parental discipline strategies used with their children, I implement a Propensity Score Matching (PSM) estimation using the data from the evaluation of HCB. For the evaluation of Hogares Comunitarios de Bienestar (HCB), data was collected between February and July of 2007. The sample covers 1,042 HCB and a bit more than 26,000 children nationwide Bernal et al. 2009. Beneficiary children were selected from a random sample of HCB in 47 (out of 1,100) municipalities in Colombia. Non-beneficiary children were sampled from children 0-6 y.o who satisfied program eligibility criteria 52 , live in the same areas of influence as the 1,042 HCB included in the study, but were not enrolled in the program Bernal and Fernandez, 2013]. Data gathers information on socio-economic characteristics of children and their families, as well as outcome variables to measure the impact of the program on nutrition, health, cognitive and non-cognitive development of participant children Bernal et al., 2009].

The sample includes children who were attending a HCB at the moment of the survey, children who have previously attended and children who have never attended. I only focus on children who attend a HCB at the moment of the survey. I focus on children 2-5 y.o as, in principle, Madres Comunitarias should only receive children from 2 y.o. Table 10 shows the sample size for children 2-5 y.o. who have attended at least 2 months the Hogar Comunitario for all type of households, households with mother and father present, households with working mothers, and households with non-working mother: 53 .

\footnotetext{
${ }^{52}$ Basically belonging to Sisben levels 1 and 2 .

${ }^{53}$ As compared to the Regression Discontinuity analysis, the data for the HCB analysis do not provide information on whether or not women work outside the household.
} 
Data provides information on how the mother punishes the child when he does not want to eat and when he does not want to obey. It does not provide information on how the father disciplines the child. Questions are framed to get information on frequency, rather than only on occurrence 54 . As in the case of the Regression Discontinuity Analysis, I implemented a factor analysis to define the measures of child discipline. I decided to put together measures of child disciplining used when the child doesn't want to eat, and when the child doesn't want to behave. I also decided to work with the factors that had an eigenvalue strictly larger than 1, which corresponds to six factors. Table 11 shows that measures of both type of situations, when the child does not want to eat and when the child does not want to obey, load on each of the six factors. Factor 1 loads mainly on physical ways of discipline, such as forcing the child to eat and hitting him with an object or with the hand. Factor 2 loads mainly on pedagogic ways of discipline, such as explaining the importance of obeying or eating. Factor 3 and 5 load mostly on neglecting ways of discipline, such as taking out the plate of food or sending the child to another room in the house. Finally, Factor 4 loads on a mix of pedagogic and neglecting ways of discipline, such as playing the child when he doesn't want to eat or verbal reprimand; and Factor 6 loads on combination of physical and neglecting ways of discipline 55 . Estimations on the impact of Hogares Comuntarios are done using the first 5 factors derived from the analysis, as factor 6 only loads on 2 measures.

I also implement a factor analysis for children's behavior. I work with some direct questions regarding children's behavior asked in the survey. I use behaviors referring to children's interaction with other children and, children's responsibility and independence 56 . The factor analysis provides three factors, which eigenvalue is larger than one. I focus my analysis on those three factors. Table 12 displays the factor loadings for each of the measures of child's behavior. Factor 1 loads mainly on measures pointing a good behavior at interacting with other children and at following instructions. Factor 2 loads mostly on measures of bad behavior at interacting with other children and, Factor 3 mainly on measures of bad behavior at respecting and following instructions.

\subsection{Identification Strategy}

Bernal and Fernandez, 2013 find evidence that treated children seem to come from more vulnerable households, which raises concerns of self-selection into the program. Selection into the program can be due to observable and unobservable characteristics. Among the observable characteristics, there is parents' education, age and labor force participation; children's age, gender and health; and household composition. Among the unobservable characteristics we can have parents' preferences or children's ability.

\footnotetext{
${ }^{54}$ The possible answers are never (1), sometimes (2), almost every time (3) and always (4).

${ }^{55}$ To estimate the factor, I use the regression scoring (Thomson (1951)), which is defined as: $\hat{f}=\Phi \wedge^{\prime} \Sigma^{-1} x$. Where, $\Phi$ is the correlation matrix of the common factors, $\wedge$ represents the factor loading matrix, and $x$ the vector of observed variables.

${ }^{56}$ For each of the behaviors, mothers were asked to classify into always, sometimes and never, the behavior of their children in that particular aspect.
} 
Following [Behrman et al., 2004a, Heckman and Todd, 2009], Bernal and Fernandez, 2013, I compare children according to the length of exposure to the program. [Bernal et al., 2009, show that the program is impacting those that have attended the HCB at least 16 months. I therefore compare children exposed 16 months or more to those exposed 2-15 months. Selection on observables is controlled for in two ways. First, beneficiary children were selected from a random sample of HCBs in 47 (out of 1,100) municipalities in Colombia and non-beneficiary children were sampled from children 0-6 y.o. who satisfied program eligibility criteria $[57$ live in the same areas of influence but were not enrolled in the program Bernal and Fernandez, 2013. Second, estimations combine regression and propensity score weighting through a Double-Robust estimator, following Imbens and Wooldridge, 2009. Combining regression and weighting can lead to additional robustness by removing the correlation between the omitted variables and, by reducing the correlation between the omitted and the included variables. Regarding selection on unobservable characteristics I do not have a good instrument that would allow me to control explicitly for selection on unobservables. Instead, I include variables in the PSM that could serve as proxies of parents preferences, such as if the mother is the main care giver of the child and if quality was the main reason to choose the care option. I decided to work only with a sample of children who are attending a $\mathrm{HCB}$ and exploit differences in length of exposure to avoid concerns regarding selection into the program. However, after controlling for observed characteristics that I consider may affect the length of exposure to the program, it is possible that there may be unobserved variables that determine how long a child stays in a HCB.

Tables A.15 shows some descriptive statistics for the two groups of interest, children who have been exposed to the program 16 months or more and those that have been exposed only 2-15 months, for all type of households; while Table A.16 shows the descriptives for households where the father is present. Similar to what was found by Bernal and Fernandez, 2013], children who have been exposed for a longer period of time to the program seem to come from more vulnerable households. Parents are less educated and there are more children 0-6 y.o. at home. The Suplementary Appendix presents the descriptive statistics for working and non-working mothers, as well as for high and low educated mothers, characteristics that I use to implement a heterogeneity analysis.

Figure 4 shows the graphs of the estimations of Equation 2 comparing children who have attended at least 16 months to the program to those that have attended 2-15 months.

$$
e(x)=\operatorname{Pr}\left(W_{i}=1 \mid X_{i}=x\right)=p(x ; \gamma) \sqrt{58}
$$

where $x$ is a vector of covariates. $W$ is a binary indicator of participation: having attended 16 months or more.

\footnotetext{
${ }^{57}$ Basically belonging to Sisben levels 1 and 2 .

${ }^{58} p(x ; \gamma)=\exp \left(\gamma_{0}+x^{\prime} \gamma_{1}\right) /\left(1+\exp \left(\gamma_{0}+x^{\prime} \gamma_{1}\right)\right)$
} 
Variables used for the estimation of the propensity score include child and parents' characteristics, households physical characteristics and variables identifying HCB availability and reasons for choosing the care option. Figure 4 shows that the distributions of the propensity score provide a good common support between treatment and control in each comparison group. The Suplementary Appendix has the figures for the other samples of interest 59

The PSM is done using kernel estimator ${ }^{60}$. Estimations are done within the common support, which is defined by dropping treatment observations whose pscore is higher than the maximum or less than the minimum pscore of the controls. Table A.17 shows the balance test by strata using the weights from the PSM estimation ${ }^{61}$. The Suplementary Appendix contains the balance test for the other sub-samples of interest. Apart from some minor differences, results show that the sample is relatively well balanced across treatment and control. The following results will refer to the Double-Robust estimator using the weights from the propensity scores.

For the Double-Robust estimator, in the first step $\gamma$ is estimated by maximum likelihood and then the propensity scores, $\hat{e}\left(X_{i}\right)=p(x ; \hat{\gamma})$. In the second step, a linear regression is used where the objective function is weighted by the inverse probability of treatment and non-treatment. We can think of the objective function to be given by Equation 3

$$
E\left(Y_{w} \mid x\right)=\alpha_{w}+\beta_{w}^{\prime}(x-\bar{X}) \quad \text { for } w=0,1
$$

Then, to estimate $\left(\alpha_{0}, \beta_{0}\right)$ and $\left(\alpha_{1}, \beta_{1}\right)$, the weighted least square problem is solved:

$$
\min _{\alpha_{0}, \beta_{0}} \sum_{i: W_{i}=0} \frac{\left(Y_{i}-\alpha_{0}-\beta_{0}^{\prime}\left(X_{i}-\bar{X}\right)\right)^{2}}{p\left(X_{i} ; \hat{\gamma}\right)} \quad \min _{\alpha_{1}, \beta_{1}} \sum_{i: W_{i}=1} \frac{\left(Y_{i}-\alpha_{1}-\beta_{1}^{\prime}\left(X_{i}-\bar{X}\right)\right)^{2}}{1-p\left(X_{i} ; \hat{\gamma}\right)}
$$

\subsection{Results}

\subsubsection{Main Results}

The upper panel of Table 13 shows the results for all types of households, and the lower panel for households where the father is present; for the five factors (standardized) of disciplining methods. Results suggest that there are not particular differences between the two type of households. Mothers of children who have been longer into the program use neglecting ways

\footnotetext{
${ }^{59}$ Households where the father is present, with working mothers, with non-working mothers, with high educated mothers and with low educated mothers

${ }^{60}$ Caliper $=0.2$

${ }^{61}$ Following Imbens, 2004
} 
of discipline (Factor 3), such as ignoring the child or taking off the plate of food, by around 0.6 standard deviations more. This group of mothers also use more a combination of pedagogic and neglecting ways of discipline (Factor 4). This set of results provides mixed evidence regarding whether mothers are moving towards more positive oriented ways of discipline, the longer their children have been in the program. However, when I perform the heterogeneity analysis by women's labor status and education, results suggest a much clearer movement towards positive ways of disciplining.

Following the hypothesis that non-working mothers or mothers that work inside the household may be more under stress. I implement a heterogeneity analysis by whether or not the mother participate in the labor market ${ }^{62}$ to see if the program is more efficient in a particular group. The upper panel of Table 14 shows the results for working mothers and the lower panel for non-working mothers. Similar to what was found in the regression discontinuity analysis, the more positive oriented differences on child discipline are observed in working mothers. Results suggest that working mothers use less physical ways of discipline and, at the same time, more pedagogic/neglecting ways, the longer their children have been in the HCB. Working mothers of children that have been exposed a longer period of time to the program, decrease the use of physical ways of discipline (factor 1) by 0.07 standard deviations; and increase the use of pedagogic/neglecting ways (factor 4 ) by 0.1 standard deviations. In the case of non-working mothers, they increase the use of neglecting ways of discipline by 0.14 standard deviations. Results suggest that the most positive oriented change in discipline methods is seen in the sample of working mothers, consistently to what was observed in the Regression Discontinuity analysis.

Table A.18 shows the differences in some household characteristics for working and nonworking mothers. As in the case for the Regression Discontinuity analysis, mothers and fathers from household where the mother works are more educated (eg. on average have around 1 more year of education, and have less children). Table 15 shows the impact by mothers' education. Consistently with the results found by whether or not the mother works, the most positive oriented change in discipline practices is seen in mothers with high education (eg. 8 years of education or more) ${ }^{63}$. Though both type of mothers use more neglecting ways of discipline (factor 3); mothers with high education use less physical ways of discipline (factor 1 ), and more pedagogic oriented ones (factor 4). On the other hand, women with low education use more physical and neglecting ways of discipline. More educated women decrease the use of physical ways of discipline by 0.07 standard deviations, and increase the use of more oriented pedagogic ways by 0.09 standard deviations. Less educated women increase the use of physical and neglecting ways of discipline by 0.06 standard deviations.

Besides the factor analysis to approach changes in mothers' disciplining methods, I also defined two additional indicators. Based on the listed ways of discipline, I defined two groups:

\footnotetext{
${ }^{62}$ In this case, we don't have information on whether or not the mother works outside the household.

${ }^{63} 8$ years of education corresponds to the median of mothers education.
} 
physical discipline ${ }^{64}$ and pedagogic discipline ${ }^{65}$. For each group, two indicators are built: "Used most of the time" and "Used any time". The top panel of Table A.19 shows the results for situations in which the child doesn't want to eat, and the bottom panel for situations in which the child doesn't want to obey. Results go in line to what was found with the factor analysis. Mothers whose children have been exposed longer to the program use more frequently pedagogic ways to discipline their children in both type of situations. On the other hand, in situations when the child doesn't want to obey, mothers use less physical punishment the longer the child has been attending the HCB.

\subsubsection{Mechanisms}

The change in disciplining practices observed by mothers of children who have been exposed a longer period of time to the program may come either from a change in mothers' behavior, or from both, a change in mothers' and children's behavior. Mothers are supposed to attend bimonthly meetings organized by the Madres Comunitarias in which different topics are addressed, such as parenting practices. Table 16 shows that mothers whose children have been attending a HCB 16 months or more, are on average 4 percentage points more likely to have attended a meeting during the last 6 months. Though mothers in all type of households are more likely to attend the meetings the longer their children have been in the HCB, the larger change is observed for working mothers. In this case, mothers of children who have been exposed longer to the program are 8 percentage points more likely to attend the meetings. Among working mothers, those whose children have been attending the HCB 2-15m have a rate of meeting attendance of $54 \%$, while those whose children have been attending the program more than 15 months, have a rate of attendance of $62 \%$.

During the time children attend a HCB, they are supposed to follow a routine. Children follow six moments during the day, 1) Welcome, 2) Let's explore, 3) Let's create, 4) Let's play, 5) Let's eat and 6) Let's go home, [ICBF, 2006. Children learn to follow some rules, for example, that when it is the "Let's eat" time they have to sit and finish the meal. This may help them to also follow better the rules at home. In qualitative interviews with beneficiary mothers, opinions on this subject were divided. Some mothers expressed that their children were behaving much better at the meal time since they were attending the HCB. After some months in the HCB, children finished their meal by themselves, without the mothers needed to push or force them to eat. However, some other mothers expressed that their children's behavior was very different at home, behaving much better at the HCB. We may think then that the program could be impacting children's behavior.

\footnotetext{
${ }^{64}$ For situations when the child does not want to eat: "take out the plate of food", "force the child to eat" and "punish the child physically". For situations in which the child does not want to obey: "punish the child physically", "hit the child with an object", "hit the child with the hand", "pinch the child" and "leave the child without food".

${ }^{65}$ For situations in which the child does not want to eat: "play with him to motivate him to eat" and "explain the importance of eating". For situations in which the child does not want to obey: "explain the importance of obeying" and "amuse him with an object".
} 
Table 17 shows the results on the impact on children's behavior by program exposure, taking into account the three (standardized) factors previously obtained. Overall, children who have been exposed to the program 16 months or more are less likely to behave bad at interacting with other children; impact that is larger for children with working mothers. Children who have been exposed to the program 16 months or more decrease the likelihood of behaving bad with other children by 0.08 standard deviations, impact that increases to 0.12 standard deviations for children of working mothers. In the analysis by mother's education, we find that children from more educated mothers are more likely to behave well the longer they have been exposed to the program.

Previous evidence suggests that the more positive oriented change in discipline methods observed in working mothers could be coming from a higher participation in the meetings organized by the Madre Comunitaria, as well as from a higher decrease in the likelihood that the child behaves bad at interacting with other children. Though these changes are observed for most type of households, magnitudes are higher in the sample of working mothers.

\section{Conclusions}

Being neglected or physically punished as a child can have adverse consequences in adult life. Yet, not much has been said on how social programs can impact the way parents discipline children. This paper contributes to the literature by showing that early childhood interventions affect the way parents discipline kids. I approach the research question through two different identification strategies. I exploit the fact that a large set of social programs in Colombia are targeted using a proxy means test instrument, Sisben index, to estimate impacts of eligibility on a set of early childhood programs using a Regression Discontinuity Design. To further validate the results, I also estimate the impact of a subsidized child care program in Colombia, Hogares Comunitarios de Bienestar (HCB), using a Propensity Score Matching. I use different lengths of exposure to the program as my identification strategy. To my knowledge, this is one of the first papers to analyze how social programs affect parents' disciplining methods, in a developing context.

Results from the Regression Discontinuity strategy show that fathers of children who benefit to a lower extent of the set of programs targeted to early childhood (eg. those above the threshold), use physical ways of discipline 0.37 standard deviations more, as compared to fathers of children who largely benefit from these programs. The difference observed in disciplining methods seems to be driven by a more frequent attendance to health checks (G\&D checks). G\&D checks include talks with parents in topics such as parenting, nutrition and health; as well as medical examination done by a doctor or a nurse. At exploring some heterogeneity by whether or not the mother works outside the household, the change in father's behavior is only observed in household with mothers that work outside. Besides, in this type of households a change in mother's behavior is also observed. Households with mothers that work outside have more educated parents, as well as less young children. Consistent with the results found by women's participation in the labor market; the change in 
parents' discipline methods is observed in households with more educated women. This first set of results suggest that interventions are more effective in generating a change on parents' behavior, the more educated parents are.

Focusing then on the impact of HCB, using a Propensity Score Matching, results suggest an increase in pedagogic and neglecting ways of discipline the longer the children have been attending the HCB. However, when I explore heterogeneity by mothers' labor market participation or education, results point that the change towards more positive oriented ways of discipline is observed in households with working mothers or with more educated mothers. Among working mothers, mothers of children who have been attending the program a longer period of time decrease the use of physical ways of discipline by 0.07 standard deviations; while increase the use of more pedagogic oriented ways by 0.1 standard deviations. The more positive oriented change in discipline practices observed for working mothers seems to be explained by a higher attendance to the meetings organized by the Madre Comunitaria, as well by a higher decrease in the likelihood that children behave bad at interacting with other children.

For the interpretation of these findings a few important caveats need to be pointed out. For the Regression Discontinuity analysis, I am working with a re-computed Sisben index based on the information provided in the DHS05, which can differ from the actual Sisben index. I rely on the similarity of the Sisben index distributions around the threshold of interest, and on the fact that DHS05 data collection falls just in the middle of data collection for the Sisben survey. Regarding the Propensity Score Matching estimation, the main drawback is the possible bias due to selection on unobservables. Though the balance test after the matching seems to work well on observable characteristics, it is not possible to know if it would be the same for unobservable ones. The comparison between those exposed 16 months or more and those exposed 2-15 months deals the best with the possible bias due to unobservable characteristics, as all children are already part of the program. Finally, I am working with self-reported data which can raise some concerns. We may think that parents under report the use of physical punishment because they are aware it corresponds to a bad behavior, though they do not necessarily stop using it. Even if it would be the case, results will suggest that social programs are changing the awareness of how bad is to punish children physically, which is already a first step.

Parenting is not an easy task and social programs can leverage it by given parents the tools they need to better face all the new situations. Early childhood development interventions addressing mostly nutritional and development outcomes, seem to have an extra benefit on children disciplining too. The remaining question is then whether or not interventions addressing parenting and child discipline directly, can intensify the impact already found. Interventions in Latin America and the Caribbean have started to focus more on parents and the interaction with their children, by including home visits. One of the first programs to include home visits was Educa a tu hijo in Cuba and then, similar interventions have been implemented such as Programa Primeira Infancia Melhor in Brazil, Cuna Más in Peru and Creciendo con Nuestros Hijos in Ecuador. These programs address mainly parenting skills such as the importance of playing, reading and singing to the child; still disciplining methods 
are typically not placed as one of the main objectives. Interventions that include home visits and community meetings with parents, in which disciplining methods are addressed, could further enhance the benefits of such programs. By doing such, social programs could further contribute to children's development and the achievement of better outcomes later in life. 


\section{Tables}



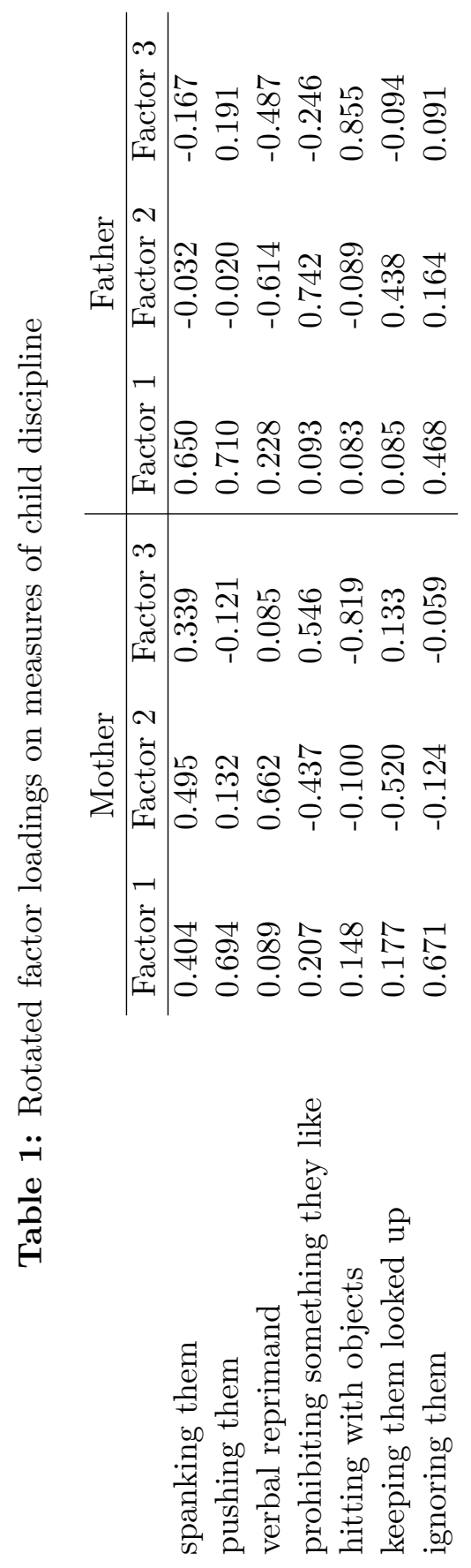


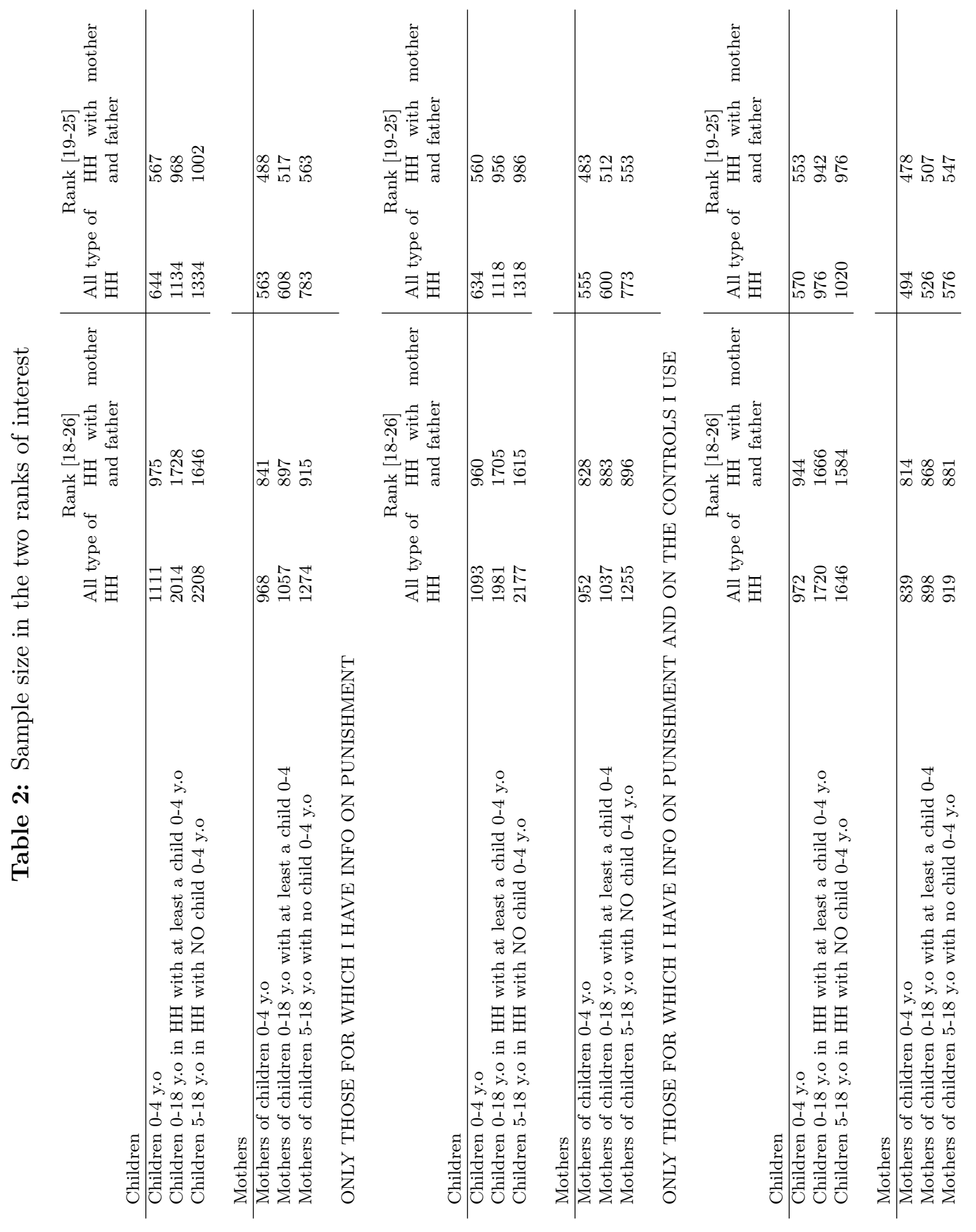


Table 3: Program Discontinuity

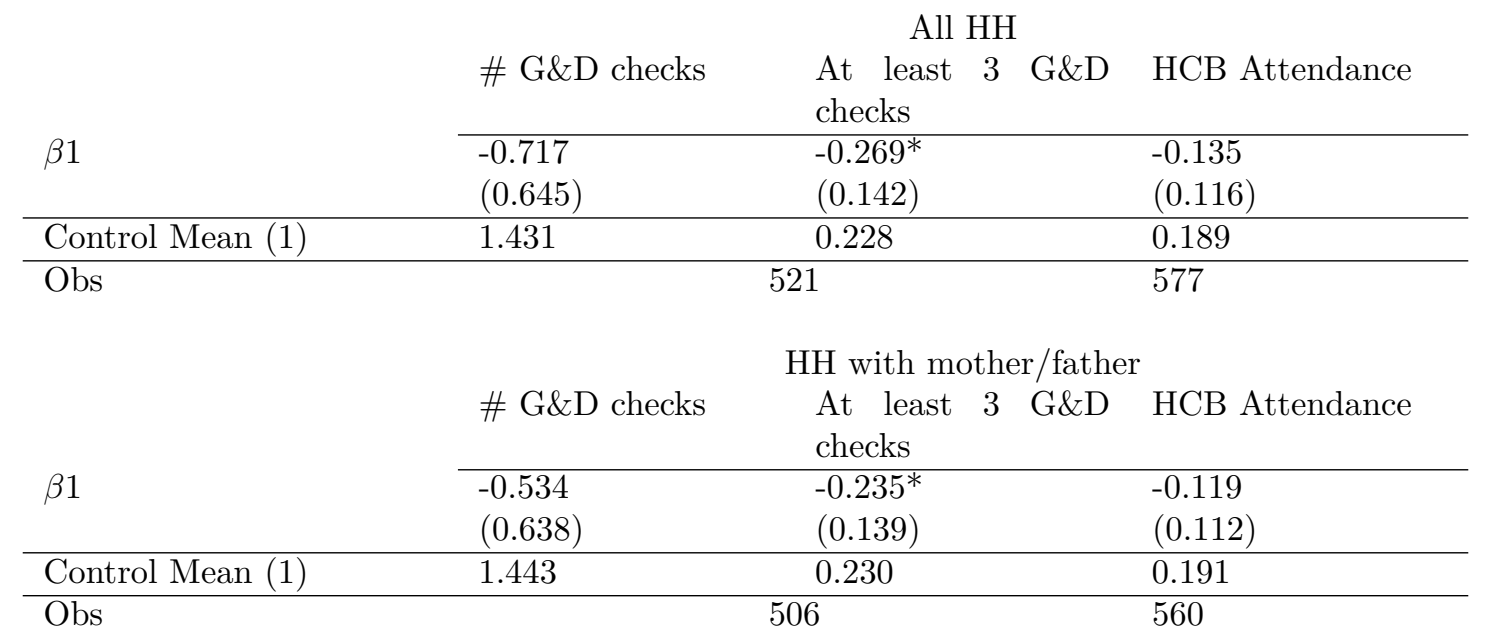

Note: (1) Mean after threshold. Rank [19-25]. Children 0-4 y.o. SE in parenthesis and clustered at sample unit level. ${ }^{* * *} \mathrm{p}<0.001{ }^{* *} \mathrm{p}<0.05^{*} \mathrm{p}<0.1$. The difference between the number of observations for G\&D checks and $\mathrm{HCB}$ attendance is due to missing values in the responses to G\&D attendance.

Table 4: Children Discipline Discontinuity (Factor 1). Mothers and Fathers

\begin{tabular}{lll|ll} 
& \multicolumn{2}{c|}{ All HH } & \multicolumn{2}{c}{ HH with mother/father } \\
$\beta 1$ & Father & Mother & Father & Mother \\
\cline { 2 - 5 }$\beta 1$ & $0.374^{* *}$ & 0.255 & $0.393^{* *}$ & 0.215 \\
& $(0.162)$ & $(0.224)$ & $(0.163)$ & $(0.293)$ \\
\hline Control Mean(1) & 0.068 & -0.015 & 0.069 & -0.024 \\
\hline Obs & 976 & 976 & 942 & 942
\end{tabular}

Note: (1) Mean after threshold. Rank [19-25]. Children 0-18 y.o in HH with at least a child 0- 4 y.o. SE in parenthesis and clustered at sample unit level. ${ }^{* * *} \mathrm{p}<0.001 * * \mathrm{p}<0.05 * \mathrm{p}<0.1$. 
Table 5: Children Discipline Discontinuity (Factor 1). Mothers and Fathers. HH in which both parents punish the children

\begin{tabular}{lll} 
& Father & Mother \\
\cline { 2 - 3 }$\beta 1$ & $0.591^{* * *}$ & 0.142 \\
& $(0.218)$ & $(0.395)$ \\
\hline Control Mean & 0.120 & -0.002 \\
\hline Obs & 651 & 651
\end{tabular}

Note: (1) Mean after threshold. Rank [19-25]. Children 0-18 y.o in HH with at least a child 0- 4 y.o. SE in parenthesis and clustered at sample unit level. ${ }^{* * *} \mathrm{p}<0.001{ }^{* *} \mathrm{p}<0.05 * \mathrm{p}<0.1$.

Table 6: Attendance to at least 3 G\&D checks, by whether or not the Mother works outside the $\mathrm{HH}$

\begin{tabular}{ll|l} 
& Works outside the HH & $\begin{array}{l}\text { Doesn't work or works in- } \\
\text { side the HH }\end{array}$ \\
\cline { 2 - 3 }$\beta 1$ & -0.351 & $-0.226^{*}$ \\
$(0.22)$ & $(0.134)$ \\
\hline Control Mean (1) & 0.323 & 0.162 \\
\hline Obs & 346 & 548
\end{tabular}

Note: (1) Mean after threshold. Rank [18-26]. Children 0-18 y.o in HH with at least a child 0- 4 y.o. SE in parenthesis and clustered at sample unit level. ${ }^{* * *} \mathrm{p}<0.001 * * \mathrm{p}<0.05 * \mathrm{p}<0.1$.

Table 7: Children Discipline Discontinuity (Factor 1). Mothers and Fathers. By whether or not mothers work outside the household

\begin{tabular}{|c|c|c|c|c|}
\hline \multirow[b]{3}{*}{$\beta 1$} & \multicolumn{2}{|c|}{ Mothers work outside the $\mathrm{HH}$} & \multicolumn{2}{|c|}{ Mothers work inside the $\mathrm{HH}$ or do not work } \\
\hline & Father & Mother & Father & Mother \\
\hline & $\begin{array}{l}1.036^{\text {*** }} \\
(0.28)\end{array}$ & $\begin{array}{l}0.891^{* *} \\
(0.424)\end{array}$ & $\begin{array}{l}-0.001 \\
(0.171)\end{array}$ & $\begin{array}{l}-0.222 \\
(0.288) \\
\end{array}$ \\
\hline Control Mean (1) & 0.220 & 0.131 & -0.031 & -0.109 \\
\hline Obs & 673 & 673 & 1047 & 1047 \\
\hline
\end{tabular}

Note: (1) Mean after threshold. Rank [18-26]. Children 0-18 y.o in HH with at least one child 0- 4 y.o. SE in parenthesis and clustered at sample unit level. ${ }^{* * *} \mathrm{p}<0.001{ }^{* *} \mathrm{p}<0.05^{*} \mathrm{p}<0.1$.

Table 8: Attendance to at least 3 G\&D checks, by whether or not the Mother has education higher than secondary

\begin{tabular}{ll|l} 
& High Education & Low Education \\
\cline { 2 - 3 }$\beta 1$ & -0.295 & -0.225 \\
& $(0.197)$ & $(0.152)$ \\
\hline Control Mean (1) & 0.224 & 0.220 \\
\hline Obs & 282 & 612
\end{tabular}

Note: (1) Mean after threshold. Rank [18-26]. Children 0-18 y.o in HH with at least a child 0- 4 y.o. SE in parenthesis and clustered at sample unit level. ${ }^{* * *} \mathrm{p}<0.001{ }^{* *} \mathrm{p}<0.05 * \mathrm{p}<0.1$. High education refers to education higher than secondary. Low education refers to education secondary or lower. 
Table 9: Children Discipline Discontinuity (Factor 1). Mothers and Fathers. By whether or not mothers' education higher than secondary

\begin{tabular}{lll|ll} 
& \multicolumn{2}{c|}{ High Education } & \multicolumn{2}{c}{ Low Education } \\
\multirow{2}{*}{$\beta 1$} & Father & Mother & Father & Mother \\
\cline { 2 - 5 } & $0.608^{* *}$ & 0.599 & 0.143 & -0.223 \\
& $(0.256)$ & $(0.369)$ & $(0.181)$ & $(0.368)$ \\
\hline Control Mean (1) & 0.263 & 0.171 & -0.022 & -0.099 \\
\hline Obs & 488 & 488 & 1232 & 1232
\end{tabular}

Note: (1) Mean after threshold. Rank [18-26]. Children 0-18 y.o in HH with at least one child 0- 4 y.o. SE in parenthesis and clustered at sample unit level. ${ }^{* * *} \mathrm{p}<0.001{ }^{* *} \mathrm{p}<0.05^{*} \mathrm{p}<0.1$. High education refers to education higher than secondary. Low education refers to education secondary or lower.

Table 10: Sample Size. HCB Analysis

\begin{tabular}{|c|c|c|c|c|}
\hline & All $\mathrm{HH}$ & $\begin{array}{l}\mathrm{HH} \text { with } \\
\text { partner }\end{array}$ & $\begin{array}{l}\text { Working } \\
\text { mothers }\end{array}$ & $\begin{array}{l}\text { Non-working } \\
\text { mothers }\end{array}$ \\
\hline $\begin{array}{l}\text { Children } 2-5 \text { yo who attend the HCB } 2 \\
\text { months or more }\end{array}$ & 10668 & 6890 & 5030 & 4840 \\
\hline $\begin{array}{l}\text { For which there is info of controls to } \\
\text { compute the PS }\end{array}$ & 7394 & 4645 & 3817 & 4039 \\
\hline $\begin{array}{l}\text { For which there is info on behavior out- } \\
\text { comes }\end{array}$ & 4879 & 3071 & 2551 & 2697 \\
\hline
\end{tabular}

Note: For around $6 \%$ of the sample there is no informantion on woman's labor force participation. 


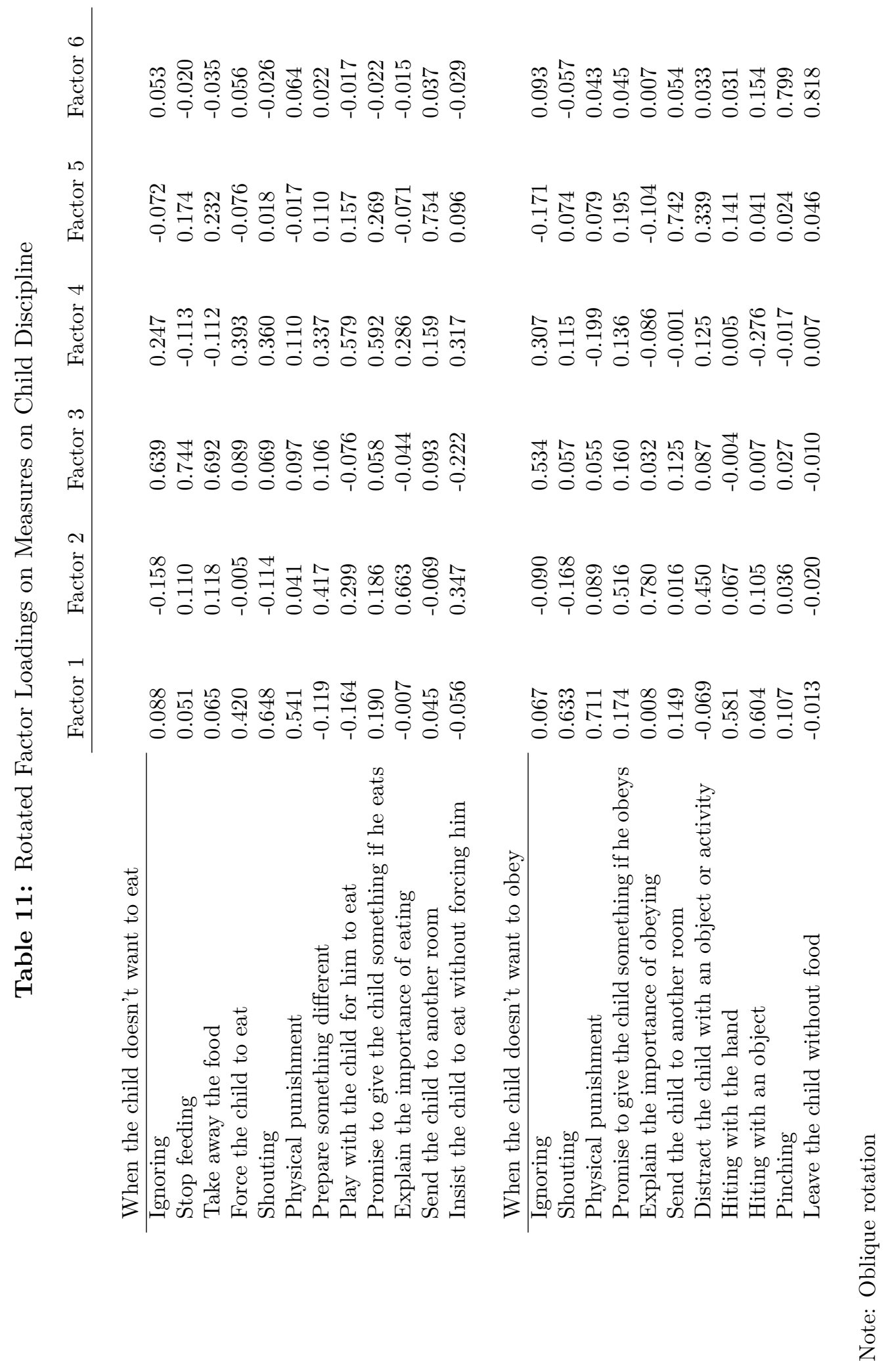


Table 12: Rotated Factor Loadings on Measures on Child's Behavior

\begin{tabular}{llll} 
& Factor 1 & Factor 2 & Factor 3 \\
\cline { 2 - 4 } Plays and works in cooperation with other children & 0.557 & -0.130 & 0.137 \\
Respects the things that belong to other children & 0.646 & -0.282 & -0.050 \\
Respects other children & 0.652 & -0.358 & -0.026 \\
Accepts the responsability of his actions & 0.643 & -0.053 & -0.095 \\
Follows instructions & 0.704 & -0.084 & -0.032 \\
Works independently & 0.602 & 0.056 & -0.030 \\
Follows the rutines at the HCB & 0.437 & -0.006 & 0.039 \\
Gets involved in fights with other children & -0.092 & 0.813 & 0.044 \\
Maltreats or is mean with other children & -0.126 & 0.836 & 0.104 \\
Hits other children or adults & -0.131 & 0.790 & 0.145 \\
Cannot be motionless & 0.002 & 0.132 & 0.810 \\
Gets easily distracted & -0.051 & 0.125 & 0.637 \\
Is restless & -0.049 & 0.109 & 0.804
\end{tabular}

Note: Oblique rotation 


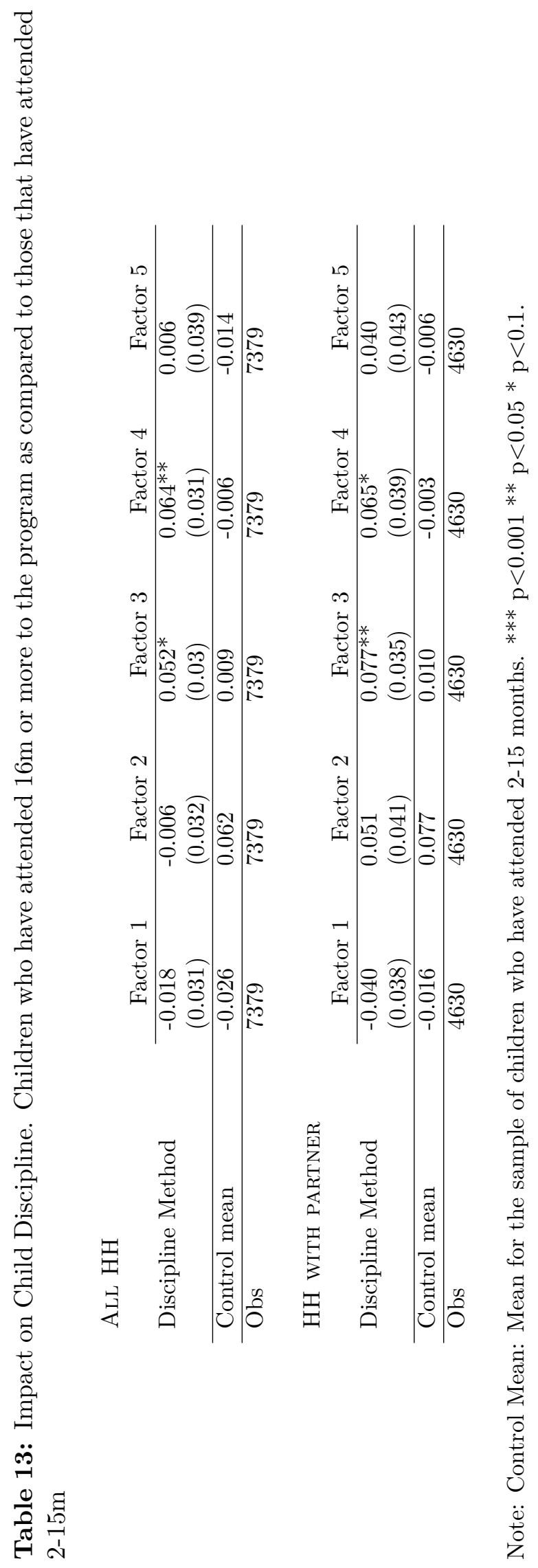




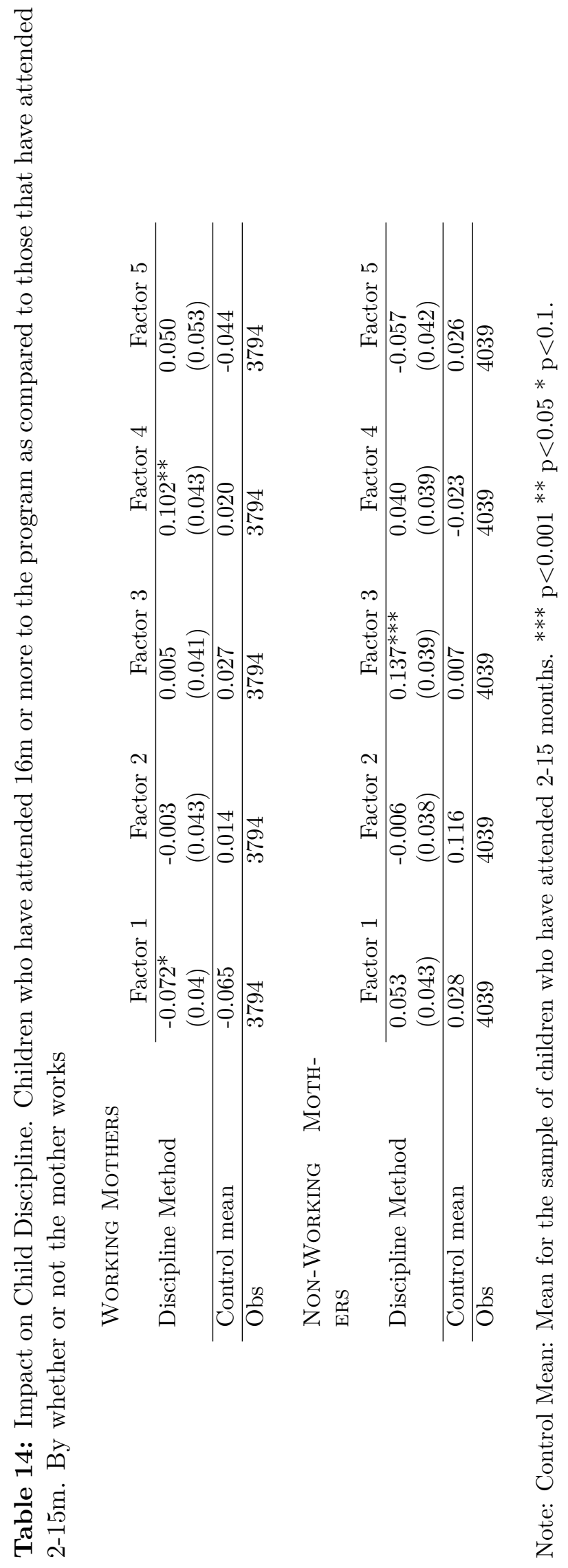




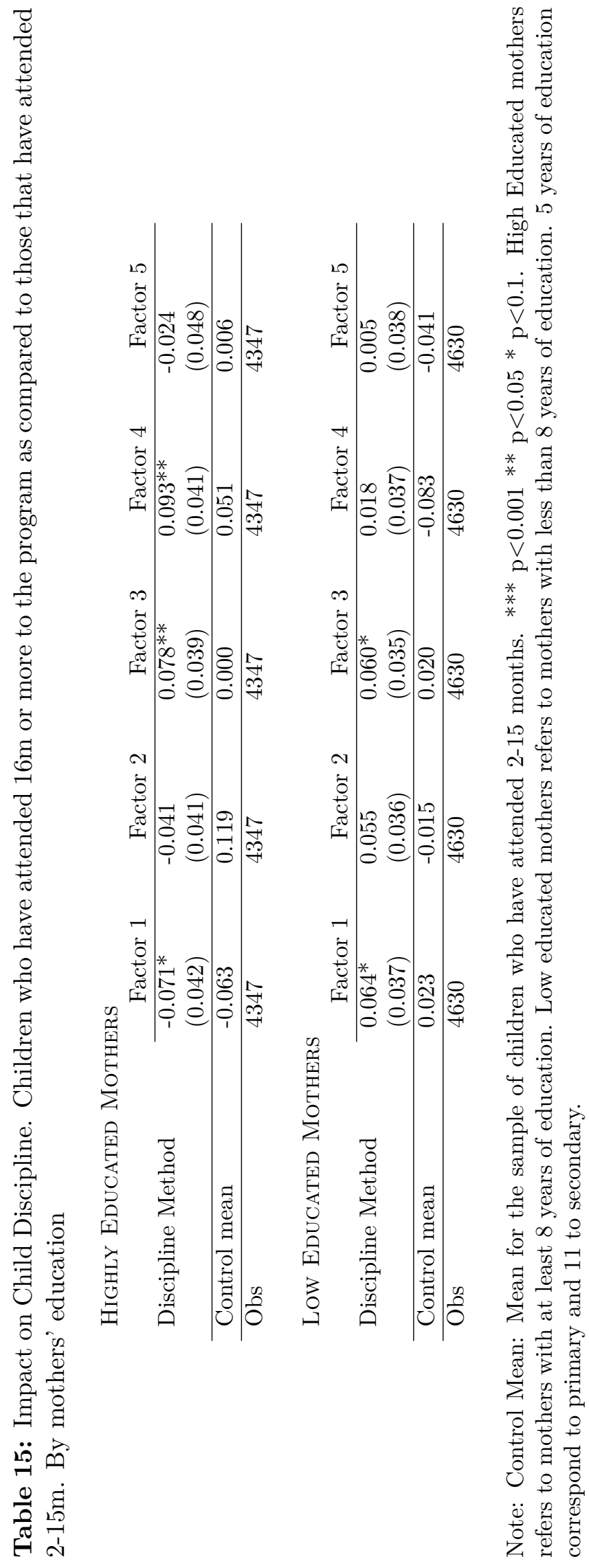




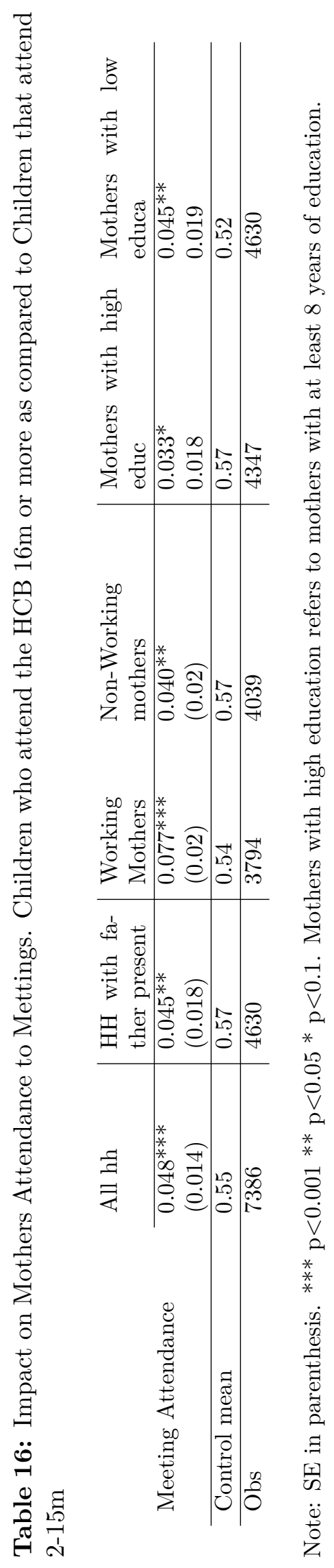


Table 17: Impact on Children's Behavior. Children who attend the HCB 16m or more as compared to Children that attend $2-15 \mathrm{~m}$

\begin{tabular}{llll} 
ALL HH & & & \\
\multirow{2}{*}{ Behavior } & Factor 1 & Factor 2 & Factor 3 \\
\cline { 2 - 4 } & 0.027 & $-0.081^{* *}$ & -0.040 \\
& $(0.033)$ & $(0.032)$ & $(0.034)$ \\
\hline Control mean & 0.003 & 0.001 & 0.004 \\
\hline Obs & 4870 & 4870 & 4870 \\
\multirow{2}{*}{ HH wiTH MOTHER/FATHER } & & \\
& & & \\
Behavior & Factor 1 & Factor 2 & Factor 3 \\
\cline { 2 - 4 } & 0.019 & $-0.081^{* *}$ & -0.054 \\
\hline Control mean & $(0.039)$ & $(0.039)$ & $(0.04)$ \\
\hline Obs & -0.021 & 0.017 & 0.002 \\
\hline
\end{tabular}

HH WITH WORKING MOTHERS

\begin{tabular}{llll} 
& Factor 1 & Factor 2 & Factor 3 \\
\cline { 2 - 4 } Behavior & -0.014 & $-0.119^{* * *}$ & 0.005 \\
& $(0.047)$ & $(0.044)$ & 0.049 \\
\hline Control mean & 0.021 & 0.030 & 0.0150977 \\
\hline Obs & 2529 & 2529 & 2529
\end{tabular}

HH WITH NON-WORKING MOTHERS

\begin{tabular}{llll} 
& Factor 1 & Factor 2 & Factor 3 \\
\cline { 2 - 4 } Behavior & $0.076^{*}$ & -0.040 & $-0.095^{* *}$ \\
& $(0.043)$ & $(0.043)$ & $(0.044)$ \\
\hline Control mean & -0.020 & -0.035 & -0.013 \\
\hline Obs & 2697 & 2697 & 2697
\end{tabular}

MOTHERS WITH EDUC 8 YRS OR MORE

\begin{tabular}{llll} 
& Factor 1 & Factor 2 & Factor 3 \\
\cline { 2 - 4 } Child Behavior & $0.082^{* *}$ & -0.014 & -0.019 \\
& 0.042 & 0.041 & 0.044 \\
\hline Control mean & -0.024 & 0.030 & 0.051 \\
\hline Obs & 2797 & 2797 & 2797
\end{tabular}

MOTHERS WITH EDUCA LESS THAN 8 YRS

\begin{tabular}{llll} 
& Factor 1 & Factor 2 & Factor 3 \\
\cline { 2 - 4 } Child Behavior & -0.003 & $-0.129^{* * *}$ & $-0.091^{* *}$ \\
& 0.042 & 0.04 & 0.04 \\
\hline Control mean & 0.037 & -0.036 & -0.055 \\
\hline Obs & 3197 & 3197 & 3197
\end{tabular}

Note: SE in parenthesis. ${ }^{* * *} \mathrm{p}<0.001{ }^{* *} \mathrm{p}<0.05 * \mathrm{p}<0.1$. 


\section{References}

M. Anandi, S. Mullainathan, E. Shafir, and J. Zhao. Poverty impedes cognitive function. Science, 341, 2013.

O. Attanasio, E. Battistin, E. Fitzsimons, A. Mesnard, and M. Vera-Hernandez. How effective are conditional cash transfers?Evidence from Colombia. Institute for Fiscal Studies Briefing Note, 54, 2005a.

O. Attanasio, L. Gomez, P. Heredia, and M-Vera-Hernandez. The short-term impact of a conditional cash subsidy on child health and nutrition in Colombia. Institute for Fiscal Studies Report Summary, 2005b.

O. Attanasio, S. Cattan, E. Fitzsimons, C. Meghir, and M. Rubio-Codina. Estimating the production function for human capital: results from a randomized control trial in Colombia. NBER Working Paper, 20965, 2015.

F. Barrera-Osorio, L. Linden, and M. Urquiola. The effects of user fee reductions on enrollment. Evidence from a quasi-experiment. Mimeo, The World Bank, 2007.

J. Dym Bartlett and A. Easterbrooks. Links between physical abuse in childhood and child neglect among adolescent mothers. Children and Youth Services Review, 34, 2012.

J. Behrman, Y. Cheng, and P. Todd. Evaluating preschool programs when length to exposure to the program varies: A nonparametric approach. The Review of Economics and Statistics, 86, 2004a.

J. Behrman, S. Parker, and P. Todd. Medium-term effects of the Oportunidades program package, including nutrition and education of rural children age 0-8 in 1997. Technical Document Number 9 on the Evaluation of Oportunidades, 2004b.

L. Berger. Income, family structure, and child maltreatment risk. Children and Youth Services Review, 26, 2004.

S. Berlinski, S. Galiani, and M. Manacorda. Giving children a better start: Preschool attendance and school-age profiles. Journal of Public Economics, 92, 2008.

S. Berlinski, S. Galiani, and P. Gertler. The effect of pre-primary education on primary school performance. Journal of Public Economics, 93, 2009.

R. Bernal and C. Fernandez. Subsidized childcare and child development in Colombia: Effects of Hogares Comunitarios de Bienestar as a function of timing of length of exposure. Social Science \&3 Medicine, 2013.

R. Bernal, C. Fernandez, C.E. Florez, A. Gaviria, P. Ocampo, F. Sanchez, and B. Samper. Evaluacion de impacto del programa Hogares Comunitarios de Bienestar del ICBF. Documento CEDE, 16, 2009. 
M. Bottia, L. Cardona-Sosa, and C. Medina. El Sisben como mecanismo de focalizacion individual del regimen subsidiado en salud en Colombia: ventajas y limitaciones. Revista de Economia del Rosario, 15, 2012.

A. Camacho and E. Conover. Manipulation of social program eligibility: Detection, explanations and consequences for empirical research. Documento CEDE, 19, 2009.

A. Camacho, E. Conover, F. Espinosa, C.E Florez, and L.M. Sanchez. El Sisben: su diseño y evolucion. Notas de Politica, N.4, CEDE-Universidad de los Andes, 2010.

T. Castañeda. Targeting social spending to the poor with proxy means testing: Colombia's Sisben system. Social Protection Discussion Paper Series. World Bank, 0529, 2005.

E. Castaño, C.E. Velez, and R. Deutsch. An economic interpretation of targeting systems for social programs: The case of Colombia's Sisben. Mimeo. Poverty and Inequality Advisory Unit, IDB Washington, 1999.

DNP. Politica publica nacional de primera infancia: Colombia por la primer infancia. Conpes Social 109, 2007.

DNP. Actualizacion de los criterios para la determinacion, identificacion y seleccion de beneficiarios de programas sociales. Conpes Social 117, 2008.

DNP. Evaluacion de impacto del programa Hogares Comunitarios de Bienestar del ICBF. Departamento Nacional de Planeacion, 2009.

M. Dong, R. Anda, V. Felitti, S. Dube, D. Williamson, and T. Thompson. The interrelatedness of multiple forms of childhood abuse, neglect, and household dysfunction". Child Abuse and Neglect, 28, 2004.

R. Duncan. Childhood maltreatment and college dropout rates: Implications for child abuse researchers. Journal of Interpersonal Violence, 15, 2000.

J. Elster. Social norms and economic theory. Journal of Economic Perspectives, 3, 1999.

A. Fiszben and N. Schady. Conditional cash transfers: Reducing present and future poverty. World Bank Policy Research Report, 2009.

J. Heckman and P. Todd. A note of adapting propensity score matching and selection models to choice based samples. NBER Working Paper, 15179, 2009.

T. Herrenkohl, C. Sousa, E. Tajima, R. Herrenkohl, and C. Moylan. Intersection of child abuse and children's exposure to domestic violence". Trauma, Violence and Abuse, 9, 2008.

A. Hoeffler and J. Fearon. Conflict and violence. Assessment paper. Copenhagen Consensus Center, 2014.

H. Hughes, D. Parkinson, and M. Vargo. Witnessing spouse abuse and experiencing physical abuse: A "double whammy". Journal of Family Violence, 1989. 
ICBF. Fundamentos tecnicos de la estrategia de atencion integral a la primera infancia. Documento base para la discusion de lineamientos, a.

ICBF. Lineamiento tecnico de salud en la pimera infancia. Documento base para la discusion de lineamientos, b.

ICBF. Lineamientos tecnicos. Modalidaes hogares infantiles-lactantes y preescolares. Ministerio de la Proteccion Social. Instituto Colombiano de Bienestar Familiar, 2006.

ICBF. Manual operativo.Modalidades de educacion inicial en el marco de una atencion integral para la primera infancia. Insitituto Colombiano de Bienestar Familiar, 2013.

G. Imbens. Nonparametric estimation of average treatment effects under exogeneity: A review. The Review of Economics and Statistics, 86, 2004.

G. Imbens and K. Kalyanaraman. Optimal bandwidth choice for the regression discontinuity estimator. cemmap working paper. IFS, 2010.

G. Imbens and J. Wooldridge. Recent developments in the econometrics of program evaluation. Journal of Economic Literature, 47, 2009.

J. Kaufman and E. Zigler. Do abused children become abusive parents? American journal of orthopsychiatry, 57, 1987.

S. Klein. The availability of neighborhood early care and education resources and the maltreatment of young children. Child Maltreatment, 16, 2011.

J. Lansford, K. Dodge, G. Petit, J. Bates, J. Crozier, and J. Kaplow. A 12-year prospective study of the long-term effects of early child physical maltreatment on psychological, behavioral, and academic problems in adolescence. Archives of Pediatrics and Adolescent Medicine, 156, 2002.

J. Lansford, S. Miller-Johnson, L. Berlin, K. Dodge, J. Bates, and G. Pettit. Early physical abuse and later violent delinquency: A prospective longitudinal study. Child Maltreatment, $12,2007$.

D. Lee and T. Lemieux. Regression discontinuity designs in economics. Journal of Economic Literature, 48, 2010.

M. MacKenzie, E. Nicklas, J. Brooks-Gunn, and J. Waldfogel. Who spanks infants and toddlers? Evidence from the fragile families and child well-being study. Children and Youth Services Review, 33, 2011.

K. Macours, N. Schady, and R. Vakis. Cash transfers, behavioral changes, and cognitive development in early childhood: Evidence from a randomized experiment. American Economic Journal: Applied Economics, 4, 2012.

J. McCrary. Manipulation of the running variable in the regression discontinuity design: A density test. Journal of Econometrics, 142, 2008. 
MinProteccion. Norma técnica para la detección temprana de alteraciones del crecimiento y desarrollo en el menor de 10 años. Ministerio de Protección Social.

C. Paxon and N. Schady. Cognitive development among young children in Ecuador: The roles of wealth, health and parenting. The Journal of Human Resources, 42, 2007.

C. Paxon and N. Schady. Does money matter?The effect of cash transfers on child health and development in rural Ecuador. Economic Development and Cultural Change, 59, 2010.

C. Paxson and J. Waldfogell. Parental resources and child abuse and neglect. The American Economic Review. Papers and Proceedings of the One Hundred Eleventh Annual Meeting of the American Economic Association, 89, 1999.

P. Pinhero. World report on violence against children. WHO. Geneva, 2006.

Profamilia. Salud sexual y reproductiva en Colombia. Resultados Encuesta Nacional de Demografia y Salud, 2005, 2005.

M. Rubio-Codina, O. Attanasio, C. Meghir, N. Varela, and S. Grantham-McGregor. The socio-economic gradient of child development. IDB Working Paper Series, 527, 2013.

N. Schady. Early childhood development in Latin America and the Caribbean. World Bank Policy and Research Working Paper, 3869, 2006.

N. Schady, J. Behrman, M. Araujo, R. Azuero, R. Bernal, D. Bravo, F. Lopez-Boo, D. Marshall, C. Paxson, R. Vakis, and K. Macours. Wealth gradients in early childhood cognitive development in five Latin American countries. IDB Working Paper Series, 482, 2014.

Unicef. Hidden in plain sight. A statistical analysis of violence against children. UNICEF, 2014.

C. Widom. The cycle of violence. Science, 244, 1989. 
Figures 
Figure 1: Sisben Distribution
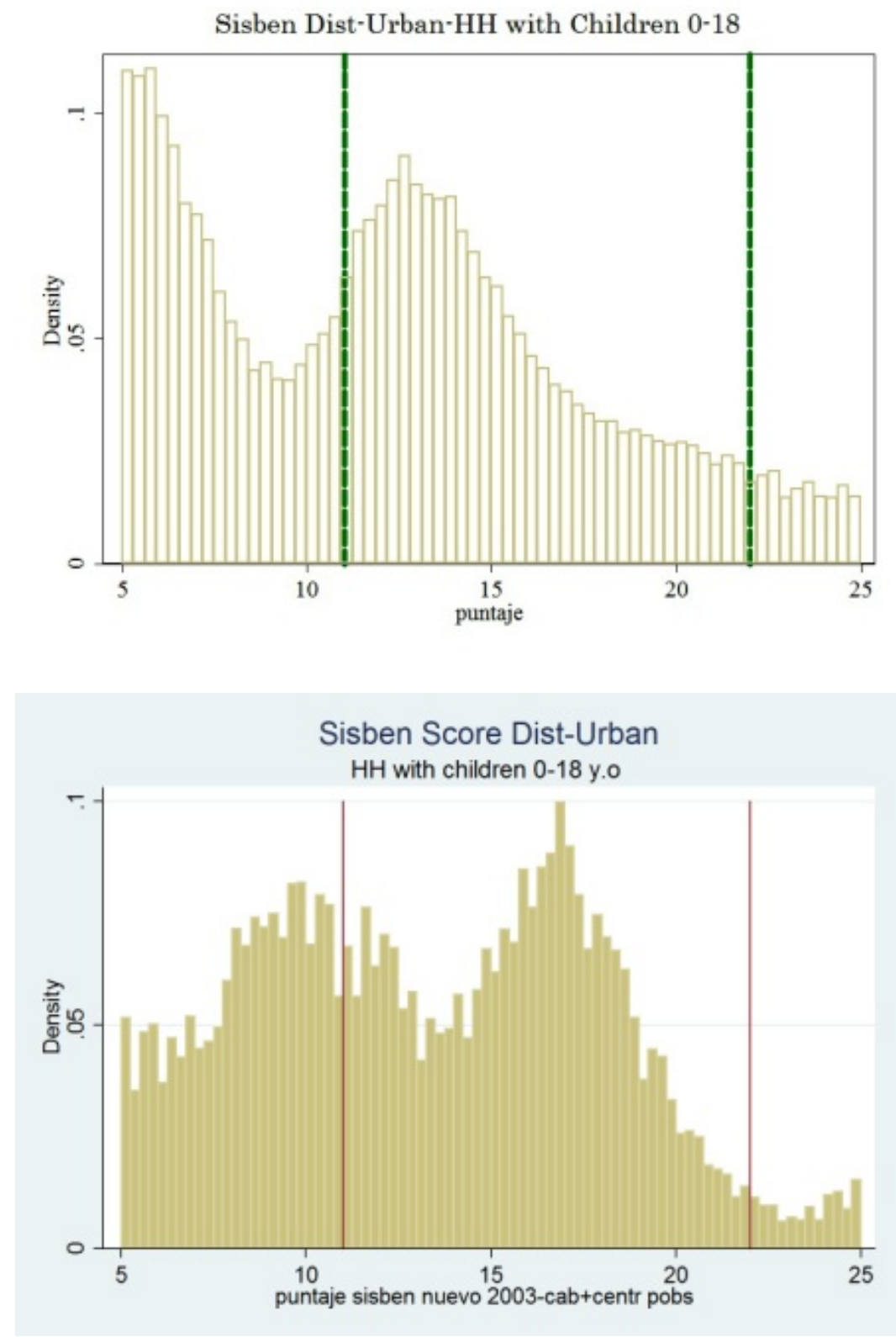

Note: Top graph corresponds to data from the Sisben Survey, while the bottom one corresponds to DHS data

Source: BanRep (Medellin) and DHS05 
Figure 2: McCray Test

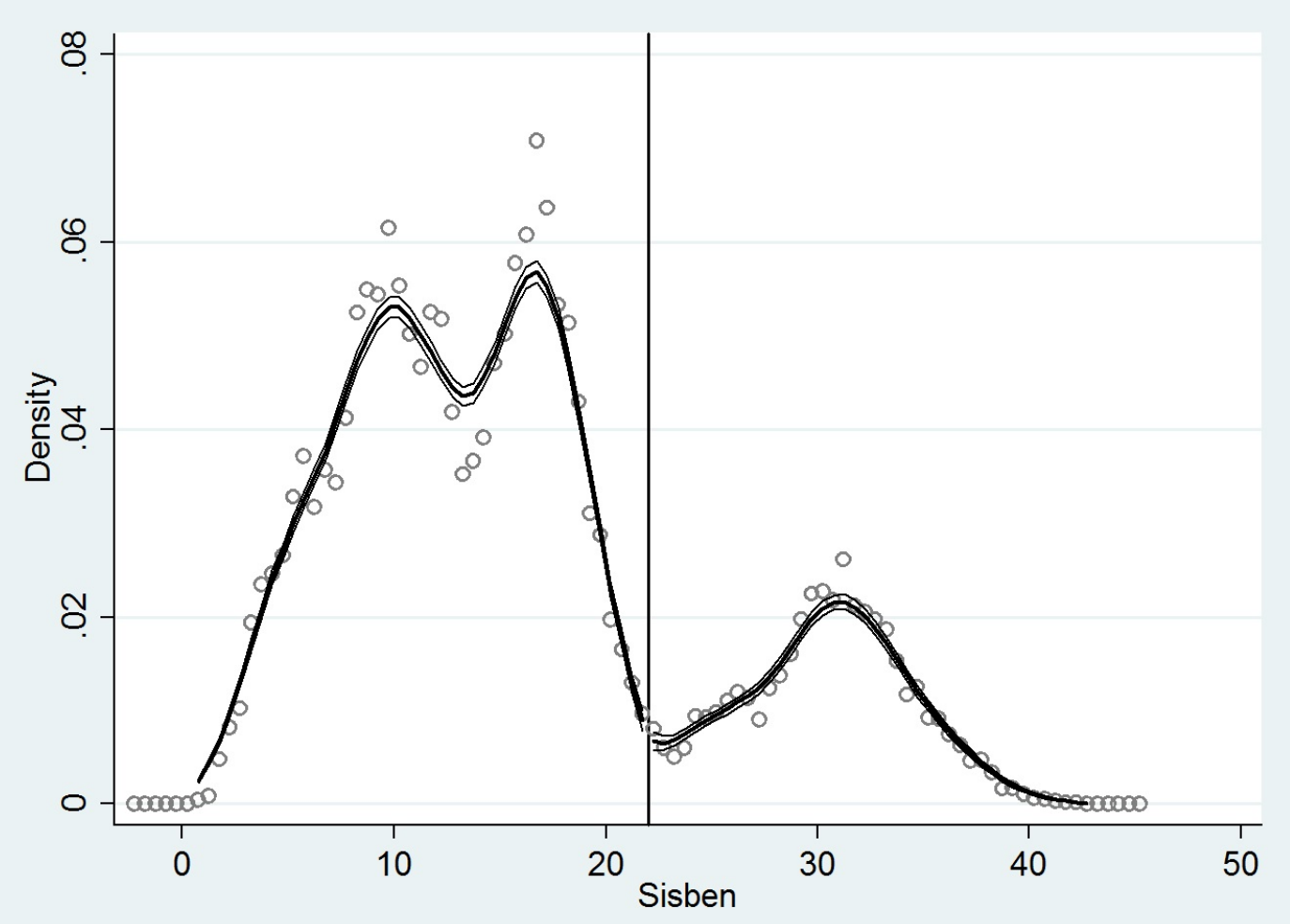

Note: Sample of HH with children 0-18 y.o. Bin Size: 0.5, Bandwidth: 3. Discontinuity estimate: $-0.0118(0.1237) \mathrm{SE}$ in parenthesis 
Figure 3: Discontinuity on Growth and Development Checks. Children 0-4 y.o.

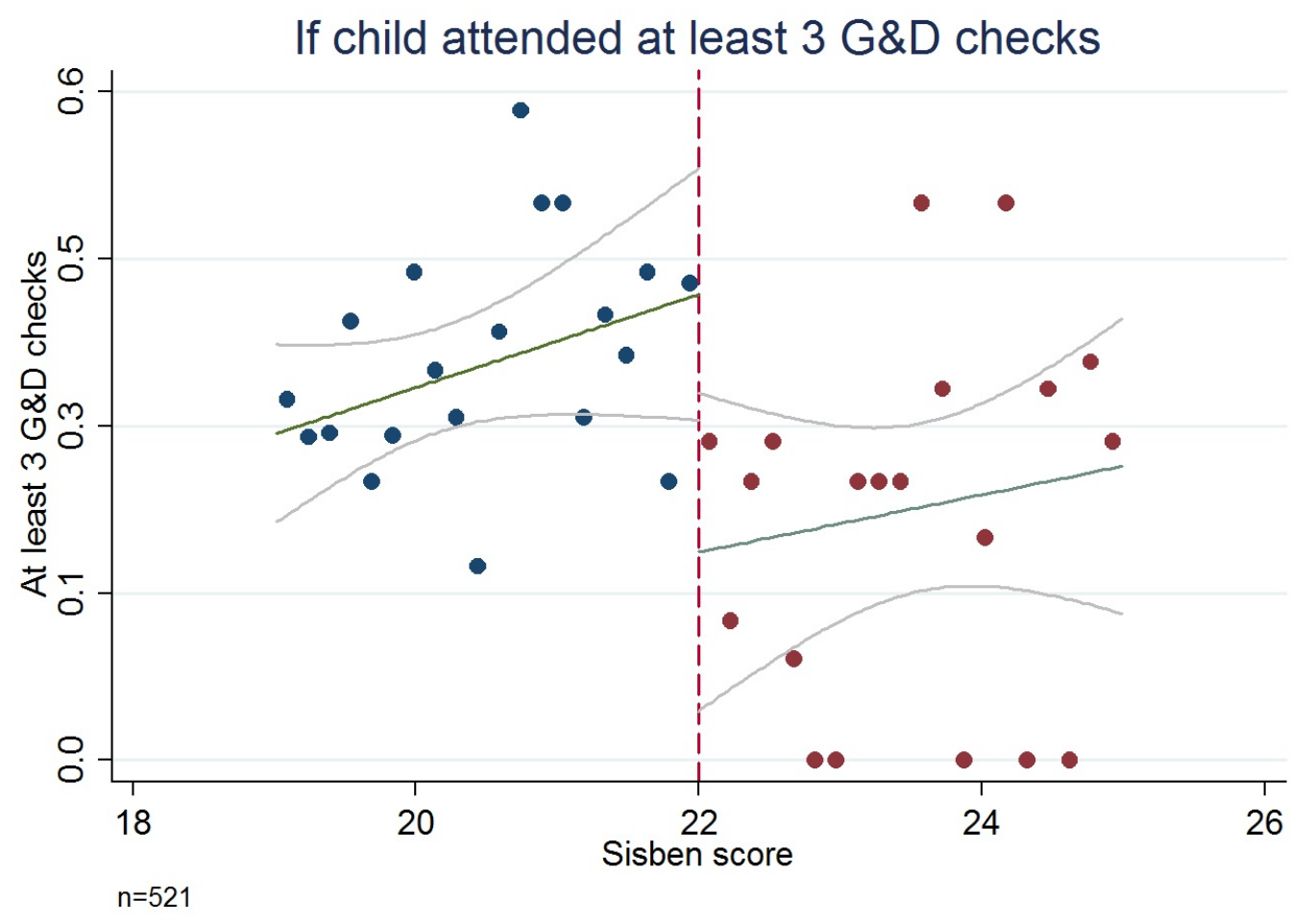

Note: Bin Size: 0.15. Linear Fit. 


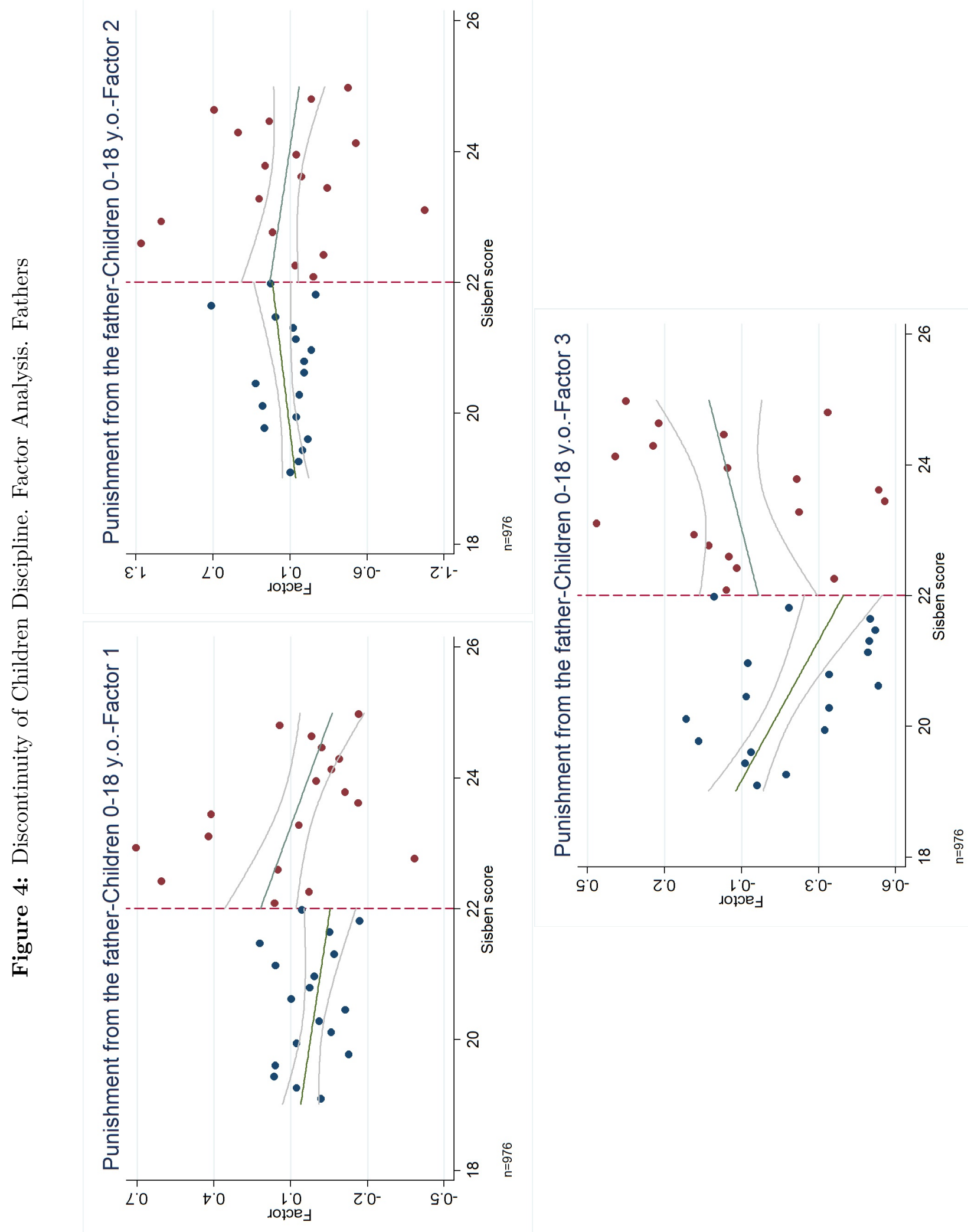

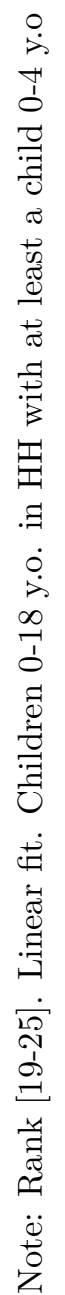




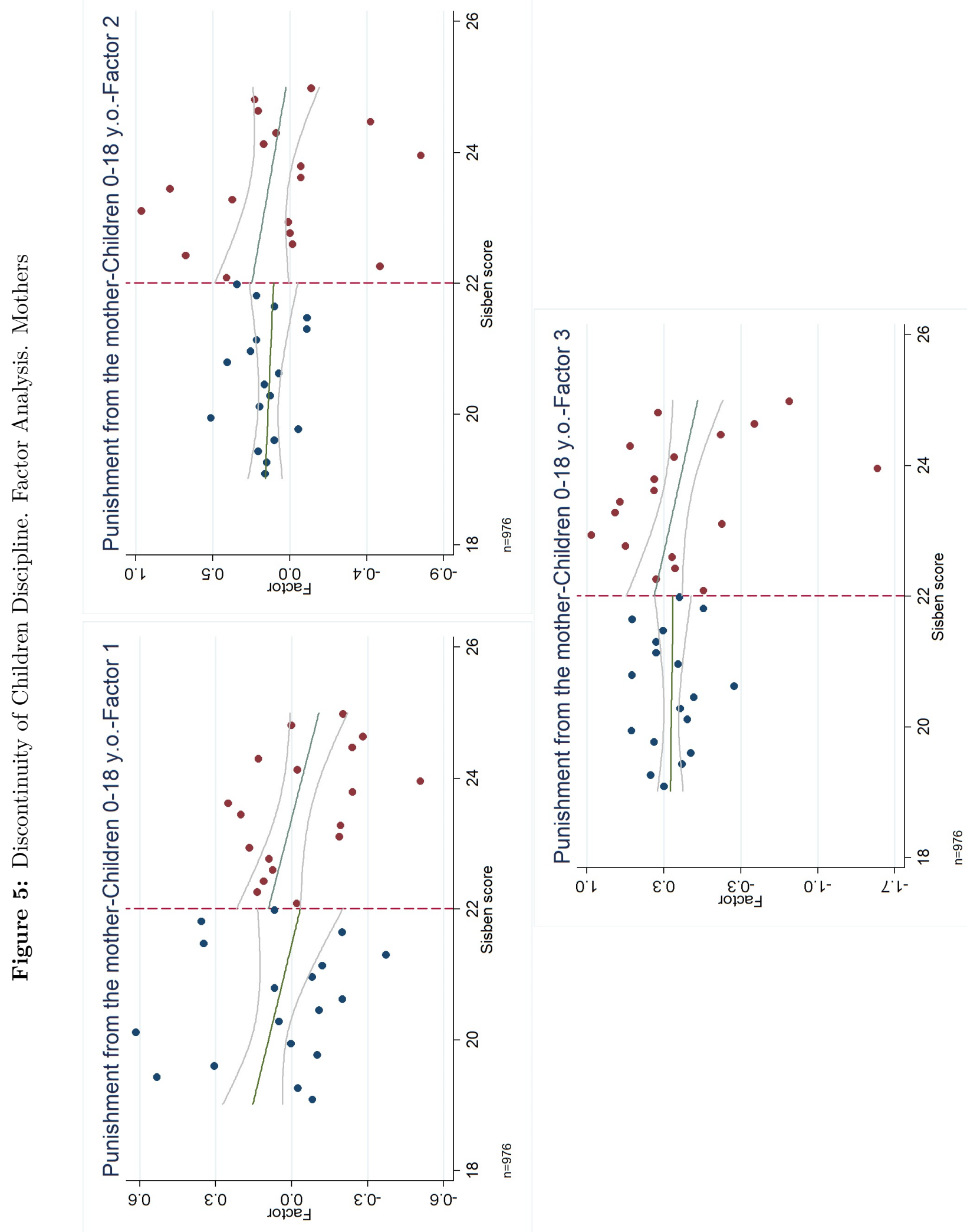

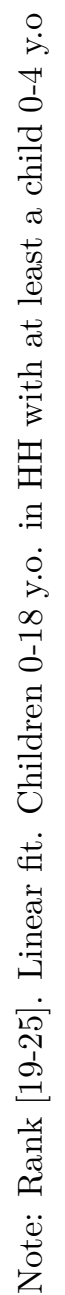


Figure 6: Discontinuity of Children Discipline. Factor Analysis. HH in which the mother works outside the $\mathrm{HH}$
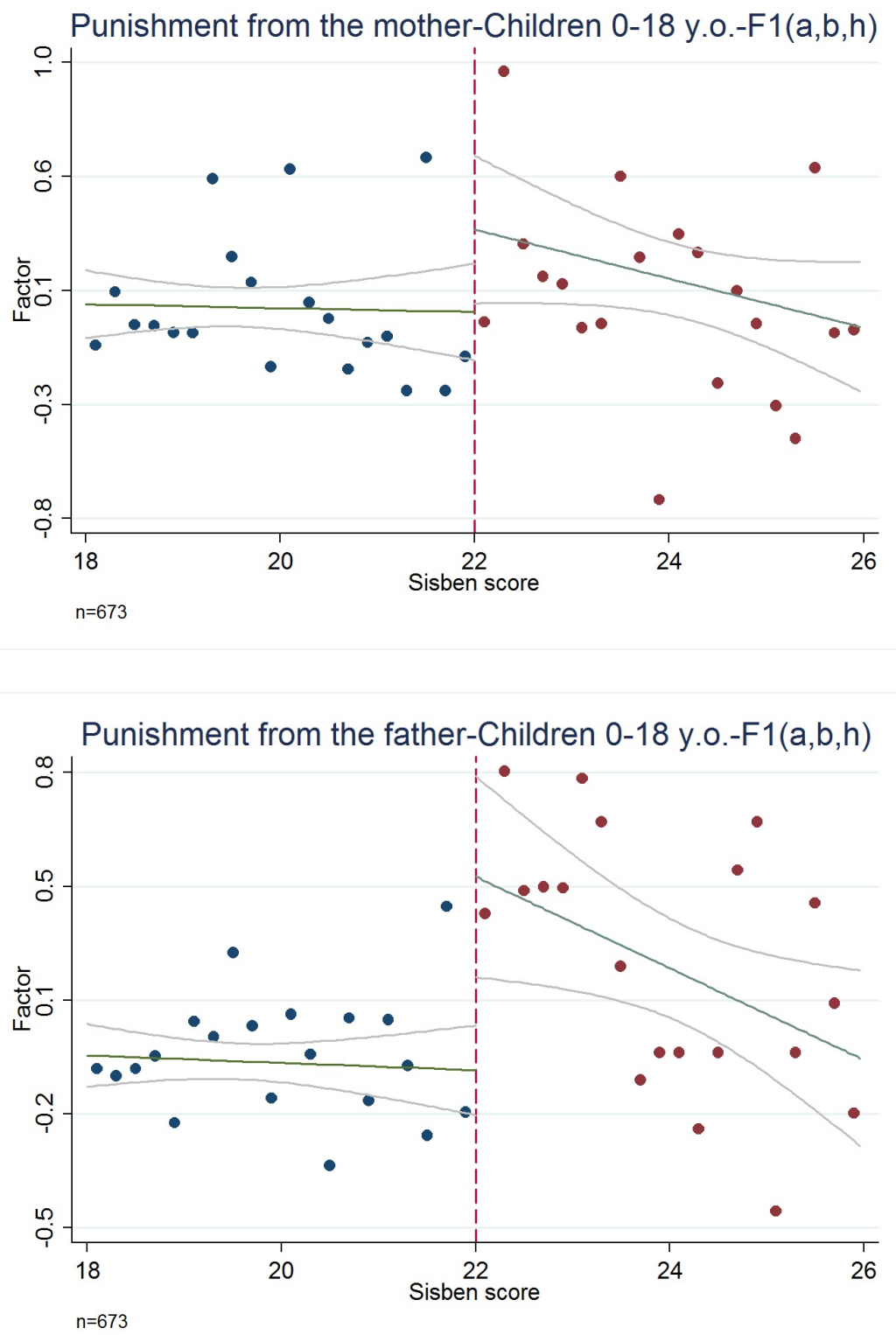

Note: Rank [18-26]. Linear fit. Children 0-18 y.o. in HH with at least a child 0-4 y.o 
Figure 7: Discontinuity of Children Discipline. Factor Analysis. HH in which the mother has education secondary or higher
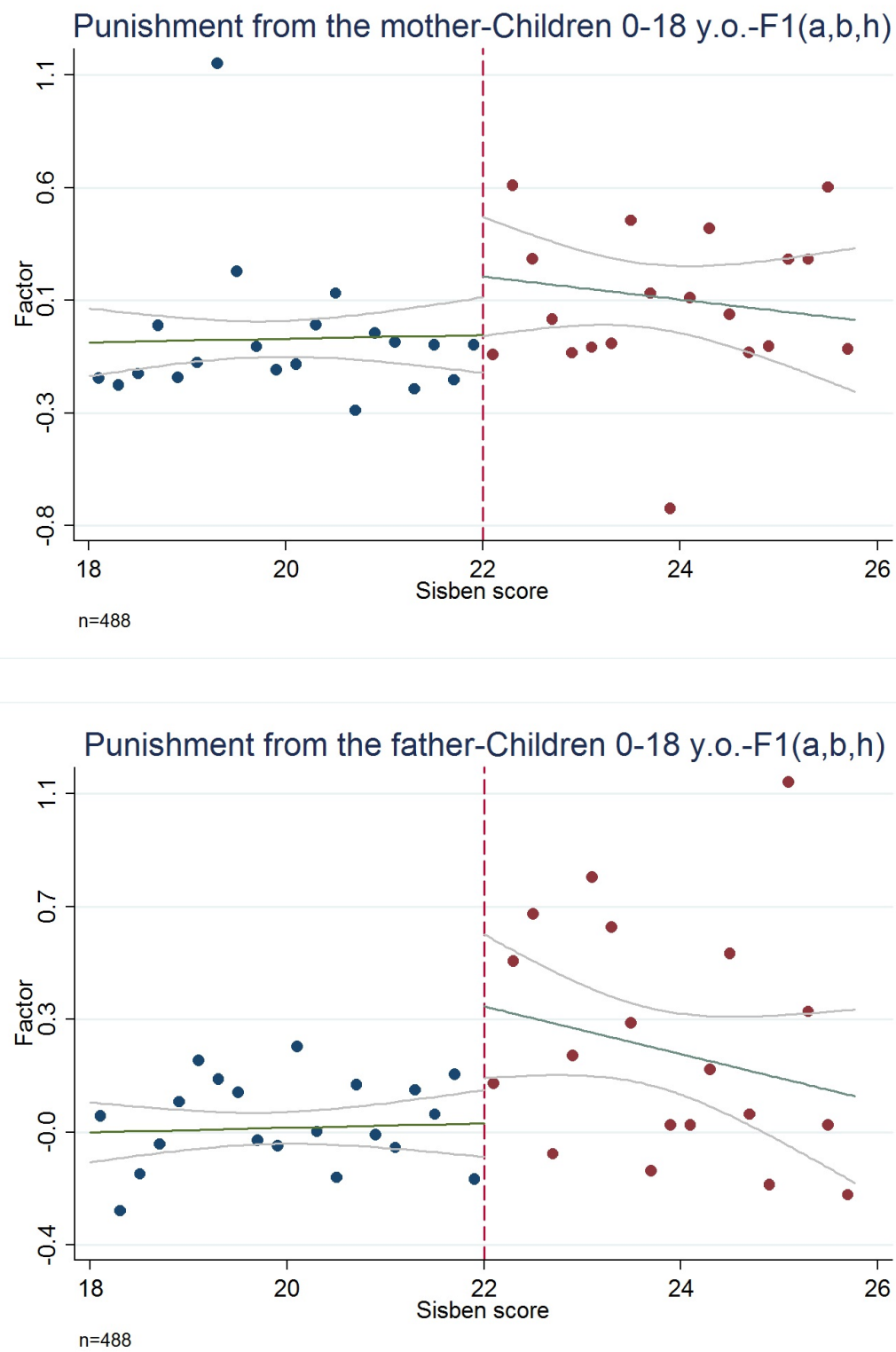

Note: Rank [18-26]. Linear fit. Children 0-18 y.o. in HH with at least a child 0-4 y.o 
Figure 8: Distribution of PSM

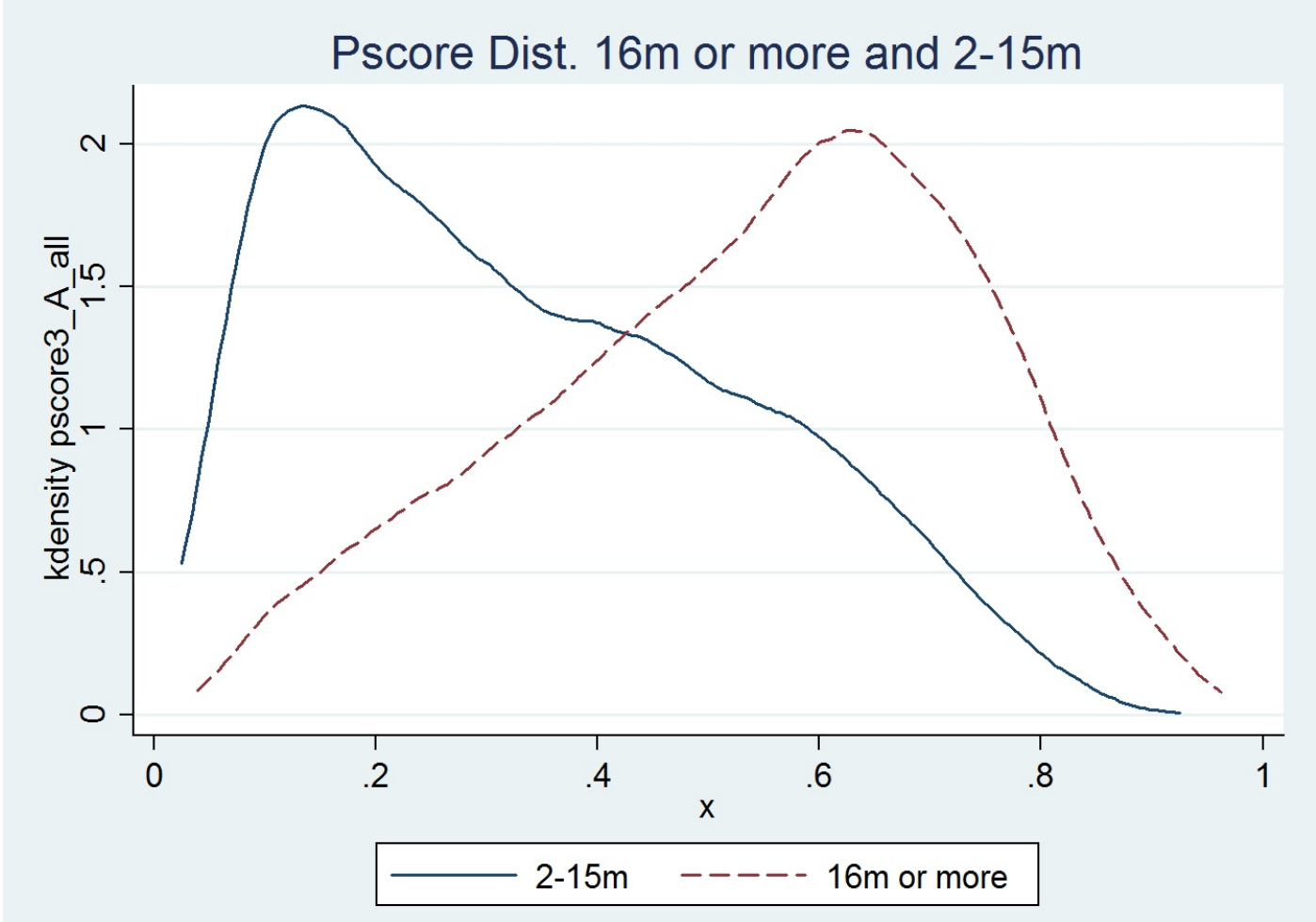




\section{A Appendix}

Table A.1: Main programs that used Sisben as one of the main targeting criteria

\begin{tabular}{|c|c|c|c|}
\hline \multirow[t]{2}{*}{ Age } & \multirow[t]{2}{*}{ Program } & \multicolumn{2}{|c|}{ Sisben level to which is targeted } \\
\hline & & Sisben 1 & Sisben 2 \\
\hline \multirow{8}{*}{$0-6$ y.o } & Hogares Fami & $\mathrm{X}$ & $\mathrm{X}$ \\
\hline & Hogares Comunitarios de Bienestar & $\mathrm{X}$ & $\mathrm{X}$ \\
\hline & Hogares Infantiles & $\mathrm{X}$ & $\mathrm{X}$ \\
\hline & Jardines Comunitarios & $\mathrm{X}$ & $\mathrm{X}$ \\
\hline & Desayunos Infantiles & $\mathrm{X}$ & $\mathrm{X}$ \\
\hline & Subsidized health regime (which includes & $\mathrm{X}$ & $\mathrm{X}$ \\
\hline & Growth and Development checks) & & \\
\hline & Familias en Accion & $\mathrm{X}$ & \\
\hline \multirow{9}{*}{ Older children and adults } & Familias en Accion & $\mathrm{X}$ & \\
\hline & Empleo en Accion & $\mathrm{X}$ & \\
\hline & Programa de Alimentacion para el adulto & $\mathrm{X}$ & $\mathrm{X}$ \\
\hline & mayor (nutritional program for the elderly) & & \\
\hline & Subsidized Health Regime & $\mathrm{X}$ & $\mathrm{X}$ \\
\hline & Housing Subsidy & $\mathrm{X}$ & $\mathrm{X}$ \\
\hline & Jovenes en Accion & $\mathrm{X}$ & $\mathrm{X}$ \\
\hline & Gratuidad (Reduction in enrollment fees) & $\mathrm{X}$ & $\mathrm{X}$ \\
\hline & $\begin{array}{l}\text { ACCESS (Acceso con Calidad a la Educacion } \\
\text { Superior) }\end{array}$ & $\mathrm{X}$ & \\
\hline
\end{tabular}

Source: DNP, 2008 
Table A.2: Outline Growth and Development Checks

\begin{tabular}{|c|c|c|}
\hline ACTIVITY & AGE & FREQUENCY \\
\hline Registration & $0-1 \mathrm{~m}$ & \\
\hline Medical appointment & $0-1 \mathrm{~m}$ & \\
\hline \multirow{5}{*}{ Monitoring (in charge of a nurse) } & $0-12 \mathrm{~m}$ & Every 3 months \\
\hline & $13-24 \mathrm{~m}$ & Every 4 months \\
\hline & $2-4 y$ & $\begin{array}{l}25-30 \mathrm{~m} \\
31-36 \mathrm{~m} \\
37-48 \mathrm{~m} \\
49-60 \mathrm{~m}\end{array}$ \\
\hline & $5-7 y$ & $\begin{array}{l}61-66 \mathrm{~m} \\
67-72 \mathrm{~m} \\
73-78 \mathrm{~m} \\
79-84 \mathrm{~m} \\
\end{array}$ \\
\hline & $8-10 y$ & Every year \\
\hline
\end{tabular}

Source: MinProteccion 


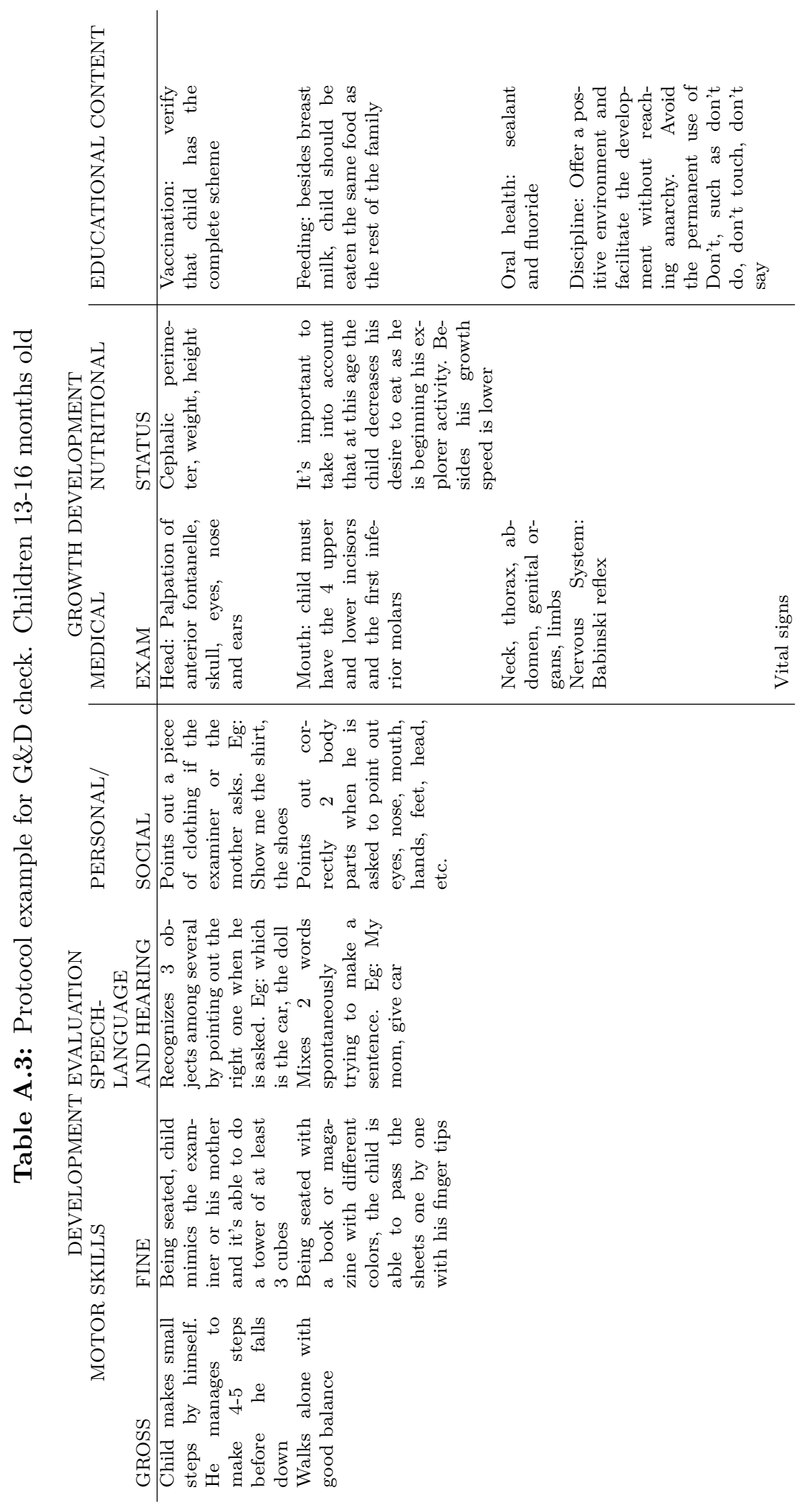

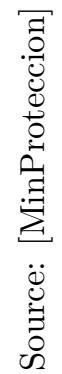


Table A.4: Sisben Thresholds. Methodology II

\begin{tabular}{c|c|c} 
& Urban & Rural \\
\hline Sisben 1 & {$[0-11)$} & {$[0-17.5)$} \\
Sisben 2 & {$[11-22)$} & {$[17.5-32)$} \\
Sisben 3 & {$[22-43)$} & {$[32-51)$} \\
Sisben 4 & {$[43-65)$} & \\
Sisben 5 & {$[65-79)$} & {$[51-100]$} \\
Sisben 6 & {$[79-100]$} &
\end{tabular}

Source: http://sisben.cali.gov.co/con_sisben/consisben.php

Note: Urban refers to capital municipalities and seat of the municipal government, while rural refers to rural dispersed areas

Table A.5: Rates in which each measure of child discipline is used by Sisben Level

\begin{tabular}{lccc|ccc} 
& \multicolumn{3}{c}{ FATHER } & \multicolumn{3}{c}{ MOTHER } \\
& \multicolumn{3}{c}{ Sisben Level } & \multicolumn{3}{c}{ Sisben Level } \\
\cline { 2 - 8 } & 1 & 2 & 3 & 1 & 2 & 3 \\
spanking them & 0.17 & 0.19 & 0.20 & 0.26 & 0.28 & 0.29 \\
pushing them & 0.01 & 0.01 & 0.01 & 0.02 & 0.02 & 0.02 \\
verbal reprimand & 0.77 & 0.74 & 0.72 & 0.77 & 0.74 & 0.71 \\
prohibiting something they like & 0.39 & 0.46 & 0.54 & 0.51 & 0.61 & 0.67 \\
depriving from food & 0.01 & 0.00 & 0.01 & 0.01 & 0.01 & 0.00 \\
hitting with objects & 0.52 & 0.45 & 0.38 & 0.61 & 0.55 & 0.47 \\
keeping them looked up & 0.01 & 0.01 & 0.01 & 0.02 & 0.02 & 0.02 \\
ignoring them & 0.00 & 0.01 & 0.01 & 0.01 & 0.02 & 0.02 \\
assigning non-appropiate work & 0.01 & 0.00 & 0.00 & 0.02 & 0.01 & 0.00 \\
leaving them out of the hh & 0.00 & 0.00 & 0.00 & 0.00 & 0.00 & 0.00 \\
throwing water at them & 0.00 & 0.00 & 0.00 & 0.00 & 0.00 & 0.00 \\
hiding their clothes & 0.00 & 0.00 & 0.00 & 0.00 & 0.00 & 0.00 \\
taking away belongings & 0.00 & 0.00 & 0.00 & 0.00 & 0.00 & 0.00 \\
withdrawing economic support & 0.00 & 0.00 & 0.01 & 0.00 & 0.00 & 0.01 \\
\hline Obs & 5681 & 7823 & 3509 & 8877 & 12668 & 5832
\end{tabular}


Table A.6: Rotated Factor Loadings on Measures of Domestic Violence

has accused you of being unfaithful

doesn't allow to meet your friends

has tried to limit contact with your family

have used insulting terms

has threatened you to leave you for other woman

has threatened you to take your children

has threatened you to take out economic support

has threatened you with a knife, fire arm or other weapon

has pushed you

has beaten you with the hand

has beaten you with an object

has bitten you

has kicked you or dragged you

has tried to strangle or burn you

has forced you to have sex

\begin{tabular}{ll} 
Factor 1 & Factor 2 \\
\hline 0.6961 & 0.2493 \\
0.6528 & 0.3019 \\
0.4036 & 0.5804 \\
0.1826 & 0.4501 \\
0.1614 & 0.7673 \\
0.2983 & 0.5772 \\
0.4855 & 0.3705 \\
0.6555 & 0.0441 \\
0.6659 & 0.0265 \\
0.6231 & 0.0915 \\
0.6568 & 0.0826 \\
0.6286 & 0.0353 \\
0.6246 & 0.0461 \\
0.6529 & 0.1324 \\
0.3171 & 0.7519
\end{tabular}




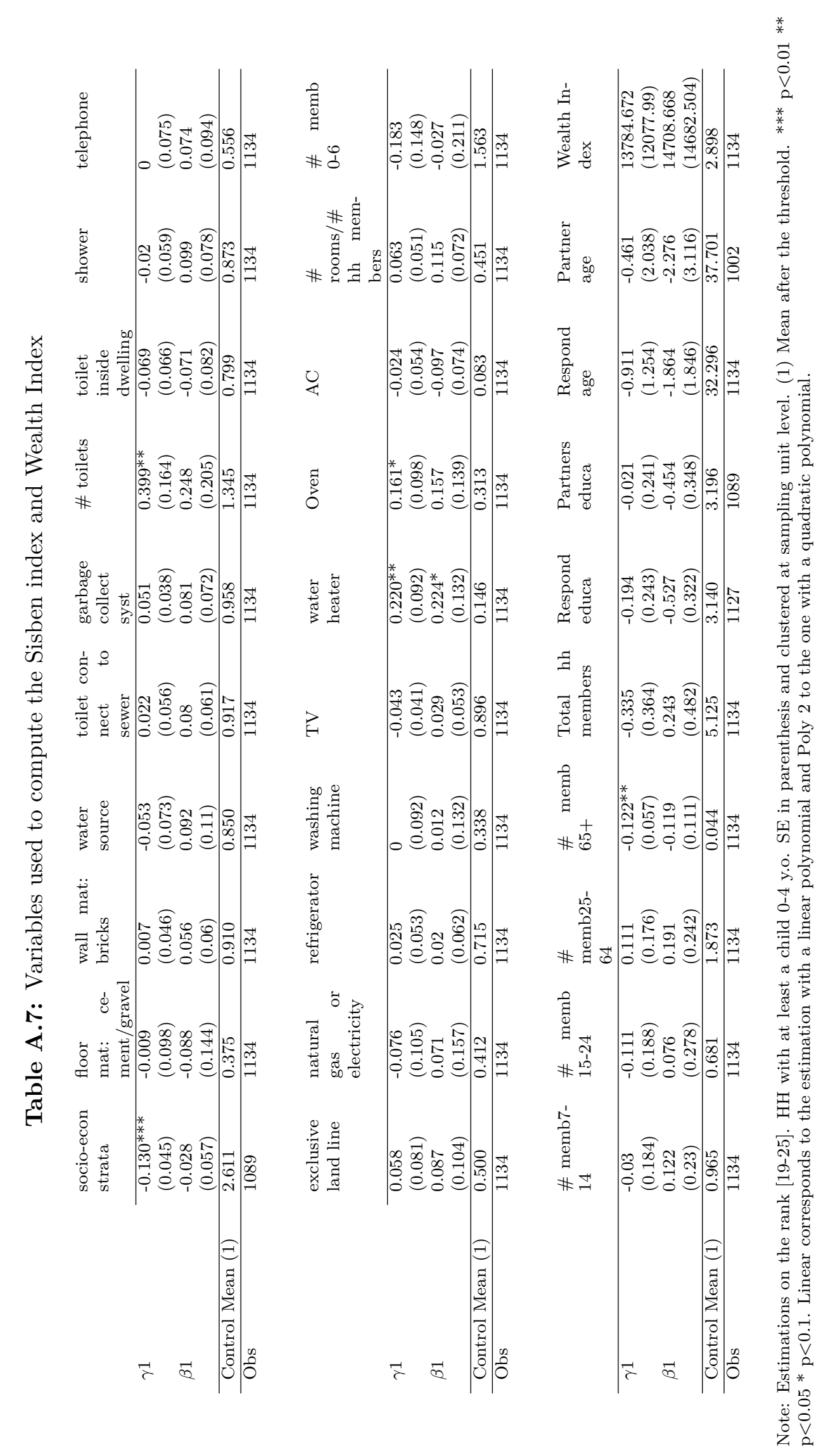


Table A.8: Differences between mothers that work outside the household and those that do not

\begin{tabular}{|c|c|c|c|c|c|c|}
\hline & All $\mathrm{HH}$ & $\begin{array}{l}\text { Work out- } \\
\text { side HH } \\
(2)\end{array}$ & $\begin{array}{l}\text { Doesnt work } \\
\text { or work in- } \\
\text { side the HH } \\
(3)\end{array}$ & $(2)-(3)$ & SE Diff & Obs \\
\hline \# members 0-6 yo & 1.515 & 1.439 & 1.566 & $-0.127^{* *}$ & $(0.053)$ & 2014 \\
\hline \# members 7-14 yo & 0.888 & 0.839 & 0.922 & -0.082 & $(0.074)$ & 2014 \\
\hline \# members $15-24$ yo & 0.626 & 0.536 & 0.686 & $-0.150^{* *}$ & $(0.059)$ & 2014 \\
\hline \# members $25-64$ yo & 1.887 & 1.875 & 1.896 & -0.021 & $(0.054)$ & 2014 \\
\hline \# members 65 or above & 0.061 & 0.066 & 0.057 & 0.01 & $(0.02)$ & 2014 \\
\hline Woman Educ (level) & 3.302 & 3.642 & 3.070 & $0.572^{* * *}$ & $(0.071)$ & 1997 \\
\hline Partner Educ(level) & 3.354 & 3.459 & 3.281 & $0.178^{* *}$ & $(0.072)$ & 1926 \\
\hline Woman Age & 31.617 & 32.237 & 31.195 & $1.042^{* *}$ & $(0.429)$ & 2014 \\
\hline Partner Age & 36.010 & 35.493 & 36.338 & -0.845 & $(0.587)$ & 1783 \\
\hline Wealth Index & 3.536 & 3.602 & 3.491 & 0.111 & $(0.07)$ & 2014 \\
\hline
\end{tabular}

Note: Analysis in the rank [18-26]. Children 0-18 y.o in HH with at least one child 0- 4 y.o. Standard errors in parenthesis. For education level, 3 corresponds to secondary and 4 to technical post-secondary.

Table A.9: Placebo Test for Children Discipline

\begin{tabular}{lll} 
& Father & Mother \\
\cline { 2 - 3 }$\beta 1$ & -0.025 & 0.220 \\
& $(0.183)$ & $(0.241)$ \\
\hline Obs & 1020 & 1020
\end{tabular}

Note: (1) Mean after threshold. Rank [19-25]. Children 5-18 y.o in HH with NO child 0- 4 y.o. SE in parenthesis and clustered at sample unit level. ${ }^{* * *} \mathrm{p}<0.001 * * \mathrm{p}<0.05^{*} \mathrm{p}<0.1$. 
Table A.10: Children Discipline Discontinuity (Factor 1). Mothers and Fathers. By Children's Age

\begin{tabular}{lll} 
Children 0-4 y.o. & Father & Mother \\
\cline { 2 - 3 }$\beta 1$ & $0.367^{* *}$ & 0.287 \\
& $(0.174)$ & $(0.272)$ \\
\hline Control Mean (1) & 0.094 & -0.019 \\
\hline Obs & 570 & 570
\end{tabular}

Children 5-18 y.o.

\begin{tabular}{lll} 
& Father & Mother \\
\cline { 2 - 3 }$\beta 1$ & $0.390^{*}$ & -0.232 \\
& $(0.231)$ & $(0.519)$ \\
\hline Control Mean (1) & 0.028 & 0.008 \\
\hline Obs & 406 & 406
\end{tabular}

Note: (1) Mean after threshold. Rank [19-25]. HH with at least a child 0-4 y.o. SE in parenthesis and clustered at sample unit level. ${ }^{* * *} \mathrm{p}<0.001 * * \mathrm{p}<0.05 * \mathrm{p}<0.1$.

Table A.11: Impact on Domestic Violence

\begin{tabular}{lll} 
& Factor 1 & Factor 2 \\
\cline { 2 - 3 }$\beta 1$ & -0.179 & 0.6 \\
& $(0.3)$ & $(0.515)$ \\
\hline Control Mean(1) & -0.328 & -0.078 \\
\hline Obs & & 942
\end{tabular}

Note: (1) Mean after threshold. Rank [19-25]. Sample of women with partner and with at least a child 0- 4 y.o. SE in parenthesis and clustered at sample unit level. ${ }^{* * *} \mathrm{p}<0.001 * * \mathrm{p}<0.05^{*} \mathrm{p}<0.1$.

Table A.12: Other Family Outcomes

\begin{tabular}{llllll} 
& $\begin{array}{l}\text { Women Em- } \\
\text { powerment }\end{array}$ & $\begin{array}{l}\text { Children liv- } \\
\text { ing at home }\end{array}$ & $\begin{array}{l}\text { Children } \\
\text { outside } \\
\text { home }\end{array}$ & $\begin{array}{l}\text { It has been } \\
\text { in more than } \\
1 \text { union }\end{array}$ & $\begin{array}{l}\text { Age at 1st } \\
\text { marriage }\end{array}$ \\
\cline { 2 - 6 }$\beta 1$ & 0.127 & 0.176 & 0.101 & -0.099 & -0.147 \\
& $(0.311)$ & $(0.145)$ & $(0.097)$ & $(0.09)$ & $(0.935)$ \\
\hline Control Mean(1) & 0.150 & 2.414 & 0.180 & 0.099 & 21.135 \\
\hline Obs & 1474 & 1743 & 1743 & 1743 & 1743
\end{tabular}

Note: (1) Mean after threshold. Rank [19-25]. Sample of women with at least a child 0- 4 y.o. SE in parenthesis and clustered at sample unit level. ${ }^{* * *} \mathrm{p}<0.001 * * \mathrm{p}<0.05 * \mathrm{p}<0.1$. 
Table A.13: Impact on Anthropometric Outcomes. Children 0-4 y.o

\begin{tabular}{llll}
\multirow{2}{*}{$\beta 1$} & & & \\
& Weight/Age & Height/Age & Weight/Height \\
\cline { 2 - 4 } & 0.086 & -0.024 & -0.269 \\
$(0.315)$ & $(0.346)$ & $(0.377)$ \\
\hline Control Mean(1) & -0.334 & -0.283 & -0.191 \\
\hline Obs & 662 & 363 & 469 \\
\multirow{2}{*}{ Boys } & & & \\
& & & \\
$\beta 1$ & Weight/Age & Height/Age & Weight/Height \\
\cline { 2 - 4 } & 0.261 & 0.221 & -0.516 \\
\hline Control Mean(1) & $(0.417)$ & $(0.552)$ & $(0.521)$ \\
Obs & -0.315 & -0.250 & -0.136 \\
& 330 & 182 & 242
\end{tabular}

\begin{tabular}{llll}
\multirow{3}{*}{ Girls } & & & \\
\cline { 2 - 4 }$\beta 1$ & Weight/Age & Height/Age & Weight/Height \\
\cline { 2 - 4 } & 0.05 & -0.018 & 0.135 \\
& $(0.447)$ & $(0.534)$ & $(0.632)$ \\
\hline Control Mean(1) & -0.286 & -0.296 & -0.236 \\
\hline Obs & 332 & 181 & 227
\end{tabular}

Note: Estimations on the rank [18-26]. Controlling for hh composition, woman and partner's age and education, wealth index and child's weight and length at birth. W/A: weight for age. H/A: height for age. $\mathrm{W} / \mathrm{H}$ : weight for height. (1) Mean after the threshold. SE in parenthesis. ${ }^{* * *} \mathrm{p}<0.01{ }^{* *} \mathrm{p}<0.05^{*} \mathrm{p}<0.1$

For the following table, Table A.14, estimations are done on the indicators "Number of yes" and "Any Yes", defined by Equation 5 and Equation 6

$$
\begin{gathered}
\text { Num_Yes }=\sum_{j=1}^{J} Q_{i} \quad \forall j=1, \ldots, J \\
\text { Any_Yes }=\begin{array}{c}
1 \\
0
\end{array} \text { if } \begin{array}{l}
Q_{j}=1 \forall j=1, \ldots, J \\
\text { otherwise }
\end{array}
\end{gathered}
$$

Equation 5 corresponds to Number of Yes defined in the rank [0-J] and Equation 6 to Any Yes defined in the rank [0-1]. $\mathrm{J}=8$ for physical punishment. $Q_{j}$ corresponds to the question that asks whether or not father or mother use way i to punish children, which is coded 1 for yes and 0 for no. 
Table A.14: Impact on Child Discipline. Other indicators.

All HH

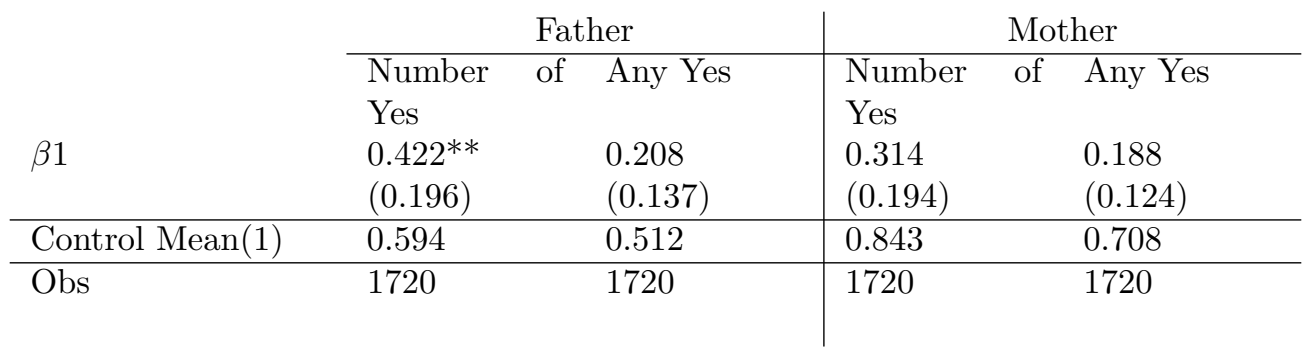

HH WITH MOTHER AND FATHER

\begin{tabular}{lll|ll} 
& \multicolumn{2}{c|}{$\begin{array}{l}\text { Father } \\
\text { Number }\end{array}$} & \multicolumn{2}{c}{$\begin{array}{l}\text { Mother } \\
\text { of }\end{array}$} \\
& Yes & & Number & Any Yes \\
\cline { 2 - 5 }$\beta 1$ & $0.416^{* *}$ & 0.202 & $0.382^{* *}$ & $0.220^{*}$ \\
& $(0.198)$ & $(0.139)$ & $(0.193)$ & $(0.126)$ \\
\hline Control Mean(1) & 0.514 & 0.462 & 0.830 & 0.700 \\
\hline Obs & 1666 & 1666 & 1666 & 1666
\end{tabular}

Note: Estimations on the rank [19-25]. Controlling for hh composition, woman and partner's age and education, wealth index and child's weight and length at birth. (1) Mean after the threshold. SE in parenthesis. $* * * \mathrm{p}<0.01 * * \mathrm{p}<0.05 * \mathrm{p}<0.1$

Table A.15: HH characteristics. Children who have attended the HCB 16 months or more vs Children who have attended 2-15 months

Child age (months)

Child gender $(1=$ boy $)$

Mother works

Mother education

Mother age

\# hh members

\# children at home

HCB in the neighborhood

Has attended another care center

Main care giver $=$ mother

Main reason to choose care option=quality

Had difficulties to find a care center

Urban area

Exposure to the program (months)

Attendance to G\&D checks

Mother in union

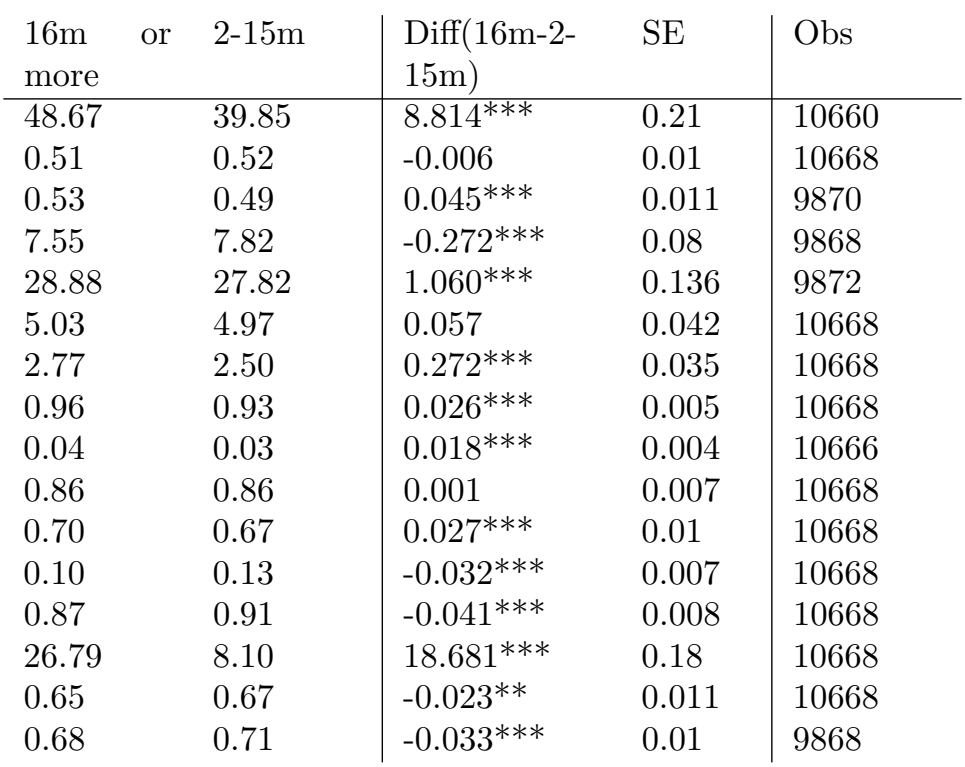

Note: SE in parenthesis. ${ }^{* * *} \mathrm{p}<0.01{ }^{* *} \mathrm{p}<0.05^{*} \mathrm{p}<0.1$ 
Table A.16: HH characteristics. Children who have attended the HCB 16 months or more vs Children who have attended 2-15 months. $\mathrm{HH}$ where the father is present.

Child age (months)

Child gender (1=boy)

Mother works

Father works

Mother education

Father education

Mother age

Father age

\# hh members

\# children at home

HCB in the neighborhood

Has attended another care center

Main care giver $=$ mother

Main reason to choose care option=quality

Had difficulties to find a care center

Urban area

Exposure to the program (months)

Attendance to G\&D checks

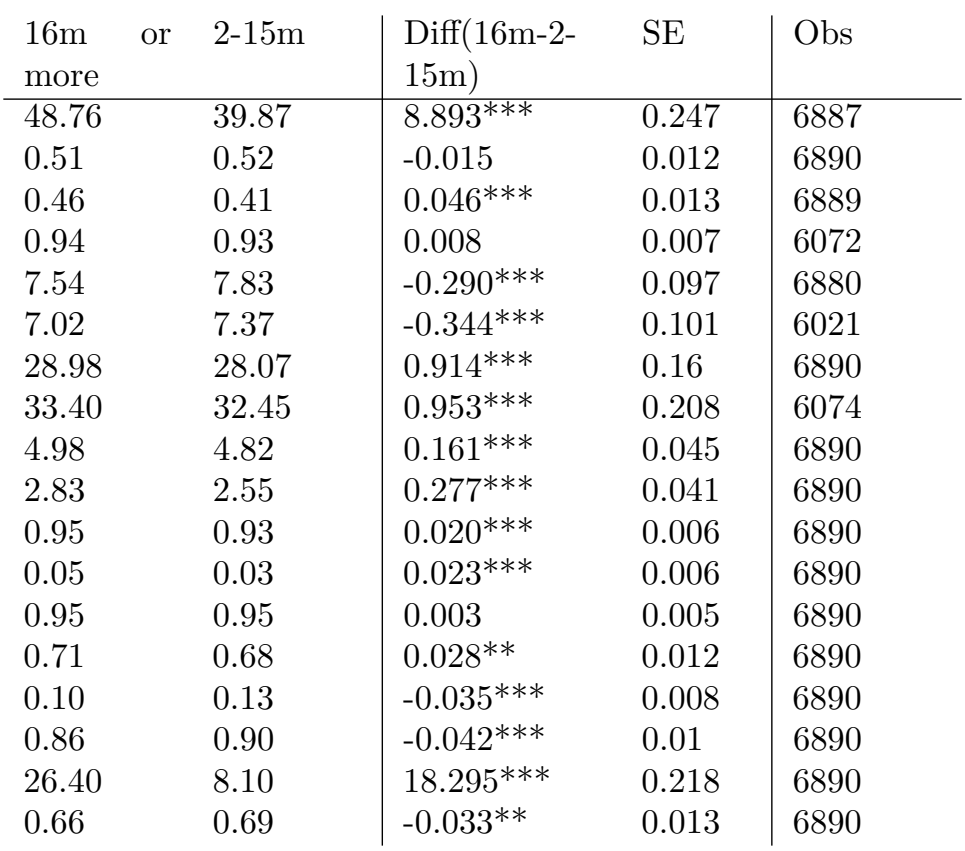

Note: SE in parenthesis. ${ }^{* * *} \mathrm{p}<0.01{ }^{* *} \mathrm{p}<0.05^{*} \mathrm{p}<0.1$ 


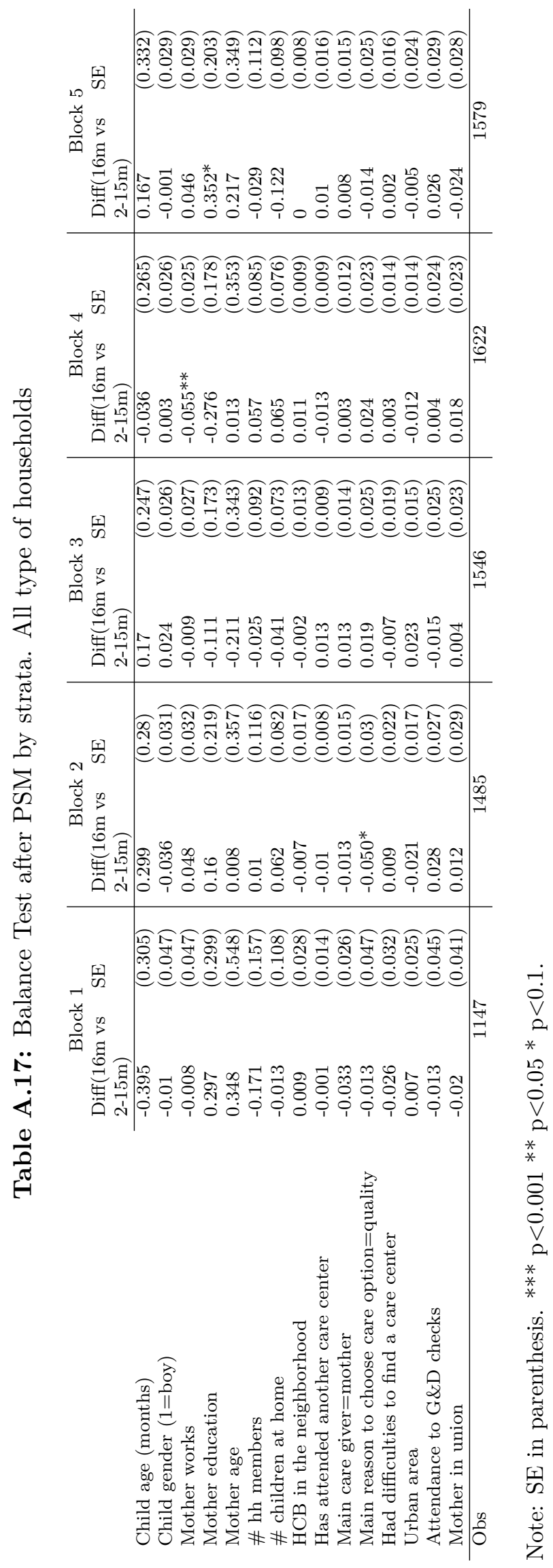


Table A.18: Differences between working and non-working mothers

\begin{tabular}{l|ll|ll|l} 
& $\begin{array}{l}\text { Working } \\
\text { Mothers }\end{array}$ & $\begin{array}{l}\text { Non- } \\
\text { Working } \\
\text { Mothers }\end{array}$ & Diff (1)-(2) & SE (1)-(2) & Obs \\
\hline Child age (months) & 43.92 & 43.48 & $0.437^{* *}$ & $(0.219)$ & 9864 \\
Child gender (1=boy) & 0.51 & 0.51 & 0 & $(0.01)$ & 9870 \\
Father works & 0.94 & 0.93 & 0.007 & $(0.007)$ & 6082 \\
Mother education (Yrs) & 8.15 & 7.25 & $0.902^{* * *}$ & $(0.085)$ & 9856 \\
Father education (Yrs) & 7.58 & 6.94 & $0.643^{* * *}$ & $(0.106)$ & 6031 \\
Mother age & 29.00 & 27.55 & $1.448^{* * *}$ & $(0.143)$ & 9870 \\
Father age & 33.04 & 32.72 & 0.319 & $(0.228)$ & 6084 \\
\# hh members & 4.76 & 5.17 & $-0.415^{* * *}$ & $(0.045)$ & 9870 \\
\# children at home & 2.49 & 2.74 & $-0.241^{* * *}$ & $(0.04)$ & 9870 \\
Urban area & 0.93 & 0.86 & $0.064^{* * *}$ & $(0.01)$ & 9870 \\
Attendance to G\&D checks & 0.66 & 0.67 & -0.004 & $(0.012)$ & 9870 \\
Mother in union & 0.59 & 0.81 & $-0.213^{* * *}$ & $(0.01)$ & 9866
\end{tabular}

Note: Sample of children 2-5 y.o. who have been attending the HCB more than 2 months. ${ }^{* * *} \mathrm{p}<0.001{ }^{* *}$ $\mathrm{p}<0.05 * \mathrm{p}<0.1$.

For the following table, Table A.19, estimations are done on the indicators "Used most of the time" and "Used any time", defined by Equation 7 and Equation 8

$$
\begin{aligned}
& \text { Used_most_of_the_time }=\begin{array}{l}
1 \\
0
\end{array} \text { if } \begin{array}{l}
Q_{j}>=3 \forall j=1, \ldots, J \\
\text { otherwise }
\end{array}
\end{aligned}
$$

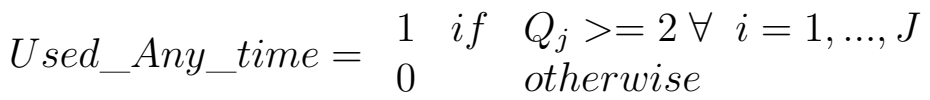

Both indicators are in the rank [0-1]. $\mathrm{J}=2$ (eat)/4(obey) for physical discipline and $\mathrm{J}=3$ (eat) $/ 5$ (obey) for pedagogic discipline. $Q_{j}$ corresponds to the question that asks if the mother punishes the child using way i, which is coded 1 for never, 2 for sometimes, 3 for almost every time and 4 for always. 

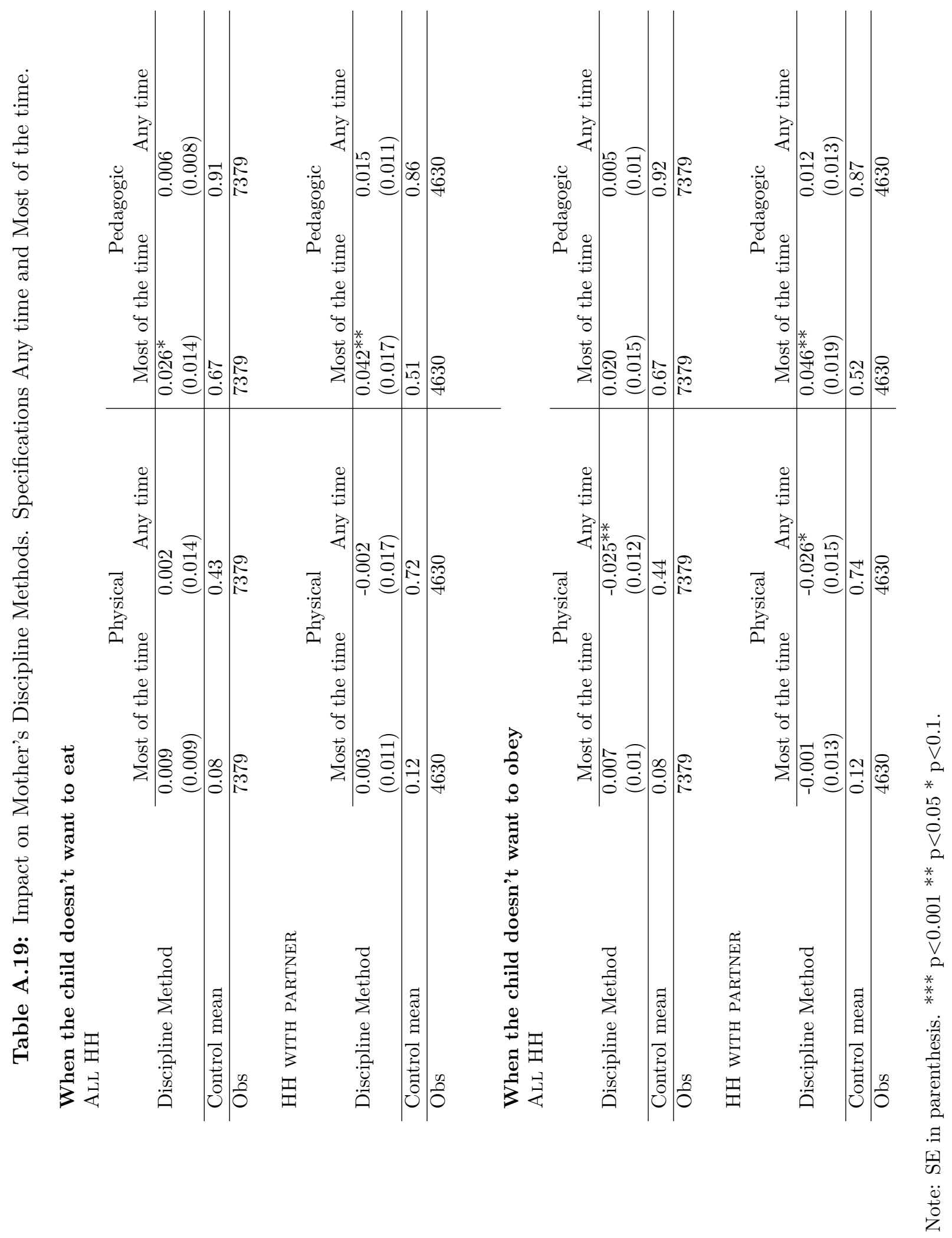


\section{B Suplementary Appendix}

\section{Estimations on the threshold from Sisben 1 to 2}

Similarly to what was done to estimate discontinuities on the threshold from Sisben 2 to 3, I estimate Equation 9 to check for discontinuities in G\&D checks and HCB attendance, as well as in physical punishment on the threshold from Sisben 1 to Sisben 2.

$$
y_{i}=\alpha_{0}+\beta_{1} 1\left\{S_{i} \geq 11\right\}+\beta_{2} f_{2}\left(\tilde{S}_{i}\right)+\beta_{3} f_{2}\left(\tilde{S}_{i}\right) * 1\left\{S_{i} \geq 11\right\}+\beta_{4} C_{i}+\mu_{i}
$$

Where $y_{i}$ is the outcome of interest at the individual or household level, $S_{i}$ is the Sisben index, $\tilde{S}_{i}=S_{i}-11$ is the normalized score, $1\left\{S_{i} \geq 11\right\}$ identifies those who are after the threshold and $f_{2}\left(\tilde{S}_{i}\right)$ corresponds to a quadratic polynomial on the normalized score, which I allow to be different after the threshold with the interaction $f_{2}\left(\tilde{S}_{i}\right) * 1\left\{S_{i} \geq 11\right\}$. C represents a the set of household controls. Impact of the program is given by $\beta_{1}$, which represents the change in $y$ at the eligibility threshold, in this case 11. All estimations are in the rank [8-14]. Test for optimal bandwidth proposed by Imbens and Kalyanaraman, 2010] suggested, on average, an optimal bandwidth of 2.2 .

Table B.1: Program's Discontinuity

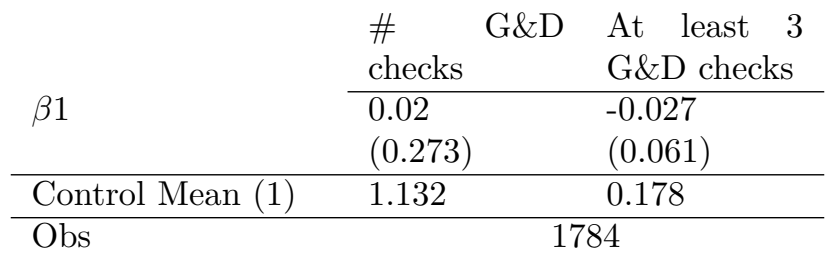

Note: Estimations on the rank [8-14]. Controlling for hh composition, woman and partner's age and education, wealth index and child's weight and length at birth. (1) Mean after the threshold. SE in parenthesis. *** $\mathrm{p}<0.01 * * \mathrm{p}<0.05^{*} \mathrm{p}<0.1$ 


\section{Linear Polynomial Specification and Regressions in the rank [19-25]}

For the linear polynomial specification I estimate Equation 10.

$$
y_{i}=\alpha_{0}+\gamma_{1} 1\left\{S_{i} \geq 22\right\}+\gamma_{2} f_{1}\left(\tilde{S}_{i}\right)+\gamma_{3} f_{1}\left(\tilde{S}_{i}\right) * 1\left\{S_{i} \geq 22\right\}+\gamma_{6} C_{i}+\mu_{i}
$$

For the quadratic polynomial specification I estimate Equation 11 .

$$
y_{i}=\alpha_{0}+\beta_{1} 1\left\{S_{i} \geq 22\right\}+\beta_{2} f_{2}\left(\tilde{S}_{i}\right)+\beta_{3} f_{2}\left(\tilde{S}_{i}\right) * 1\left\{S_{i} \geq 22\right\}+\beta_{4} C_{i}+\mu_{i}
$$

Where $y_{i}$ is the outcome of interest at the individual or household level, $S_{i}$ is the Sisben index, $\tilde{S}_{i}=S_{i}-22$ is the normalized score, $1\left\{S_{i} \geq 22\right\}$ identifies those who are after the

threshold, $f_{1}\left(\tilde{S}_{i}\right)$ corresponds to a linear polynomial in the normalized score and $f_{2}\left(\tilde{S}_{i}\right)$ to a quadratic one. $\mathrm{C}$ represents a the set of household controls. Impact of the program is given by $\beta_{1}$ for the quadratic polynomial, and by $\gamma_{1}$, for the linear one.

Table B.2: Program's Discontinuity

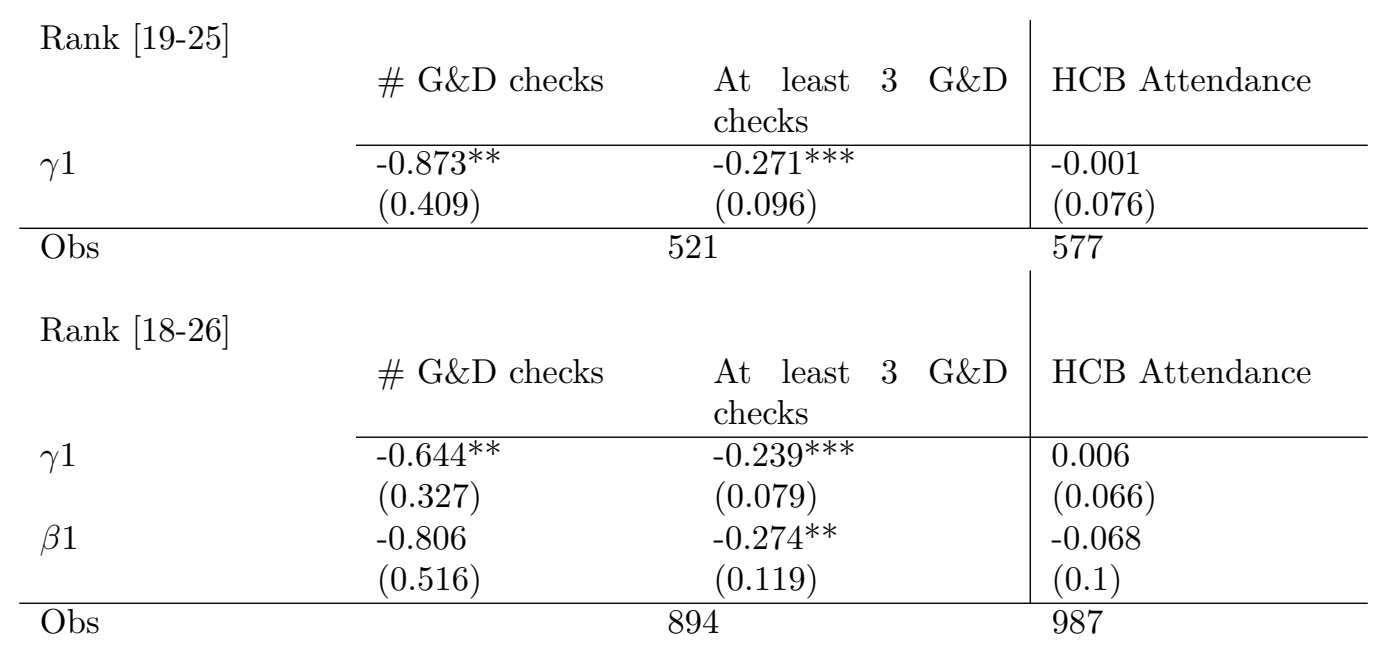

Note: Controlling for hh composition, woman and partner's age and education, wealth index and child's weight and length at birth. (1) Mean after the threshold. SE in parenthesis. ${ }^{* * *} \mathrm{p}<0.01{ }^{* *} \mathrm{p}<0.05{ }^{*} \mathrm{p}<0.1$ 
Table B.3: Children Discipline Discontinuity (Factor 1). Mothers and Fathers.

\begin{tabular}{lll} 
Rank [19-25] & Father & Mother \\
\cline { 2 - 3 }$\gamma 1$ & $\begin{array}{l}0.318^{* *} \\
(0.126)\end{array}$ & $\begin{array}{l}0.152 \\
(0.181)\end{array}$ \\
& 976 & 976 \\
\hline Obs & & \\
Rank [18-26] & Father & Mother \\
\cline { 2 - 3 }$\gamma 1$ & $0.198^{*}$ & 0.024 \\
& $(0.115)$ & $(0.143)$ \\
$\beta 1$ & $0.365^{* *}$ & 0.151 \\
& $(0.149)$ & $(0.236)$ \\
\hline Obs & 1720 & 1720
\end{tabular}

Note: Controlling for hh composition, woman and partner's age and education, wealth index and child's weight and length at birth. (1) Mean after the threshold. SE in parenthesis. ${ }^{* * *} \mathrm{p}<0.01{ }^{* *} \mathrm{p}<0.05^{*} \mathrm{p}<0.1$

Table B.4: Children Discipline Discontinuity (Factor 1). Mothers and Fathers. Only HH in which Mothers work outside

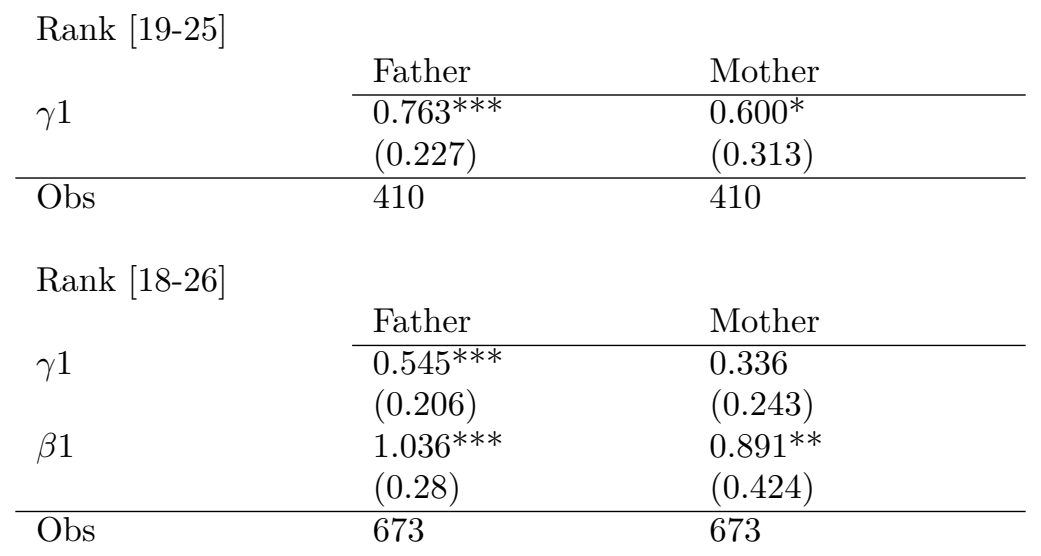

Note: Controlling for hh composition, woman and partner's age and education, wealth index and child's weight and length at birth. (1) Mean after the threshold. SE in parenthesis. ${ }^{* * *} \mathrm{p}<0.01{ }^{* *} \mathrm{p}<0.05{ }^{*} \mathrm{p}<0.1$ 
Table B.5: Children Discipline Discontinuity (Factor 1). Mothers and Fathers. Only HH in which Mothers have education higher than secondary

\begin{tabular}{lll} 
Rank [19-25] & Father & Mother \\
\cline { 2 - 3 }$\gamma 1$ & $\begin{array}{l}0.588^{* * *} \\
(0.202)\end{array}$ & $\begin{array}{l}0.458^{*} \\
(0.263)\end{array}$ \\
\hline Obs & 362 & 362 \\
& & \\
Rank [18-26] & & \\
& & Mother \\
$\gamma 1$ & $0.410^{* *}$ & 0.247 \\
& $(0.196)$ & $(0.215)$ \\
$\beta 1$ & $0.608^{* *}$ & 0.599 \\
& $(0.256)$ & $(0.369)$ \\
\hline Obs & 488 & 488
\end{tabular}

Note: Controlling for hh composition, woman and partner's age and education, wealth index and child's weight and length at birth. (1) Mean after the threshold. SE in parenthesis. ${ }^{* * *} \mathrm{p}<0.01{ }^{* *} \mathrm{p}<0.05^{*} \mathrm{p}<0.1$ 


\section{Instrumental Variable Specification}

In the first stage, programs' attendance is estimated by Equation 11, where $y_{i}$ represents either whether or not the child has attended 3 G\&D checks over the year. The second stage is given by Equation 12 .

$$
\text { discipline }_{i}=\alpha_{0}+\delta_{1} \hat{y}_{i}+\delta_{2} C_{i}+\mu_{i}
$$

Where discipline $_{i}$ represents how child $\mathrm{i}$ is punished. $\hat{y}_{i}$ is the estimated change in program attendance after estimating Equation 11 . As before, $\mathrm{C}$ represents a the set of household controls. Impact of the program is given by $\delta_{1}$, which represents the change in discipline $_{i}$ when the child is more likely to attend at least 3 G\&D checks over the year.

Table B.6: Children Discipline Discontinuity (Factor 1). Mothers and Fathers. IV estimation. Children 0-4 y.o.

\begin{tabular}{lll|ll} 
& \multicolumn{2}{c|}{ RANK [18-26] } & \multicolumn{2}{c}{ RANK [19-25] } \\
$\delta 1$ & Father & Mother & Father & Mother \\
\cline { 2 - 5 } & -0.672 & -0.275 & -0.793 & -0.341 \\
& $(0.499)$ & $(0.607)$ & $(0.525)$ & $(0.56)$ \\
\hline Control Mean(1) & 0.058 & 0.083 & 0.054 & 0.078 \\
\hline Obs & 880 & 880 & 515 & 515
\end{tabular}

Note: Controls include hh composition, woman and partner's age and education, and wealth. (1) Mean for those who do not attend at least 3 G\&D checks over the year within the rank [19-25]. SE in parenthesis and clustered at sample unit level. ${ }^{* * *} \mathrm{p}<0.01 * * \mathrm{p}<0.05^{*} \mathrm{p}<0.1$ 


\section{Other Figures and Tables of PSM Estimation}

Table B.7: HH characteristics. Children who have attended the HCB 16 months or more vs Children who have attended 2-15 months. Working-mother $\mathrm{HH}$

Child age (months)

Child gender (1=boy)

Mother education

Mother age

\# hh members

\# children at home

$\mathrm{HCB}$ in the neighborhood

Has attended another care center

Main care giver $=$ mother

Main reason to choose care option $=$ quality

Had difficulties to find a care center

Urban area

Attendance to G\&D checks

Mother in union

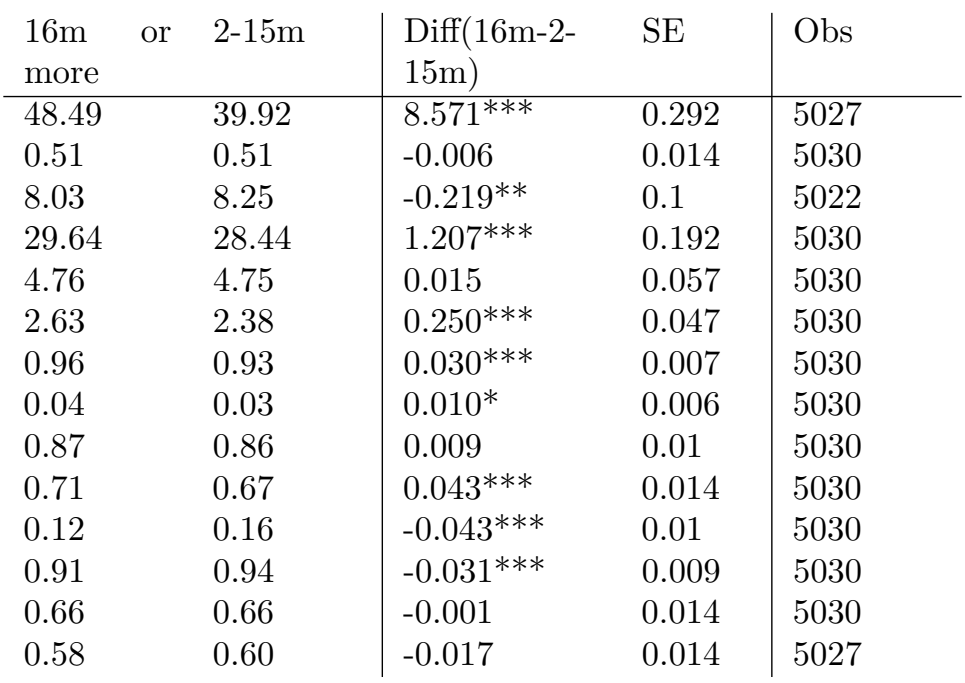

Note: SE in parenthesis. ${ }^{* * *} \mathrm{p}<0.01 * * \mathrm{p}<0.05^{*} \mathrm{p}<0.1$ 
Table B.8: HH characteristics. Children who have attended the HCB 16 months or more vs Children who have attended 2-15 months. Non-Working-mother HH

Child age (months)

Child gender (1=boy)

Mother education

Mother age

\# hh members

\# children at home

HCB in the neighborhood

Has attended another care center

Main care giver $=$ mother

Main reason to choose care option=quality

Had difficulties to find a care center

Urban area

Attendance to G\&D checks

Mother in union

\begin{tabular}{|c|c|c|c|c|}
\hline $\begin{array}{l}16 \mathrm{~m} \text { or } \\
\text { more }\end{array}$ & $2-15 \mathrm{~m}$ & $\begin{array}{l}\operatorname{Diff}(16 \mathrm{~m}-2- \\
15 \mathrm{~m})\end{array}$ & SE & Obs \\
\hline 48.79 & 39.60 & $9.197^{* * *}$ & 0.297 & 4837 \\
\hline 0.51 & 0.52 & -0.01 & 0.014 & 4840 \\
\hline 7.00 & 7.43 & $-0.426^{* * *}$ & 0.118 & 4834 \\
\hline 28.00 & 27.22 & $0.782^{* * *}$ & 0.198 & 4840 \\
\hline 5.29 & 5.09 & $0.202^{* * *}$ & 0.059 & 4840 \\
\hline 2.92 & 2.60 & $0.322^{* * *}$ & 0.052 & 4840 \\
\hline 0.95 & 0.93 & $0.018^{* *}$ & 0.008 & 4840 \\
\hline 0.05 & 0.03 & $0.026^{* * *}$ & 0.007 & 4840 \\
\hline 0.98 & 0.97 & 0.004 & 0.004 & 4840 \\
\hline 0.69 & 0.68 & 0.013 & 0.015 & 4840 \\
\hline 0.09 & 0.11 & $-0.028^{* * *}$ & 0.009 & 4840 \\
\hline 0.83 & 0.89 & $-0.059^{* * *}$ & 0.013 & 4840 \\
\hline 0.64 & 0.68 & $-0.041^{* * *}$ & 0.015 & 4840 \\
\hline 0.79 & 0.82 & $-0.030 * *$ & 0.012 & 4839 \\
\hline
\end{tabular}

Note: SE in parenthesis. ${ }^{* * *} \mathrm{p}<0.01{ }^{* *} \mathrm{p}<0.05 * \mathrm{p}<0.1$

Table B.9: HH characteristics. Children who have attended the HCB 16 months or more vs Children who have attended 2-15 months. Mothers with at least 8 yrs of education

Child age (months)

Child gender ( $1=$ boy)

Mother works

Mother education

Mother age

\# hh members

\# children at home

HCB in the neighborhood

Has attended another care center

Main care giver $=$ mother

Main reason to choose care option=quality

Had difficulties to find a care center

Urban area

Attendance to G\&D checks

Mother in union

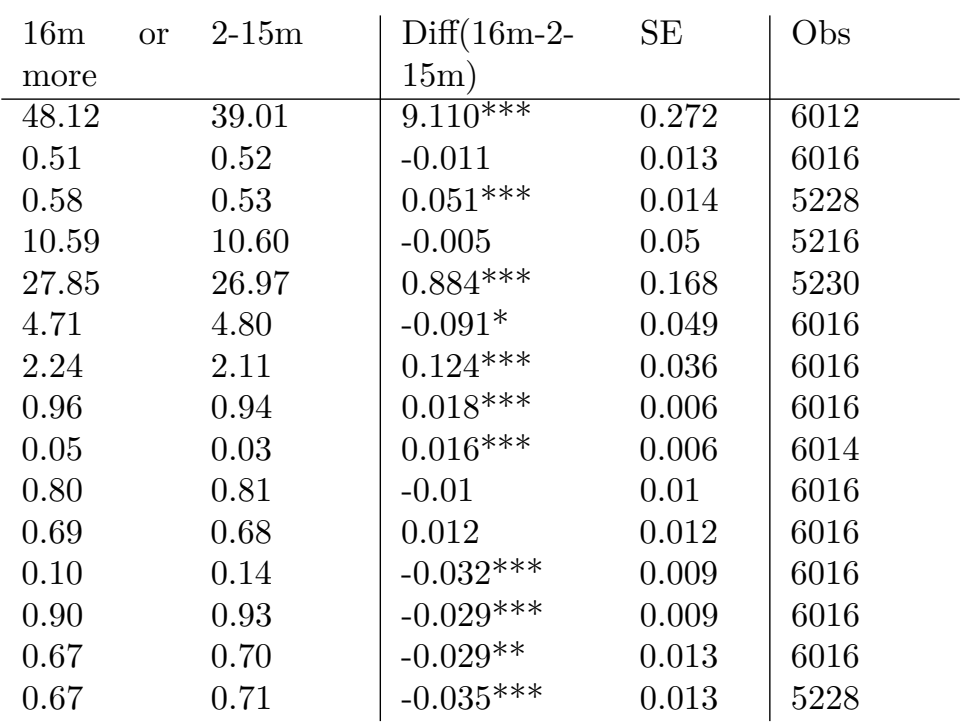

Note: SE in parenthesis. ${ }^{* * *} \mathrm{p}<0.01 * * \mathrm{p}<0.05 * \mathrm{p}<0.1$ 
Table B.10: HH characteristics. Children who have attended the HCB 16 months or more vs Children who have attended 2-15 months. Mothers with less than 8 yrs of education

Child age (months)

Child gender (1=boy)

Mother works

Mother education

Mother age

\# hh members

\# children at home

HCB in the neighborhood

Has attended another care center

Main care giver $=$ mother

Main reason to choose care option=quality

Had difficulties to find a care center

Urban area

Attendance to G\&D checks

Mother in union

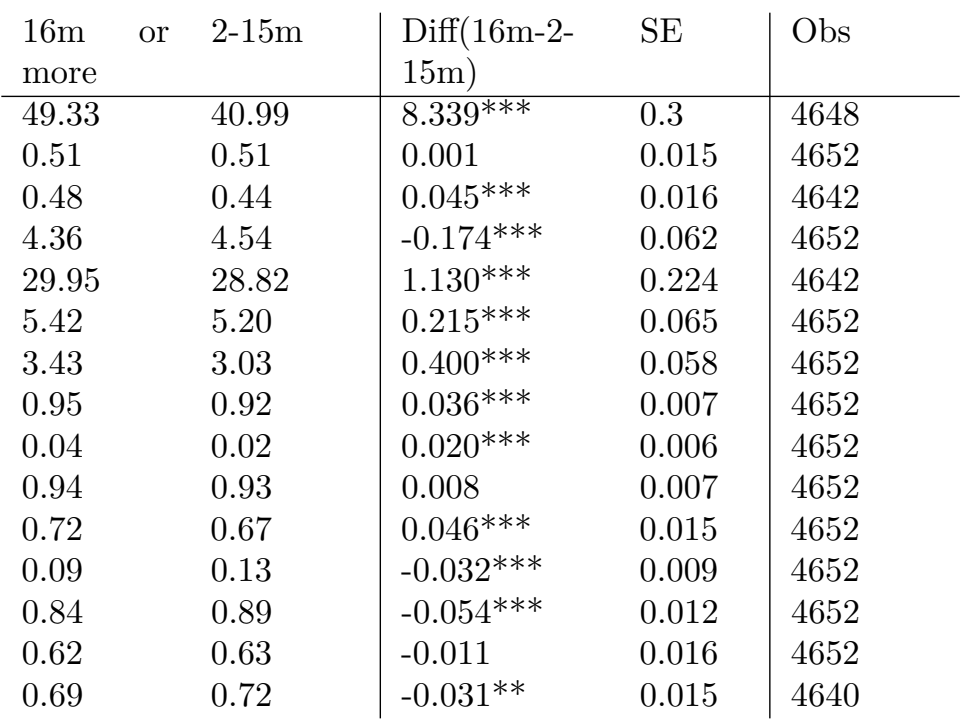

Note: SE in parenthesis. ${ }^{* * *} \mathrm{p}<0.01{ }^{* *} \mathrm{p}<0.05 * \mathrm{p}<0.1$ 


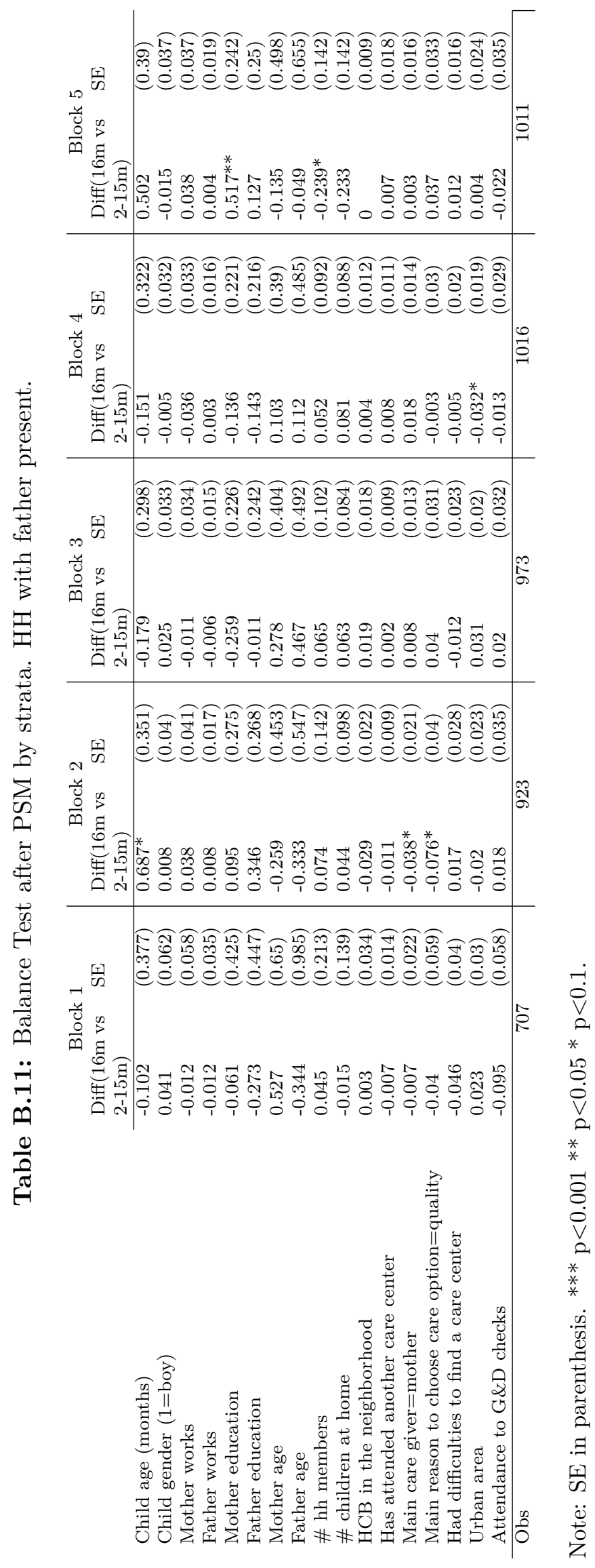




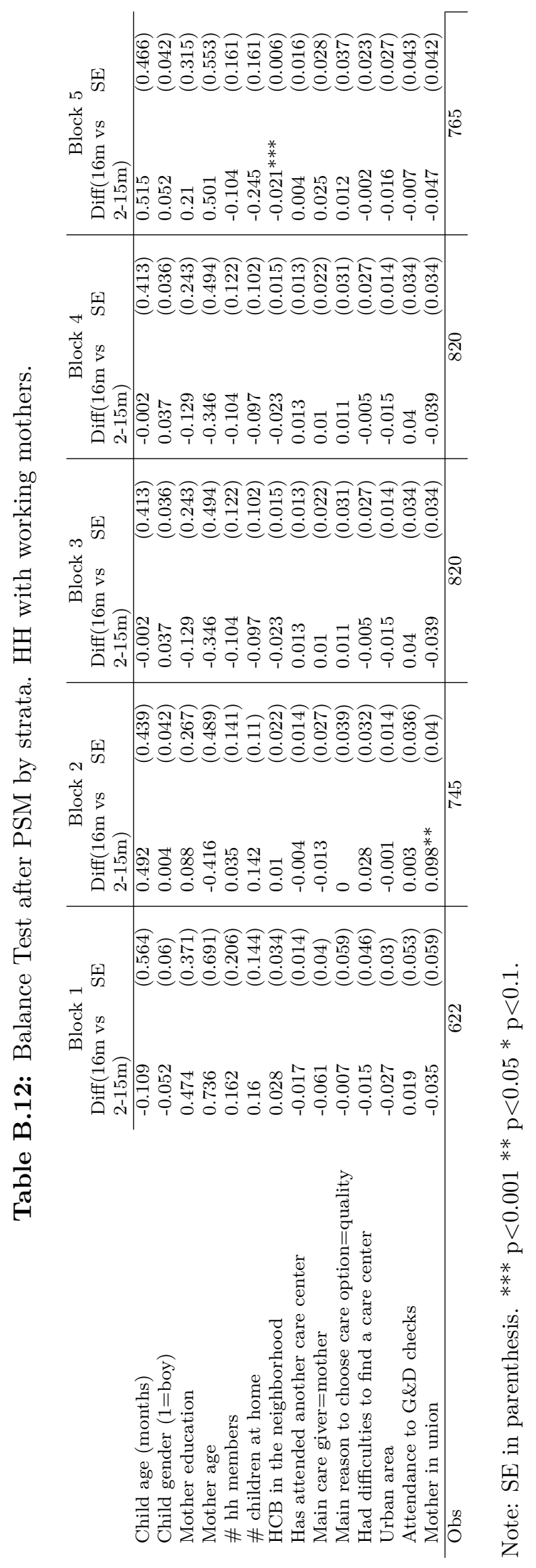




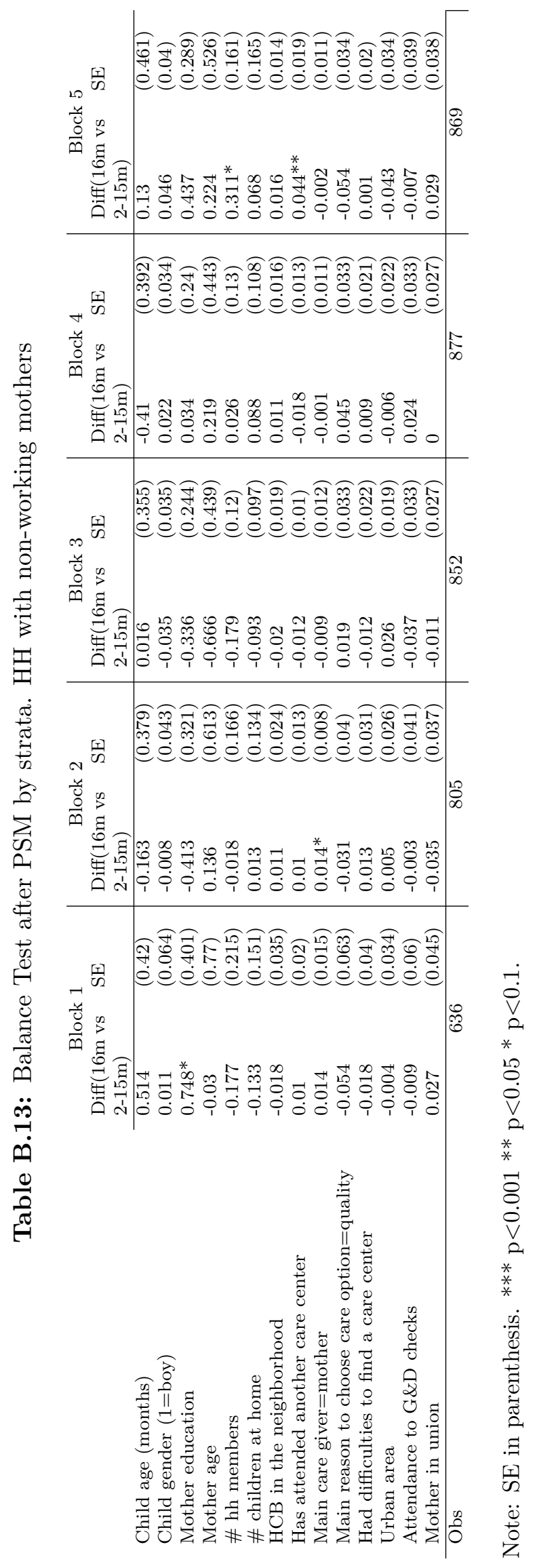




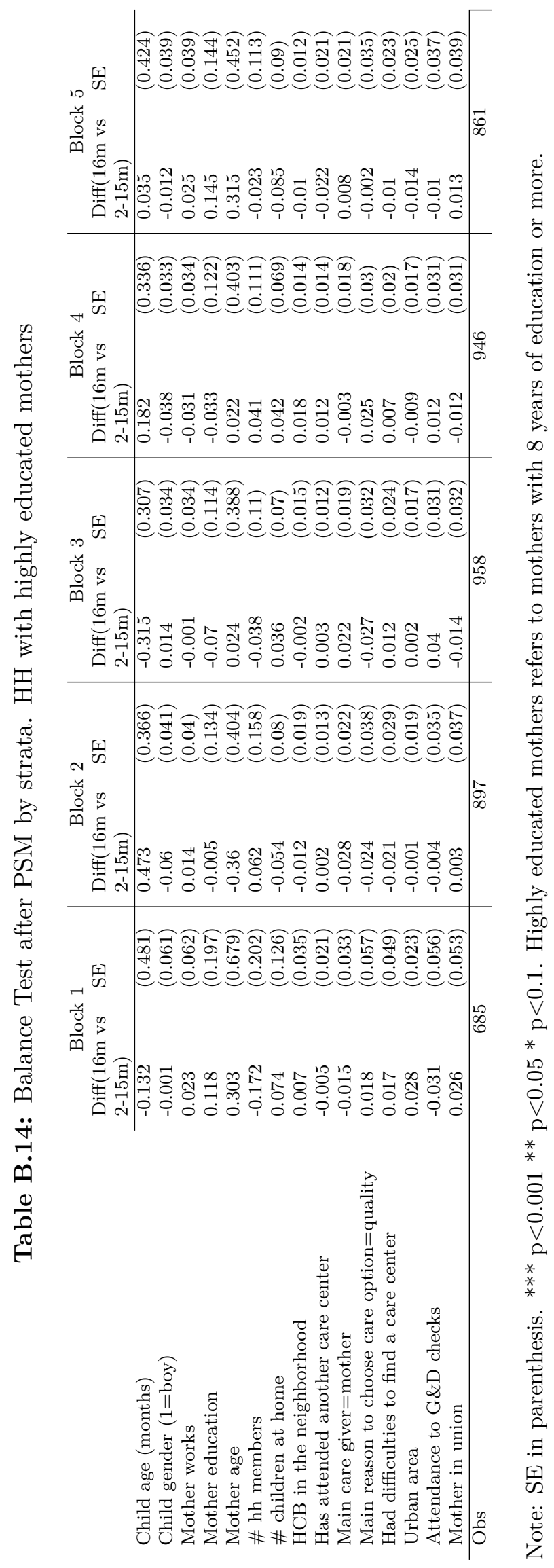




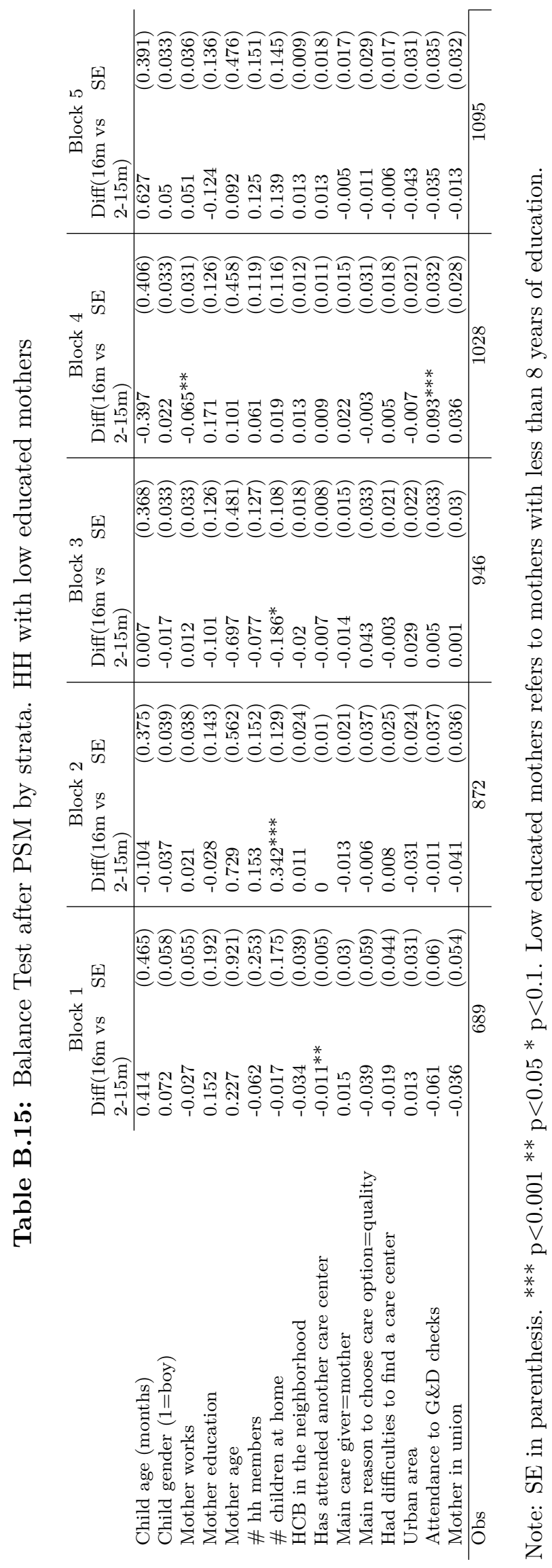


Figure 9: Distribution of PSM. HH with father present.

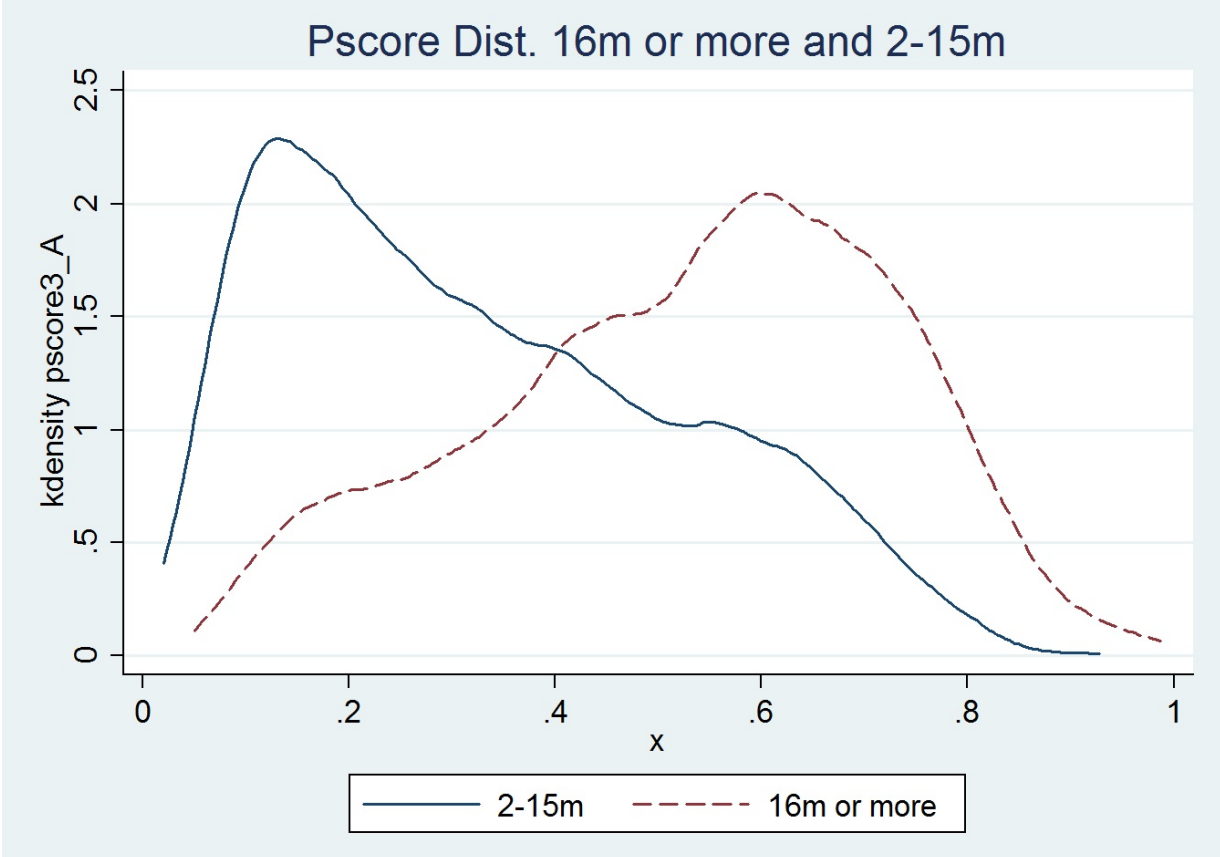



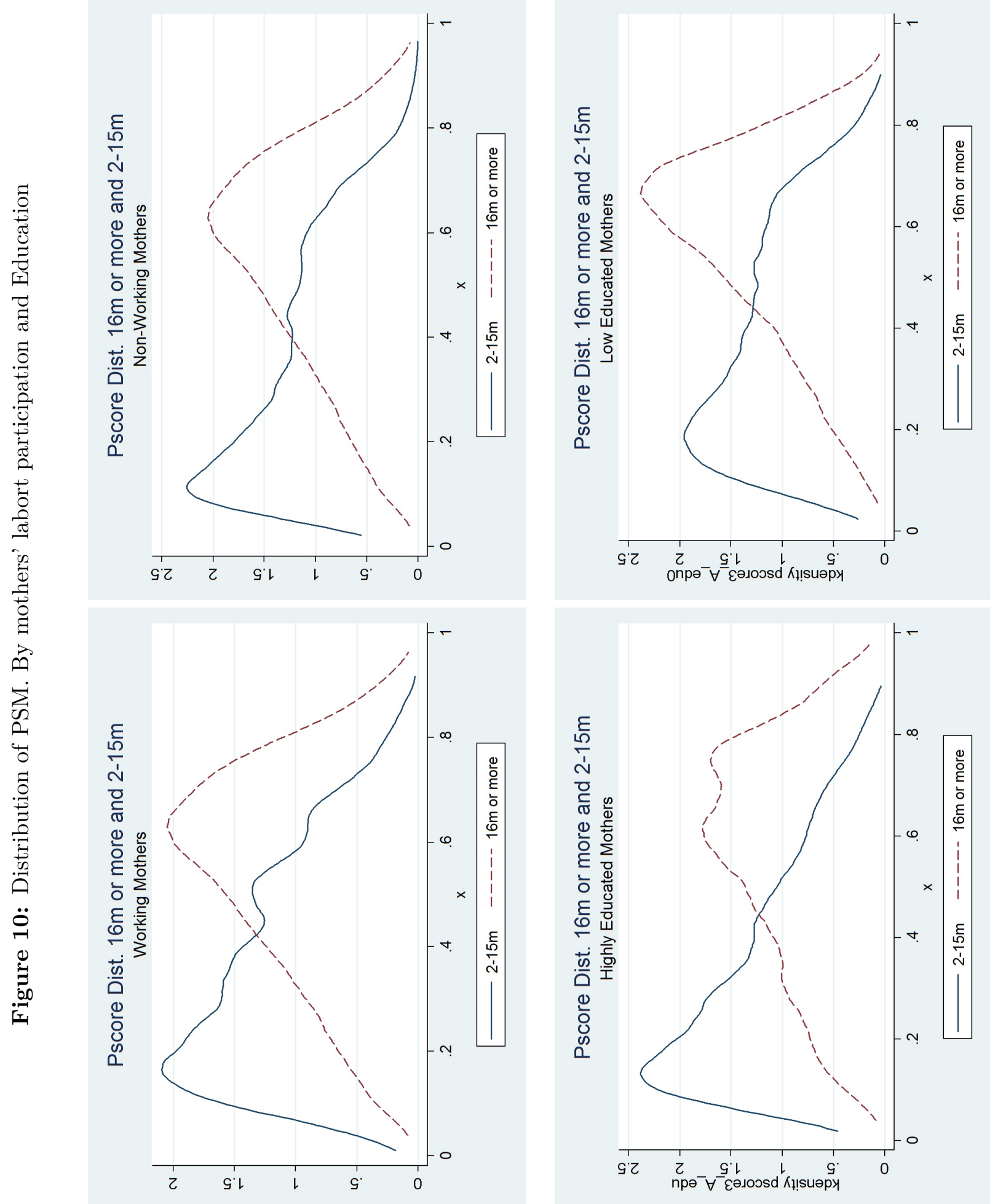